\title{
Discovery, Synthesis and Evaluation of 2,4-diaminoquinazolines as a Novel Class of Pancreatic $\beta$ Cell-Protective Agents against Endoplasmic Reticulum (ER) Stress
}

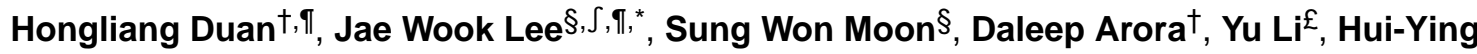 \\ Lim $^{\#}$, and Weidong Wang ${ }^{\dagger, £, *}$ \\ †Immunobiology and Cancer Program, Oklahoma Medical Research Foundation, $825 \mathrm{NE} 13^{\text {th }}$ \\ Street, Oklahoma City, Oklahoma 73104, United States \\ $\S$ Natural Product Research Center, Korea Institute of Science and Technology, 679 Saimdang-ro, \\ Gangneung, Gangwon-do, 210-340, Republic of Korea \\ ${ }^{5}$ Department of Biological Chemistry, Korea University of Science and Technology (UST), \\ Daejeon, 305-333, Republic of Korea \\ \#Department of Physiology, The University of Oklahoma Health Science Center, 941 Stanton L. \\ Young Blvd., Oklahoma City, Oklahoma 73104, United States \\ ${ }^{E}$ Department of Medicine, Division of Endocrinology, Department of Physiology, Harold Hamm \\ Diabetes Center, The University of Oklahoma Health Science Center, 941 Stanton L. Young Blvd., \\ Oklahoma 73104, United States
}

\section{Abstract}

\begin{abstract}
Pancreatic insulin-producing $\beta$-cell dysfunction and death plays central roles in the onset and progression of both type 1 and type 2 diabetes. Current antidiabetic drugs cannot halt the ongoing progression of $\beta$-cell dysfunction and death. In diabetes, a major cause for the decline in $\beta$ cell function and survival is endoplasmic reticulum (ER) stress. Here, we identified quinazoline derivatives as a novel class of $\beta$ cell protective agents against ER stress-induced dysfunction and death. A series of quinazoline derivatives were synthesized from dichloroquiazoline utilizing a sequence of nucleophilic reactions. Through SAR optimization, a 2,4-diaminoquinazoline compound 9c markedly protects $\beta$ cells against ER stress-induced dysfunction and death with $80 \%$ maximum rescue activity and an $\mathrm{EC}_{50}$ value of $0.56 \mu \mathrm{M}$. Importantly, $9 \mathrm{c}$ restores the ER stressimpaired glucose-stimulated insulin secretion response and survival in primary human islet $\beta$ cells. We showed that $9 \mathbf{c}$ protects $\beta$ cells by alleviating ER stress through the suppression of the induction of key genes of the unfolded protein response and apoptosis.
\end{abstract}

\footnotetext{
*Corresponding Authors: Weidong-wang@ouhsc.edu and jwlee5@kist.re.kr. IlEqual contribution

Supporting Information

Table of the purity and NMR spectra. This material is available free of charge via the Internet at http://pubs.acs.org.

The authors declare no competing financial interests.
} 


\section{INTRODUCTION}

Diabetes has become a serious public health problem with tremendous social and economic burden on society; currently, it is estimated that 380 million people are suffering from diabetes worldwide. ${ }^{1}$ Loss of pancreatic insulin-producing $\beta$ cell mass or function is a critical event in the pathogenesis of both type 1 diabetes (T1D) and type 2 diabetes (T2D) ${ }^{2-5}$ Thus, preservation and expansion of $\beta$ cells is a promising therapeutic approach for patients with diabetes. Unfortunately, currently the most commonly prescribed antidiabetic drugs cannot halt the progression of $\beta$ cell dysfunction and death.

In diabetes, a major cause for the decline of pancreatic $\beta$ cell function and mass is ER stress, a condition in which misfolded or unfolded proteins accumulate in the ER. ${ }^{6-8}$ In T2D, insulin resistance forces $\beta$ cells to synthesize more insulin that exceeds the cellular capacity of ER for protein folding, thus causing ER stress. If this threshold is crossed, $\beta$ cell dysfunction and apoptosis will ensue. ${ }^{4}$ In T1D in which $\beta$ cells are known to be destroyed by auto-immune reaction, ER stress has also been implicated, and ER stress-reducing chemical chaperon has been shown to protect $\beta$ cells and prevent the onset of T1D in mouse models. ${ }^{9-11}$

ER stress is mediated by three ER membrane-associated proteins, inositol-requiring protein 1a (IRE1a), PKR-like ER kinase (PERK) and activating transcription factor 6 (ATF6), which act as unfolded protein sensors. ${ }^{6-8,12}$ In unstressed cells, these sensors are maintained in an inactivate state through interaction with the protein chaperone binding immunoglobulin protein (BiP). Under ER stress, unfolded and misfolded proteins accumulate in the ER and bind to and sequester BiP, thereby releasing and activating the sensors. ${ }^{13}$ IRE1a, PERK, and ATF6 each activates a series of events aimed at restoring ER homeostasis by altering the translation, folding, and post-translational modification of secreted and membrane proteins, a process termed the unfolded protein response (UPR). Failure to re-establish ER homeostasis eventually triggers cell death under chronic or severe ER stress.

As $\beta$ cells must produce and rapidly secrete insulin in response to postprandial increases in blood glucose levels, they maintain a very large pool of proinsulin mRNA ( $20 \%$ of the total cellular mRNA) and can increase proinsulin protein synthesis 25 -fold upon glucose stimulation. ${ }^{14,15}$ This surge in proinsulin synthesis places a heavy burden on the proteinfolding capacity of the ER; $\beta$ cells are therefore particularly susceptible to ER stress. ${ }^{7}$ Thus, compounds that prevent $\beta$ cells from ER stress-induced damage hold promise as potential therapeutic agents for diabetes.

Small molecules have been identified that can regulate ER stress and/or the UPR. However, some of these small molecules are tissue- and/or cell type-specific as they inhibit ER stress in one cell type but not in others. ${ }^{16-25}$ For instance, salubrinal, which inhibits dephosphorylation of eIF2a (a PERK target), protects neuronal cells and PC12 cells from ER stress but triggers apoptosis in $\beta$ cells. ${ }^{26-28}$ The aforementioned unique features of $\beta$ cells may in part explain why compounds that protect other cell types from ER stress fail to protect $\beta$ cells ${ }^{27,28}$ and contribute to a scarcity of $\beta$ cell-protective small molecules. 
To date, only a few chemotypes have been reported to exhibit $\beta$ cell-protective activities against ER stress through a high throughput $\beta$ cell survival screen. ${ }^{29}$ Examples include 1((3s,5s,7s)-adamantan-1-yl)-3-(2-(methylthio)benzyl)urea (1) (Figure 1), 5-((4-chloro-2nitro-5-(1 H-pyrrol-1-yl)phenyl)thio)-4H-1,2,4-triazol-3-amine (2) (Figure 1), and several bacteriostatic antibiotics. There are also several other $\beta$ cell-protective small molecules that do not target ER stress and are not effective against ER stress, such as the STAT1 signaling inhibitor BRD0476 (N-(((2R,3R)-5-((S)-1-hydroxypropan-2-yl)-3-methyl-10-(3(naphthalen-1-yl)ureido)-6-oxo-3,4,5,6-tetrahydro-2H-benzo[b][1,5] oxazocin-2-yl)methyl)$\mathrm{N}$-methyl-2,3-dihydrobenzo[b][1,4]dioxine-6-sulfonamide). ${ }^{30,31}$ In a further extended $\beta$ cell survival screen, a 2,4-diaminoquinazoline compound (5a) was identified as $\beta$ cell-protective agent against ER stress. Therefore, a series of 2,4-diaminoquinazoline analogs were synthesized for their capacity to protect $\beta$ cells from ER stress. SAR studies identified $\mathbf{9 c}$ as a potent compound that suppresses ER stress-induced death and dysfunction of INS- $1 \beta$ cells with $80 \%$ maximum rescue activity and an $\mathrm{EC}_{50}$ of $0.56 \mu \mathrm{M}$. Importantly, compound $\mathbf{9 c}$ is also effective in primary human islet $\beta$ cells. In addition, we show that $9 \mathbf{c}$ inhibits ER stressinduced expression of UPR and apoptotic genes in $\beta$ cells. Compound $9 \mathrm{c}$ represents a new $\beta$ cell-protective chemotype with a 2,4-diaminoquinazoline skeleton.

\section{CHEMISTRY}

To identify potent $\beta$ cell-protective quinazoline analogs, we initiated structure activity guided optimization of 2,4-diaminoquinazoline. We planned modification of chemical structure at C-4 position and following to C-2 of 2,4-diaminoquinazoline. The synthetic route employed for the synthesis of 2,4-diaminoquinazolines is summarized in Scheme 1. The key intermediate, dichloroquinazoline $\mathbf{3}$, was synthesized by the chlorination of benzoyleneurea with phosphorus oxychloride and catalytic amount of $N, N$ dimethylaniline. ${ }^{32}$ After a regioselective nucleophilic substitution at $\mathrm{C}-4$ was performed with various benzyl amines and phenethyl amine in the presence of DIEA, intermediate $\mathbf{3}$ was converted into a series of monoamine derivatives, 4a-n, bearing methoxy, bromo, chloro, and fluoro in $\mathrm{R}_{1}$.

A second nucleophilic substitution at the C-2 of 4a-n with L-prolinol in the presence of DIEA yield compounds, $\mathbf{5 a}-\mathbf{m}$. The $\beta$ cells protection activities of compounds (5a-m) were summarized in Table 1. To investigate the structure-activity relationship between five member ring and six membered ring, we introduced 2-piperidinylmethanol at C-2 position of quinazoline. Compounds (6a-n) were synthesized by nucleophilic substitution at the C-2 of 4a-n with 2-piperidinylmethanol in the presence of DIEA. Bioactivities of compounds (6a-n) were summarized in Table 2. We next investigated the bioactivities related with length of amine linker at C-4 substitution. Benzyl amines were selected to compare with phenethylamines. The synthesis of intermediate (7a-d) was performed with various benzyl amines in the presence of DIEA. A nucleophilic substitution at C-2 position with L-prolinol or 2-piperidinylmethanol in the presence of DIEA yielded compounds, $\mathbf{8 c}-\mathbf{d}$ and $\mathbf{9 a - d}{ }^{33}$ 


\section{RESULTS AND DISCUSSION}

A series of 2,4-diaminoquinazoline derivatives incorporating a 2-

(hydroxymethyl)pyrrolidin-1-yl group at the $\mathrm{C}-2$ position of a quinazoline ring were first synthesized and tested for their $\beta$ cell-protective activity against ER stress using a CellTiterGlo cell viability assay in rat INS-1 $\beta$ cells. Treatment of INS- $1 \beta$ cells with tunicamycin (Tm), a potent ER stress inducer that causes the accumulation of misfolded proteins due to inhibition of $N$-linked glycosylation, drastically reduced cell viability at $72 \mathrm{~h}$ compared with DMSO-treated cells, as measured by intracellular ATP levels with a CellTiter-glo kit (Figure 2). The maximum activities and the concentrations that reach half-maximal activity $\left(\mathrm{EC}_{50}\right)$ of the compounds were evaluated by the degree of increase in viability of INS-1 cells cotreated with the compounds in the presence of Tm compared with Tm treatment alone. As shown in Table 1, derivatives of the phenethylamine moieties substituted at para, meta, and ortho positions exhibited maximum activities ranging from $\sim 34.2 \%$ to $57.3 \%$ as opposed to that as $100 \%$ in the absence of Tm, with no position being conferred to be more potent. However, more derivatives substituted at para position, including $5 \mathbf{5 a}, \mathbf{5 c}, \mathbf{5 d}$ and $\mathbf{5 e}$, appeared to exhibit lower $\mathrm{EC}_{50} \mathrm{~s}$ at approcimately $0.5 \mu \mathrm{M}$ than derivatives substituted at meta and ortho positions (Table 1).

We then changed the 2-(hydroxymethyl)pyrrolidin-1-yl group at the C-2 position of the quinazoline ring to 2-(hydroxymethyl)piperidin-1-yl as racemic mixtures to explore the SAR (Table 2). Compared to the 2-(hydroxymethyl)pyrrolidin-1-yl derivatives, the maximum activities of the 2-(hydroxymethyl)piperidin-1-yl derivatives remained in a similar range except $\mathbf{6 j}$ (Table 2). However, the $\mathrm{EC}_{50}$ s of these compounds improved over their 2(hydroxymethyl)pyrrolidin-1-yl counterparts by $\sim 2-3$ fold (6a, 6c, 6d, 6e, 6h, 6l, and 6n versus $5 \mathbf{a}, 5 \mathbf{c}, 5 \mathbf{d}, 5 \mathbf{e}, 5 \mathbf{g}, \mathbf{5 k}$, and $\mathbf{5 m}$ respectively), with $\mathbf{6 b}$ improving by $\sim 7$ fold (6b versus 5b). 6 j showed significantly improved maximum activity at $69.2 \%$ vs. its $2-$ (hydroxymethyl)pyrrolidin-1-yl counterpart $5 \mathbf{i}$ (54.9\%), but its $\mathrm{EC}_{50}$ also increased. Notably, among the 2-(hydroxymethyl)piperidin-1-yl derivatives, except bromo substitution which showed similar $\mathrm{EC}_{50}$, the derivatives with para substitution, including $\mathbf{6 a - f}$, exhibited relatively low $\mathrm{EC}_{50} \mathrm{~s}$ compared to ortho- or meta-substituted derivatives $(\mathbf{6 g}-\mathbf{n})$ (Table $\mathbf{2}$ ). Taken together, this series of SAR studies indicates the 2-(hydroxymethyl)piperidin-1-yl moiety to be more favorable than its 2-(hydroxymethyl)pyrrolidin-1-yl counterpart in $\beta$ cell protection against ER stress.

Next, we shifted the SAR study to the phenethylamine moiety. When the amine linker length was shortened from two carbons to one, most resulting benzylamine compounds exhibited similar potency and maximum activity to their phenethylamine counterparts (6a versus $9 a$, and $\mathbf{6 c}$ versus 9b) (Tables $\mathbf{2}$ and $\mathbf{3}$ ). However, for the $4-\mathrm{OCH}_{3}$ derivatives, a benzyl group (9c) significantly improved the maximum activity over its phenethylamine counterpart $\mathbf{6 f}$ (80.4\% versus 58.6\%), with an $\mathrm{EC}_{50}$ in the sub-micromolar range $(0.56 \mu \mathrm{M})$ (Tables 2 and 3 and Figure 2A). However, a derivative substituted at both meta and para positions with $\mathrm{OCH}_{3}$ moieties (9d) exhibited less favorable activity than $\mathbf{9 c}$ (Table 3). We also synthesized the 2-(hydroxymethyl)pyrrolidine counterparts of both $9 \mathbf{c}$ and $9 \mathbf{d}$, and observed that $9 \mathbf{c}$ and 9d showed more favorable activities than their 2-(hydroxymethyl)pyrrolidine derivatives in maximum activity ( $80.4 \%$ vs $57.2 \%$ and $69.4 \%$ vs $44.9 \%$, respectively) (Table 3). Overall, 
all the SAR studies established that $\mathbf{9 c}$ is a more potent $\beta$ cell-protective compound against ER stress in this series. Compared to RH01687 (a compound known to be $\beta$ cell-protective against ER stress, as shown in Figure 2B, 9c exhibited similar maximum activity to that of RH01687 but at significantly lower concentration ( $5 \mu \mathrm{M}$ for $9 \mathrm{c}$ vs. $30 \mu \mathrm{M}$ for RH01687).

To explore whether the chirality of $9 \mathbf{c}$ influenced its potency, the R (R-9c) and S (S-9c) isomers of compound 9c were synthesized. As shown in Figure 2C, both R-9c, and S-9c compounds exhibited similar $\mathrm{EC}_{50} \mathrm{~s}$ and maximum activities in increasing the viability of INS-1 cells after Tm treatment. We therefore chose racemic $\mathbf{9 c}$ for further characterization of its mechanism of action in promoting $\beta$ cell survival and function against ER stress.

In the above SAR studies, we used the intracellular ATP level measured by the CellTiter-glo assay as a surrogate for cell viability. To rule out the possibility of an ATP-specific (rather than viability) effect of the compounds, we used the MTT assay, which measures the activity of $\mathrm{NAD}(\mathrm{P}) \mathrm{H}$-dependent cellular oxidoreductase enzymes, as an orthogonal method to measure cell viability. As shown in Figure 3A, Tm treatment reduced the MTT reading in INS-1 cells compared to that of DMSO treatment, and co-treatment with $9 \mathrm{c}$ resulted in an increase in viability of INS- 1 cells. To confirm that the protective effect of $9 \mathbf{c}$ on $\beta$ cells is not INS- 1 cell-specific, another $\beta$ cell line, $\beta$ TC6, was used. As expected, Tm induced a reduction in viability in $\beta$ TC6 cells, and co-treatment with 9c rescued the viability of $\beta$ TC6 cells in a dose-dependent manner, as assessed by both intracellular ATP level and activity of NAD(P)H-dependent cellular oxidoreductase enzymes (Figures $\mathbf{3 B}$ and $\mathbf{3 C}$ ). To determine whether the protective effect of $9 \mathbf{c}$ on $\beta$ cells is specific to Tm-induced stress, we used another ER stressor, BFA, which inhibits a key guanine nucleotide exchange factor essential for the transport of proteins from the ER to the Golgi, to treat INS-1 cells. ${ }^{34}$ Indeed, compound 9c also protected INS-1 cells against BFA (Figure 3D). ${ }^{34}$ All these results indicate that compound $\mathbf{9 c}$ protects $\beta$ cell survival against ER stress.

To determine whether the increase in cell viability following treatment with $\mathbf{9 c}$ was caused by a suppression of apoptotic cell death, levels of cleaved caspase- 3 and cleaved PARP were assessed by Western blotting. Caspase-3, a member of executioner caspases, plays essential roles in initiating apoptotic signaling and executing the final stages of cell death as it is responsible for the proteolytic cleavage of many key proteins, such as the nuclear enzyme poly (ADP-ribose) polymerase (PARP) which is a family of proteins involved in a number of cellular processes involving DNA repair and cell death. Under normal condition, caspase 3 exists as inactive proenzyme. However, upon severe ER stress, caspase 3 undergoes proteolytic cleavage to produce two subunits that dimerize to form the active enzyme, which in turns cleaves PARP. Hence, appearance of the cleaved forms of both caspase- 3 and PARP is an indication of apoptosis. ${ }^{35,36} \mathrm{Tm}$ treatment for $24 \mathrm{~h}$ significantly induced both cleaved caspase-3 and cleaved PARP protein levels in INS-1 cells (Figure 4A). However, 9c cotreatment significantly reversed Tm-induced cleavage of both caspase-3 and PARP (Figure 4A). These results demonstrate that $9 \mathrm{c}$ inhibits Tm-induced activation of caspase 3 and apoptosis in INS-1 cells. Consistent with this, significantly more viable cells were observed with $\mathrm{Tm}$ and 9c co-treatment than with Tm alone (Figure 4B). 
ER stress also impairs the most important function of $\beta$ cells: the biosynthesis and secretion of insulin. Multiple steps of insulin synthesis and secretion are impaired under ER stress; they include insulin gene transcription, insulin mRNA stability, protein translation, and the insulin protein secretory process. 6 , 7, 37, 38 First, we examined whether compound 9 c could rescue Tm-suppressed mRNA levels of insulin genes. As expected, Tm treatment of INS-1 cells decreased the mRNA levels of both insulin genes, INS1 and INS2, but this reduction was completely rescued by $\mathbf{9 c}$ (Figure $\mathbf{5 A}$ and $\mathbf{B}$ ). Second, we examined whether compound 9c affects the expression of $\beta$ cell transcription factors PDX1 and MafA, which control $\beta$ cell identity and the expression of insulin genes. ${ }^{39,40}$ Chronic exposure to supraphysiologic concentrations of glucose and its associated ER stress cause the down-regulation of expression of PDX1 and MafA. ${ }^{41-45}$ Consistent with this notion, Tm decreased the levels of PDX1 and MafA mRNA expression levels in INS-1 cells. Co-treatment with 9c almost completely reversed this decrease to normal levels (Figure $\mathbf{5 C}$ and $\mathbf{D}$ ). Next, we explored whether compound $\mathbf{9 c}$ re-establishes Tm-impaired glucose-stimulated insulin secretion (GSIS). As shown in Figure 5E, Tm treatment abolished the insulin secretion caused by high concentration of glucose treatment $(25 \mathrm{mM})$ in INS-1 cells. Addition of $9 \mathbf{c}$ significantly rescued the GSIS in Tm-treated cells. Taken together, these data demonstrate that $\mathbf{9 c}$ restores ER stress-impaired $\beta$ cell survival and function.

Next, we investigated the mechanism by which 9c protects $\beta$ cells against ER stress. In response to ER stress, all three branches of the UPR, IRE1 $\alpha$, PERK and ATF6, are activated to either restore cellular homeostasis/survival or lead to cell death, depending on the severity of ER stress. First, we asked whether 9c affects the activation of IRE1a in $\beta$ cells under ER stress. Activated IRE1a cleaves X-box binding protein-1 (XBP1) mRNA to generate a spliced form (XBP1s) that is translated into a potent transcription factor which controls expression of UPR genes encoding factors involved in ER protein folding and degradation. ${ }^{7}, 12,46$ We therefore determined the effect of 9c on IRE1a-mediated XBP1 splicing in INS-1 cells in the presence of Tm. As shown in Figure 6A, INS-1 cells treated with Tm exhibited an increase in XBP1s mRNA, and this increase was suppressed by $\mathbf{9 c}$ cotreatment, as measured by qRT-PCT using XBP1 splicing-specific primers. Likewise, electrophoretic separation of spliced and unspliced forms of XBP1 after RT-PCR amplification of total XBP1 mRNA revealed that $9 \mathrm{c}$ inhibits the Tm-induced generation of XBP1s mRNA (Figure 6B). These results indicate that $9 \mathbf{c}$ inhibits the activation of the IRE1a-XBP1 pathway of the UPR.

Second, we asked whether 9c affects the activation of ATF6 in $\beta$ cells under ER stress. Activated ATF6 acts as a homodimer or as an ATF6-XBP1s heterodimer to control the upregulation of select UPR target genes including the chaperone proteins BiP and GRP94. ${ }^{12}, 46$ We evaluated the effect of $\mathbf{9 c}$ on the mRNA levels of chaperones Bip and GRP94 in $\beta$ cells in the presence of Tm. As expected, we found that both Bip and GRP94 mRNAs were upregulated in INS-1 cells treated with $\mathrm{Tm}$. These increases were almost completely suppressed by $9 \mathbf{c}$ co-treatment (Figure 7A and $\mathbf{B}$ ).

We then determined the effect of $\mathbf{9 c}$ on the activation of the PERK pathway in $\beta$ cells under ER stress. Activated PERK phosphorylates eukaryotic translation initiator factor $2 a$ (eIF2a), which in turn attenuates general protein synthesis to relieve ER load. EIF2a 
phosphorylation also allows the selective translation of ATF4 mRNA, which encodes a transcription factor that induces the expression of the pro-apoptotic gene C/EBPhomologous protein (CHOP). ${ }^{6,}$, $, 9,46$ Thus, we used ATF4 and CHOP expression levels as markers of PERK pathway activation. Tm treatment of INS-1 cells significantly increased the mRNA levels of both ATF4 and CHOP, whereas co-treatment with 9c resulted in a decrease in both their levels (Figure $\mathbf{8 A}$ and $\mathbf{B}$ ). Tm treatment also increased the ATF4 protein level with the peak time at $8 \mathrm{~h}$ and CHOP protein level starting at $8 \mathrm{~h}$ (Figure 8C). Consistent with its effects on ATF4 and CHOP mRNA transcription, 9c co-treatment also decreased ATF4 and CHOP protein levels in Tm-treated INS-1 cells (Figure 8C). Together, our results that $9 \mathrm{c}$ inhibited the ER stress-mediated activation of all three UPR pathways indicate that $9 \mathrm{c}$ protects $\beta$ cell survival by alleviating ER stress.

Finally, we investigated whether $9 c$ exhibits similar protective effects on primary human islet $\beta$ cells to exclude the possibility that our findings are merely unique to rodent $\beta$ cells. Rodent models of mammalian $\beta$ cell biology have been invaluable tools for the understanding of $\beta$ cell physiology and diabetes pathogenesis; however, human and rodent $\beta$ cells differ in fundamental ways. For example, the pancreatic islet architecture is markedly different between humans and rodents. In rodents, the islets are more organized, comprising a large core of $\beta$ cells (representing $~ 80 \%$ of islet cells) enveloped by a layer of a cells and other endocrine cells. However, in humans, $\beta$ cells account for only $\sim 50 \%$ of islet cells and are scattered throughout the islet. ${ }^{47}$ Rodent $\beta$ cells also show significant regenerative capacity that human $\beta$ cells lack. ${ }^{47}$ Moreover, among hundreds of manipulations reported to prevent or cure T1D in the NOD diabetic mouse model, very few demonstrate a limited efficacy in T1D patients. ${ }^{48,49}$ Therefore, agents that function well in rodent systems need to be confirmed in human systems. We utilized primary human islets to evaluate whether $\mathbf{9 c}$ protects $\beta$ cell survival and function impaired by ER stress. Another advantage of human islets is that they are primary cells and, therefore, share more authentic properties with $\beta$ cells than immortalized cell lines.

First, we determined whether $9 \mathrm{c}$ suppresses the apoptosis of primary human $\beta$ cells induced by Tm treatment as assessed by TUNEL, which detects fragmentation of DNA, a marker of apoptotic cell death,. As expected, Tm treatment markedly increased TUNEL staining in insulin ${ }^{+}$cells ( $15 \%$ TUNEL $^{+}$insulin ${ }^{+}$cells compared to $2.5 \%$ with DMSO) (Figure $9 \mathrm{~A}$ and B). Compound $9 \mathbf{c}$ co-treatment significantly decreased the percentage of $\mathrm{TUNEL}^{+}$insulin $^{+}$ cells to 3.5\% (Figure 9A and $\mathbf{B}$ ). Next, we investigated whether $\mathbf{9 c}$ restored the Tm-induced insulin secretion defect. Tm treatment markedly diminished the high glucose-stimulated increase in insulin secretion, but the addition of $\mathbf{9 c}$ significantly reversed this effect and restored the Tm-impaired GSIS (Figure $\mathbf{9 C}$ ). These data indicate that $\mathbf{9 c}$ is equally effective for the protection of human $\beta$ cells as for rodent $\beta$ cells.

\section{Conclusion}

In summary, we discovered and optimized 2,4-diaminoquinazoline analogs as a novel class of agents that suppress ER stress-induced $\beta$ cell death and dysfunction. The 2(hydroxymethyl)piperidin-1-yl-containing analogues showed improved potency and maximum activity over their 2-(hydroxymethyl)pyrrolidin-1-yl counterparts, of which the 4- 
$\mathrm{OCH}_{3}$ - and benzylamine-containing $9 \mathbf{c}$ exhibited optimal $\beta$ cell-protective activity. In addition, we have demonstrated that $9 \mathbf{c}$ alleviates ER stress/UPR response by inhibiting Tminduced up-regulation of key genes involved in the unfolded protein response and apoptosis. Figure 10 proposes a model of signaling events leading to the protective effect of $9 \mathbf{c}$ in $\beta$ cells against ER stress-induced dysfunction and cell death. Importantly, the $9 \mathrm{c}$ effects on rodent $\beta$ cells are translatable to human cells as $9 \mathbf{c}$ also shows potent protective activities on primary human islet $\beta$ cells, a prerequisite for potential drug development for human diabetes. Studies to improve the pharmacokinetic properties of $\mathbf{9 c}$ are ongoing as part of our program to develop novel chemotypes as a $\beta$ cell-protective leads for further anti-diabetic drug development.

\section{EXPERIMENTAL SECTION}

\section{Cell culture}

INS-1 cells were cultured in RPMI 1640 (Corning, NY, USA) supplemented with 10\% FBS (Atlanta Biologicals, Norcross, GA), HEPES (10 mM, Life Technologies, CA, USA), sodium pyruvate (1 mM, Corning), 2-mercaptoethanol (50 $\mu \mathrm{M}$, Sigma, St Louis, MO, USA) and antibiotics (100 UI/mL penicillin and $100 \mu \mathrm{g} / \mathrm{mL}$ streptomycin, Corning). $\beta$ TC6 cells were cultured in DMEM (Corning) with 15\% FBS, sodium pyruvate (1 mM, Corning), nonessential amino acids ( $1 \mathrm{mM}$, Thermo, IL, USA), GlutaMAX ( $1 \mathrm{mM}$, Life Technologies) and antibiotics (100 UI/mL penicillin and $100 \mu \mathrm{g} / \mathrm{mL}$ streptomycin). Human islets were obtained from the Integrated Islet Distribution Program (Duarte, CA) in accordance with Oklahoma Medical Research Foundation's internal review board (IRB) and ethical guidelines for the use of human tissue. Standard viability was $80-90 \%$ and purity was $>80 \%$. Islets were maintained in CMRL medium (Life Technologies) supplemented with $10 \%$ FBS. All cells were grown at $37{ }^{\circ} \mathrm{C}$ in a humidified $5 \% \mathrm{CO}_{2}$ atmosphere.

\section{Cell survival assay}

INS- 1 cells or $\beta$ TC6 cells were seeded at $3 \times 10^{3}$ cells/well in a 384-well plate and treated with compounds at the indicated concentrations. After $3 \mathrm{~d}$ treatment, the medium was aspirated and $20 \mu \mathrm{L} /$ well of CellTiter-Glo reagent (Promega, WI, USA) was added. Cell viability was measured with an EnVision multilabel plate reader (PerkinElmer, MA, USA).

\section{RNA isolation and qRT-PCR}

INS- 1 cells were seeded at $4 \times 10^{5}$ cells/well in 6-well plates and treated with compounds for the indicated times. Total RNA was extracted using TRIzol reagent (Invitrogen,

Carlsbad, CA) according to the manufacturer's protocol, and $2 \mu \mathrm{g}$ of total RNA was reverse transcribed using a Superscript kit (Invitrogen). Real-time PCR was performed in 96-well format using SYBR Select Master Mix (Applied Biosystems, Foster City, CA) with an ABI 7500 PCR system (Applied Biosystems). The primer sequences used were: Rat CHOP: F, 5'-GAAATCGAGCGCCTGACCAG-3' and R, 5'-GGAGGTGATGCCAACAGTTCA-3'. Rat ATF4: F, 5'-TCCTGAACAGCGAAGTGTTG-3' and R, 5'GTGTCTGAGGCACTGACCAA-3'. Rat Bip: F, 5'-CTATTCCTGCGTCGGTGTATT-3' and R, 5'-GGTTGGACGTGAGTTGGTTCT-3'. Rat GRP94: F, 5'TCCCCCTTAATGTTTCCCGTG-3' and R, 5' '-TAGCCCTTCTTCAGAAGCCTC-3'. Rat 
XBP1s: F, 5'-CTGAGTCCGAATCAGGTGCAG-3' and R, 5'-

ATCCATGGGAAGATGTTCTGG-3'. Rat XBP1 for regular PCR (XBP1u and XBP1s): F, 5'-GCTTGTGATTGAGAACCAGG-3', R, 5'-GAAAGGGAGGCTGGTAAGGAAC-3'. Rat Ins1: F, 5'-GTCCTCTGGGAGCCCAAG-3' and R, 5'-ACAGAGCCTCCACCAGG-3'. Rat Ins2: F, 5'-ATCCTCTGGGAGCCCCGC-3' and R, 5'-AGAGAGCTTCCACCAAG-3'. Rat PDX1: F, 5'-GAGGACCCGTACAGCCTACA-3' and R, 5' CGTTGTCCCGCTACTACGTT-3'. Rat MafA: F, 5'-AGCGGTCATATTTTCGCAAC-3' and R, 5'-CTCTACAGGGAGCAGCGAAC-3'. Rat Cyclophilin A: F, 5'GGTGACTTCACACGCCATAA-3' and R, 5'-CTTCCCAAAGACCACATGCT-3'.

\section{Western blotting}

INS- 1 cells were seeded in 60 -mm dishes at $8 \times 10^{5}$ cells/dish and treated for the indicated times. Cells were then washed with PBS and lysed with lysis buffer (Cell Signaling Technology, Danvers, MA) containing EDTA (Thermo, IL) and phosphatase inhibitors (Thermo). Aliquots of $20 \mu \mathrm{g}$ total protein were separated on 7\% SDS-PAGE gels (Life Technologies) and transferred to PVDF membranes (Life Technologies). The membranes were probed with primary antibodies followed by the appropriate HRP-conjugated secondary antibodies (goat anti-rabbit IgG and goat anti-mouse IgG, 1:3000; Santa Cruz Biotechnology, CA, USA). Blots were then developed. The primary antibodies and dilutions used were: CHOP (1:1000, MA1-250, Thermo), ATF4 (1:1000, 10835-1-AP, ProteinTech Group, IL, USA), cleaved caspase 3 (1:1000, 9661, Cell Signaling Technology, MA, USA), PARP (1:1000, 9542L, Cell Signaling Technology), and a-tubulin (1:3000, SC-8035, Santa Cruz Biotechnology).

\section{MTT assay}

INS- 1 cells or $\beta$ TC 6 cells were seeded at $3 \times 10^{3}$ cells/well in a 384 -well plate and treated with compounds at the indicated concentrations. After $3 \mathrm{~d}$ treatment, the medium was aspirated and $10 \mu \mathrm{l}$ of MTT reagent (Cayman Chemical, MI, USA, prepared according to manufacturer's instruction) to each well was added and mixed gently for one minute on an orbital shaker. The cells were then incubated for three hours at $37{ }^{\circ} \mathrm{C}$ in a $\mathrm{CO}_{2}$ incubator. After incubation, add $100 \mu \mathrm{l}$ of crystal dissolving solution to each well, and incubate for 4 hours in a $37{ }^{\circ} \mathrm{C} \mathrm{CO}_{2}$ incubator. Viability will be measured for the absorbance to each sample at $570 \mathrm{~nm}$ using EnVision multilabel plate reader (PerkinElmer, MA, USA).

\section{Glucose-stimulated insulin secretion}

INS-1 or primary human islet cells were plated in 96-well plates. The second day, Tm and compound $9 \mathrm{c}$ were added and maintained for $24 \mathrm{~h}$ (INS-1) or $48 \mathrm{~h}$ (human islets). Cells were then incubated in fresh KRBH buffer $\left(115 \mathrm{mM} \mathrm{NaCl}, 5 \mathrm{mM} \mathrm{KCl}, 24 \mathrm{mM} \mathrm{NaHCO}_{3}, 2.5 \mathrm{mM}\right.$ $\mathrm{CaCl}_{2}, 1 \mathrm{mM} \mathrm{MgCl} 2,10 \mathrm{mM}$ HEPES, $2 \%$ w/v BSA, pH 7.4) containing $2.5 \mathrm{mM}$ glucose for $1 \mathrm{~h}$. Cells were incubated for an additional hour in KRBH buffer containing 2.5, 25 (for INS-1 cells), or 20 (for human islets) $\mathrm{mM}$ glucose. The secreted insulin was measured with insulin ELISA kits (for mouse insulin from Millipore and for human insulin from LifeTech). Cells were lysed with RIPA buffer (50 mM Tris $\mathrm{HCl}$ pH 7.4, $1 \%$ NP-40, $0.25 \%$ sodium 
deoxycholate, $150 \mathrm{mM} \mathrm{NaCl}$ ), and total cellular protein was determined with a Bradford protein assay. The secreted insulin levels were corrected for total protein.

\section{Immunofluorescent and TUNEL Staining}

Primary human islets were washed with PBS and fixed with 4\% paraformaldehyde for 30 min. Fixed cells were then blocked in 5\% normal donkey serum for $30 \mathrm{~min}$. Polyclonal guinea pig anti-insulin (A0564, Dako, 1:500 dilution) was used as primary antibody. Donkey Cy3 anti-guinea pig IgG was used as the secondary antibody. TUNEL staining was performed with In Situ Cell Death Detection Kit-Fluorescein (Roche) according to the manufacturer's instructions. DAPI was used for nuclear counter-staining. Images were taken with an Olympus FV1000 confocal microscope.

\section{Statistical analysis}

Data are presented as means \pm SD unless specified. Comparisons were performed by twotailed paired Student's $t$-test. A $P$ value of $<0.05$ was considered statistically significant.

\section{Chemistry}

Materials and Methods. Unless otherwise stated, all reagents and solvents were purchased from commercial suppliers (Sigma-Aldrich and Fisher Scientific) and were used without further purification. All compounds were purified by flash column chromatography on Sorbent Technologies silica geL, 60^ (63-200 mesh). TLC was done on SAI F254 precoated silica gel plates ( $250 \mu \mathrm{m}$ layer thickness). ${ }^{1} \mathrm{H}$ NMR and ${ }^{13} \mathrm{C}$ NMR spectra were recorded on a Bruker AVANCE III $400 \mathrm{MHz}$ spectrometer using tetramethylsilane as an internal reference. ESI-MS spectra were obtained on a Krats MS 80 mass spectrometer. The purity of all tested compounds was at least above $95 \%$ as determined by HPLC (Agilent 1260, Agilent ChemStation, Agilent Eclipse XDB-C18, $5 \mu \mathrm{M}, 4.6 \times 150 \mathrm{~mm}$, UV $254 \mathrm{~nm}$, $30{ }^{\circ} \mathrm{C}$, flow rate $=1.0 \mathrm{~mL} / \mathrm{min}$ ).

2,4-dichloroquinazoine (3)-To a mixture of benzoyleneurea ( $800 \mathrm{mg}, 4.93 \mathrm{mmol}$ ) in $\mathrm{POCl}_{3}(10 \mathrm{~mL})$, dimethylaniline $(640.5 \mathrm{mg}, 5.26 \mathrm{mmol})$ was added at room temperature. The reaction mixture was stirred at $120^{\circ} \mathrm{C}$ for $24 \mathrm{~h}$. The reaction mixture was quenched with ice-cold water. The reddish solid, compound $\mathbf{3}$, was precipitated, vacuum filtered, and then washed with hexane and dried under vacuum. It was used without further purification $(672.3 \mathrm{mg}, 68.6 \%) .{ }^{1} \mathrm{H} \mathrm{NMR}\left(400 \mathrm{MHz}, \mathrm{CDCl}_{3}\right) \delta 8.27$ (ddd, $\left.J=8.4,2.0,0.8 \mathrm{~Hz}, 1 \mathrm{H}\right)$, 8.03-8.00 (m, 2H), 7.77-7.73 (m, 1H). ${ }^{13} \mathrm{C}$ NMR $\left(100 \mathrm{MHz}, \mathrm{CDCl}_{3}\right) \delta$ 164.0, 155.1, 152.4, 136.2, 129.3, 128.0, 126.1, 122.4. LC-MS (ESI, formic) $\mathrm{m} / \mathrm{z} 199.0[\mathrm{M}+\mathrm{H}]^{+}$.

2-chloro-N-phenethylquinazolin-4-amine (4a)_A solution of compound $\mathbf{3}$ (100 mg, $0.56 \mathrm{mmol})$ in $\mathrm{n}-\mathrm{BuOH}(3 \mathrm{~mL})$ was treated with DIEA (215.9 mg, $1.67 \mathrm{mmol})$ and phenethylamine $(67.9 \mathrm{mg}, 0.56 \mathrm{mmol})$. The reaction mixture was stirred for $2 \mathrm{~h}$ at $40{ }^{\circ} \mathrm{C}$ and the solvent was evaporated. The residue was extracted with methylene chloride $(30 \mathrm{~mL}, 3$ times) and water. The organic layer was dried over $\mathrm{Na}_{2} \mathrm{SO}_{4}$ and evaporated. Compound $4 \mathbf{4 a}$ was purified from this crude material by column chromatography (silicagel, n-hexane/ EtOAc $=3: 1)(117.4 \mathrm{mg}, 73.9 \%) .{ }^{1} \mathrm{H}$ NMR $\left(400 \mathrm{MHz}, \mathrm{CDCl}_{3}\right) \delta$ 7.77-7.74 (dd, $J=8.4,1.2$ Hz, 1H), 7.72 (ddd, $J=8.4,6.8,1.2 \mathrm{~Hz}, 1 \mathrm{H}$ ), 7.49 (d, $J=7.6 \mathrm{~Hz}, 1 \mathrm{H}$ ), 7.40 (ddd, $J=8.4$, 
6.8, 1.6 Hz, 1H), 7.37-7.33 (m, 2H), 7.29-7.25 (m, 3H), 5.94 (br s, $1 \mathrm{H}), 3.95$ (q, $J=6.8,5.6$ $\mathrm{Hz}, 2 \mathrm{H}), 3.03(\mathrm{t}, J=6.8 \mathrm{~Hz}, 2 \mathrm{H}) .{ }^{13} \mathrm{C}$ NMR $\left(100 \mathrm{MHz}, \mathrm{CDCl}_{3}\right) \delta 160.8,157.8,150.8$, 138.5, 133.5, 128.9, 127.9, 126.8, 126.2, 120.5, 113.3, 42.5, 35.0. LC-MS (ESI, formic) $\mathrm{m} / \mathrm{z}$ $284.1[\mathrm{M}+\mathrm{H}]^{+}$.

(1-(4-(phenethylamino)quinazolin-2-yl)pyrrolidin-2-yl)methanol (5a)-A solution of $4 \mathbf{a}(50 \mathrm{mg}, 0.176 \mathrm{mmol})$ in $\mathrm{n}-\mathrm{BuOH}(2 \mathrm{~mL})$ was treated with DIEA $(68.3 \mathrm{mg}, 0.529$ $\mathrm{mmol}$ ) and L-prolinol (53.5 $\mathrm{mg}, 0.529 \mathrm{mmol})$. The resulting mixture was stirred overnight at $120{ }^{\circ} \mathrm{C}$ and the solvent was evaporated. The residue was extracted with methylene chloride (20 mL, 3 times) and water. The organic layer was dried over $\mathrm{Na}_{2} \mathrm{SO}_{4}$ and evaporated. Compound $\mathbf{5 a}$ was purified from this crude material by column chromatography (silicagel, $\mathrm{CH}_{2} \mathrm{Cl}_{2}: \mathrm{MeOH}$ :triethylamine $\left.=10: 1: 0.1\right)(39.6 \mathrm{mg}, 64.6 \%)$. purity $(97.96 \%) ;{ }^{1} \mathrm{H} \mathrm{NMR}(400$ $\left.\mathrm{MHz}, \mathrm{CDCl}_{3}\right) \delta 7.48(\mathrm{ddd}, J=8.4,6.8,1.2 \mathrm{~Hz}, 1 \mathrm{H}), 7.40(\mathrm{t}, J=8.8 \mathrm{~Hz}, 2 \mathrm{H}), 7.35-7.31(\mathrm{~m}$, 2H), 7.27-7.23 (m, 3H), 7.01 (ddd, $J=8.4,7.2,1.2 \mathrm{~Hz}, 1 \mathrm{H}), 5.97$ (br s, $1 \mathrm{H}), 4.40-4.35$ (m, $1 \mathrm{H}), 3.99-3.93(\mathrm{~m}, 1 \mathrm{H}), 3.88-3.78(\mathrm{~m}, 3 \mathrm{H}), 3.72-3.63(\mathrm{~m}, 2 \mathrm{H}), 3.02(\mathrm{t}, J=7.2 \mathrm{~Hz}, 2 \mathrm{H})$, 2.20-2.12 (m, 1H), 1.99-1.83 (m, 2H), 1.71-1.63 (m,1H). $\left.{ }^{13} \mathrm{C} \mathrm{NMR} \mathrm{(100} \mathrm{MHz,} \mathrm{CDCl}_{3}\right) \delta$ 159.6, 158.4, 139.1, 132.9, 128.9, 128.7, 126.6, 124.5, 121.1, 120.8, 110.2, 68.7, 61.1, 48.5, 42.5, 35.3, 30.0, 24.1. HRMS calculated for $\mathrm{C}_{21} \mathrm{H}_{25} \mathrm{~N}_{4} \mathrm{O}\left([\mathrm{M}+\mathrm{H}]^{+}\right) \mathrm{m} / z$ 349.2028, found $\mathrm{m} / \mathrm{z} 349.2029 ; \mathrm{mp} 171.8-175.5^{\circ} \mathrm{C}$.

(1-(4-(phenethylamino)quinazolin-2-yl)piperidin-2-yl)methanol (6a)-A solution of $4 \mathbf{a}(50 \mathrm{mg}, 0.176 \mathrm{mmol})$ in $\mathrm{n}-\mathrm{BuOH}(2 \mathrm{~mL})$ was treated with DIEA $(68.3 \mathrm{mg}, 0.529$ $\mathrm{mmol})$ and 2-piperidinemethanol $(60.9 \mathrm{mg}, 0.529 \mathrm{mmol})$. The reaction mixture was stirred overnight at $120{ }^{\circ} \mathrm{C}$ and the solvent was evaporated. The residue was extracted with methylene chloride ( $20 \mathrm{~mL}, 3$ times) and water. The organic layer was dried over $\mathrm{Na}_{2} \mathrm{SO}_{4}$ and evaporated. Compound $6 \mathrm{a}$ was purified from this crude material by column chromatography (silicagel, $\mathrm{CH}_{2} \mathrm{Cl}_{2}: \mathrm{MeOH}$ :triethylamine $\left.=10: 1: 0.1\right)(43.3 \mathrm{mg}, 67.9 \%$ ). purity $(99.90 \%) ;{ }^{1} \mathrm{H} \mathrm{NMR}\left(400 \mathrm{MHz}, \mathrm{CDCl}_{3}\right) \delta 7.53(\mathrm{~d}, J=8.0 \mathrm{~Hz}, 1 \mathrm{H}), 7.48-7.36(\mathrm{~m}, 4 \mathrm{H})$, $7.11(\mathrm{~d}, J=8.4 \mathrm{~Hz}, 2 \mathrm{H}), 7.07-7.03(\mathrm{~m}, 1 \mathrm{H}), 6.39$ (br s, $1 \mathrm{H}), 4.99$ (d, $J=4.0 \mathrm{~Hz}, 1 \mathrm{H}), 4.77$ $(\mathrm{d}, J=13.6 \mathrm{~Hz}, 1 \mathrm{H}), 4.09(\mathrm{t}, J=10.8,10.4 \mathrm{~Hz}, 1 \mathrm{H}), 3.82-3.75(\mathrm{~m}, 3 \mathrm{H}), 3.21-3.14(\mathrm{~m}, 1 \mathrm{H})$, 2.96 (t, $J=7.2 \mathrm{~Hz}, 2 \mathrm{H}), 1.76-1.58(\mathrm{~m}, 6 \mathrm{H}) .{ }^{13} \mathrm{C} \mathrm{NMR}\left(100 \mathrm{MHz}, \mathrm{CDCl}_{3}\right) \delta 159.4,138.0$, 133.1, 131.8, 130.6, 122.1, 121.2, 120.5, 110.2, 53.9, 42.4, 40.0, 34.6, 29.7, 26.3, 25.2, 20.0. HRMS calcd for $\mathrm{C}_{22} \mathrm{H}_{27} \mathrm{~N}_{4} \mathrm{O}\left([\mathrm{M}+\mathrm{H}]^{+}\right) \mathrm{m} / \mathrm{z} 363.2185$, found $\mathrm{m} / \mathrm{z} 363.2177$; mp 159.0-161.1.

2-chloro-N-(4-fluorophenethyl)quinazolin-4-amine) (4b)-A solution of compound 3 (100 mg, $0.56 \mathrm{mmol})$ in n-BuOH (3 mL) was treated with DIEA (215.9 mg, $1.67 \mathrm{mmol})$ and 4-fluorophenethylamine $(77.9 \mathrm{mg}, 0.56 \mathrm{mmol})$. The reaction mixture was stirred for $2 \mathrm{~h}$ at $40{ }^{\circ} \mathrm{C}$ and the solvent was evaporated. The residue was extracted with methylene chloride (20 mL, 3 times) and water. The organic layer was dried over $\mathrm{Na}_{2} \mathrm{SO}_{4}$ and evaporated.

Compound $\mathbf{4 b}$ was purified from this crude material by column chromatography (silicagel, n-hexane/EtOAc $=3: 1)(114.3 \mathrm{mg}, 67.6 \%) .{ }^{1} \mathrm{H}$ NMR $\left(400 \mathrm{MHz}, \mathrm{CDCl}_{3}\right) \delta$ 7.76-7.70 (m, $2 \mathrm{H}), 7.52(\mathrm{~d}, J=8.0 \mathrm{~Hz}, 1 \mathrm{H}), 7.42(\mathrm{ddd}, J=8.0,6.4,1.6 \mathrm{~Hz}, 1 \mathrm{H}), 7.23-7.18(\mathrm{~m}, 2 \mathrm{H})$, 7.04-6.99 (m, 2H), 5.99 (br s, 1H), $3.92(\mathrm{q}, J=7.0 \mathrm{~Hz}, 2 \mathrm{H}), 3.01(\mathrm{t}, J=7.0 \mathrm{~Hz}, 2 \mathrm{H}) .{ }^{13} \mathrm{C}$ 
$\operatorname{NMR}\left(100 \mathrm{MHz}, \mathrm{CDCl}_{3}\right) \delta 163.0,160.8,160.6,157.8,150.8,133.5,130.3,130.2,127.9$, $126.3,120.5,115.8,115.5,113.2,42.6,34.3$. LC-MS (ESI, formic) $\mathrm{m} / \mathrm{z} 302.1[\mathrm{M}+\mathrm{H}]^{+}$.

(1-(4-((4-fluorophenethyl)amino)quinazolin-2-yl)pyrrolidin-2-yl)methanol (5b)A solution of $4 \mathbf{b}(50 \mathrm{mg}, 0.166 \mathrm{mmol})$ in $\mathrm{n}-\mathrm{BuOH}(2 \mathrm{~mL})$ was treated with DIEA $(64.2 \mathrm{mg}$, $0.497 \mathrm{mmol}$ ) and L-prolinol $(50.3 \mathrm{mg}, 0.497 \mathrm{mmol})$. The reaction mixture was stirred overnight at $120{ }^{\circ} \mathrm{C}$ and the solvent was evaporated. The residue was extracted with methylene chloride ( $30 \mathrm{~mL}, 3$ times) and water. The organic layer was dried over $\mathrm{Na}_{2} \mathrm{SO}_{4}$ and evaporated. Compound $\mathbf{5 b}$ was purified from this crude material by column chromatography (silicagel, $\mathrm{CH}_{2} \mathrm{Cl}_{2}: \mathrm{MeOH}$ :triethylamine $\left.=10: 1: 0.1\right)(31.5 \mathrm{mg}, 51.8 \%$ ). purity (99.30\%); ${ }^{1} \mathrm{H}$ NMR $\left(400 \mathrm{MHz}, \mathrm{CDCl}_{3}\right) \delta 7.48(\mathrm{ddd}, J=8.4,7.2,1.2 \mathrm{~Hz}, 1 \mathrm{H}), 7.39(\mathrm{t}$, $J=7.2,6.4 \mathrm{~Hz}, 2 \mathrm{H}), 7.20-7.17$ (m, 2H), 7.03-6.98 (m, 3H), $5.92(\mathrm{br} \mathrm{s}, 1 \mathrm{H}), 4.40-4.34$ (m, $1 \mathrm{H}), 3.98-3.92(\mathrm{~m}, 1 \mathrm{H}), 3.84-3.78(\mathrm{~m}, 3 \mathrm{H}), 3.71-3.62(\mathrm{~m}, 2 \mathrm{H}), 2.99(\mathrm{t}, J=7.2 \mathrm{~Hz}, 2 \mathrm{H})$, 2.20-2.11 (m, 1H), 2.01-1.84 (m, 2H), 1.70-1.63 (m, 1H). ${ }^{13} \mathrm{C} \mathrm{NMR}\left(100 \mathrm{MHz}, \mathrm{CDCl}_{3}\right) \delta$ $162.9,160.5,159.6,158.5,132.9,130.3,130.2,121.1,120.7,115.6,115.4,110.2,68.8$, 61.1, 48.5, 42.6, 34.5, 29.9, 24.1. HRMS (FAB) calcd for $\mathrm{C}_{21} \mathrm{H}_{24} \mathrm{FN}_{4} \mathrm{O}\left([\mathrm{M}+\mathrm{H}]^{+}\right) \mathrm{m} / \mathrm{z}$ 367.1934 , found $\mathrm{m} / \mathrm{z} 367.1931$.

(1-(4-((4-fluorophenethyl)amino)quinazolin-2-yl)piperidin-2-yl)methanol (6b)A solution of $4 \mathbf{b}(50 \mathrm{mg}, 0.166 \mathrm{mmol})$ in $\mathrm{n}-\mathrm{BuOH}(2 \mathrm{~mL})$ was treated with DIEA $(64.2 \mathrm{mg}$, $0.497 \mathrm{mmol}$ ) and 2-piperidinemethanol $(57.3 \mathrm{mg}, 0.497 \mathrm{mmol})$. The reaction mixture was stirred overnight at $120^{\circ} \mathrm{C}$ and the solvent was evaporated. The residue was extracted with methylene chloride ( $30 \mathrm{~mL}, 3$ times) and water. The organic layer was dried over $\mathrm{Na}_{2} \mathrm{SO}_{4}$ and evaporated. Compound $\mathbf{6 b}$ was purified from this crude material by column chromatography (silicagel, $\mathrm{CH}_{2} \mathrm{Cl}_{2}: \mathrm{MeOH}$ :triethylamine = 10:1:0.1) $(37.4 \mathrm{mg}, 59.2 \%)$. purity (97.70\%); ${ }^{1} \mathrm{H}$ NMR $\left(400 \mathrm{MHz}, \mathrm{CDCl}_{3}\right) \delta 7.49(\mathrm{~d}, J=4.4 \mathrm{~Hz}, 2 \mathrm{H}), 7.37(\mathrm{~d}, J=8.0$ $\mathrm{Hz}, 1 \mathrm{H}), 7.22-7.18(\mathrm{~m}, 2 \mathrm{H}), 7.07-6.99(\mathrm{~m}, 3 \mathrm{H}), 5.95(\mathrm{br} \mathrm{s}, 1 \mathrm{H}), 5.05-5.02(\mathrm{~m}, 1 \mathrm{H}), 4.80(\mathrm{~d}, J$ $=13.6 \mathrm{~Hz}, 1 \mathrm{H}), 4.11(\mathrm{t}, J=10.8,10.0 \mathrm{~Hz}, 1 \mathrm{H}), 3.84-3.77(\mathrm{~m}, 3 \mathrm{H}), 3.22-3.16(\mathrm{~m}, 1 \mathrm{H}), 2.99(\mathrm{t}$, $J=7.2,6.8 \mathrm{~Hz}, 2 \mathrm{H}), 2.04-2.00(\mathrm{~m}, 1 \mathrm{H}), 1.76-1.71(\mathrm{~m}, 3 \mathrm{H}), 1.68-1.58(\mathrm{~m}, 4 \mathrm{H}) .{ }^{13} \mathrm{C}$ NMR $\left(100 \mathrm{MHz}, \mathrm{CDCl}_{3}\right) \delta 162.9,159.5,134.6,132.9,130.3,130.2,121.6,120.7,115.7,115.4$, 110.3, 63.9, 53.7, 42.6, 40.0, 34.4, 29.7, 26.4, 25.3, 20. HRMS calcd for $\mathrm{C}_{22} \mathrm{H}_{26} \mathrm{FN}_{4} \mathrm{O}([\mathrm{M}+$ $\mathrm{H}]^{+}$) $\mathrm{m} / \mathrm{z} 381.2091$, found $\mathrm{m} / \mathrm{z} 381.2094$; mp $147.1-149.5^{\circ} \mathrm{C}$.

2-chloro-N-(4-chlorophenethyl)quinazolin-4-amine (4c)-A solution of compound 3 (100 mg, $0.56 \mathrm{mmol})$ in n-BuOH (3 mL) was added DIEA (215.9 mg, $1.67 \mathrm{mmol})$ and 4chlorophenethylamine $(87.1 \mathrm{mg}, 0.56 \mathrm{mmol})$. The reaction mixture was stirred for 2 hours at $40{ }^{\circ} \mathrm{C}$ and the solvent was evaporated. The residue was extracted with methylene chloride (30 mL, 3 times) and water. The organic layer was dried over $\mathrm{Na}_{2} \mathrm{SO}_{4}$ and evaporated. Compound $\mathbf{4 c}$ was purified from this crude material by column chromatography (silicagel, n-hexane/EtOAc = 3:1) $(129.7 \mathrm{mg}, 72.8 \%) .{ }^{1} \mathrm{H} \mathrm{NMR}\left(400 \mathrm{MHz}, \mathrm{CDCl}_{3}\right) \delta$ 7.77-7.70 (m, 2H), $7.53(\mathrm{~d}, J=8.0 \mathrm{~Hz}, 1 \mathrm{H}), 7.42(\mathrm{ddd}, J=8.0,6.4,1.6 \mathrm{~Hz}, 1 \mathrm{H}), 7.31-7.28(\mathrm{~m}, 2 \mathrm{H})$, 7.20-7.16 (m, 2H), 5.96 (br s, 1H), 3.92 (q, $J=7.2,6.8,5.6 \mathrm{~Hz}, 2 \mathrm{H}), 3.01$ (t, $J=6.8 \mathrm{~Hz}$, $2 \mathrm{H}) .{ }^{13} \mathrm{C} \mathrm{NMR}\left(100 \mathrm{MHz}, \mathrm{CDCl}_{3}\right) \delta 160.8,157.7,150.9,137.0,133.6,132.7,130.2,128.9$, $127.9,126.3,120.5,113.2,42.4,34.4$. LC-MS (ESI, formic) $\mathrm{m} / \mathrm{z} 318.0[\mathrm{M}+\mathrm{H}]^{+}$. 
(1-(4-((4-chlorophenethyl)amino)quinazolin-2-yl)pyrrolidin-2-yl)methanol (5c)A solution of $4 \mathbf{c}(50 \mathrm{mg}, 0.157 \mathrm{mmol})$ in $\mathrm{n}-\mathrm{BuOH}(2 \mathrm{~mL})$ was treated with DIEA (60.9 mg, $0.471 \mathrm{mmol})$ and L-prolinol $(47.7 \mathrm{mg}, 0.471 \mathrm{mmol})$. The reaction mixture was stirred overnight at $120^{\circ} \mathrm{C}$ and the solvent was evaporated. The residue was extracted with methylene chloride (20 mL, 3 times) and water. The organic layer was dried over $\mathrm{Na}_{2} \mathrm{SO}_{4}$ and evaporated. Compound $\mathbf{5 c}$ was purified from this crude material by column chromatography (silicagel, $\mathrm{CH}_{2} \mathrm{Cl}_{2}: \mathrm{MeOH}$ :triethylamine $\left.=10: 1: 0.1\right)(47.2 \mathrm{mg}, 78.5 \%)$. purity $(98.75 \%) ;{ }^{1} \mathrm{H}$ NMR $\left(400 \mathrm{MHz}, \mathrm{CDCl}_{3}\right) \delta 7.52-7.48(\mathrm{~m}, 1 \mathrm{H}), 7.42(\mathrm{~d}, J=8.0 \mathrm{~Hz}, 1 \mathrm{H})$, $7.37(\mathrm{~d}, J=7.6 \mathrm{~Hz}, 1 \mathrm{H}), 7.31-7.27(\mathrm{~m}, 2 \mathrm{H}), 7.17(\mathrm{~d}, J=7.6 \mathrm{~Hz}, 2 \mathrm{H}), 7.05-7.01(\mathrm{~m}, 1 \mathrm{H})$, $5.80(\mathrm{br} \mathrm{s}, 1 \mathrm{H}), 4.40-4.35(\mathrm{~m}, 1 \mathrm{H}), 3.98-3.91(\mathrm{~m}, 1 \mathrm{H}), 3.86-3.78(\mathrm{~m}, 3 \mathrm{H}), 3.72-3.62(\mathrm{~m}, 2 \mathrm{H})$, $3.00(\mathrm{t}, J=7.2,6.8 \mathrm{~Hz}, 2 \mathrm{H}), 2.21-2.12(\mathrm{~m}, 1 \mathrm{H}), 2.01-1.83(\mathrm{~m}, 3 \mathrm{H}), 1.71-1.63(\mathrm{~m}, 1 \mathrm{H}) .{ }^{13} \mathrm{C}$ NMR $\left(100 \mathrm{MHz}, \mathrm{CDCl}_{3}\right) \delta 159.6,158.5,137.6,133.0,132.4,130.2,128.8,121.2,120.6$, 110.1, 68.8, 61.1, 48.5, 42.4, 34.6, 29.9, 24.1. HRMS calcd for $\mathrm{C}_{21} \mathrm{H}_{24} \mathrm{ClN}_{4} \mathrm{O}\left([\mathrm{M}+\mathrm{H}]^{+}\right)$ $\mathrm{m} / \mathrm{z} 383.1639$, found $\mathrm{m} / \mathrm{z} 383.1634$; $\mathrm{mp} 101.6-104.6^{\circ} \mathrm{C}$.

(1-(4-((4-chlorophenethyl)amino)quinazolin-2-yl)piperidin-2-yl)methanol (6c)A solution of $4 \mathbf{c}(50 \mathrm{mg}, 0.157 \mathrm{mmol})$ in $\mathrm{n}-\mathrm{BuOH}(2 \mathrm{~mL})$ was treated with DIEA (60.9 mg, $0.471 \mathrm{mmol}$ ) and 2-piperidinemethanol $(54.2 \mathrm{mg}, 0.471 \mathrm{mmol})$. The reaction mixture was stirred overnight at $120^{\circ} \mathrm{C}$ and the solvent was evaporated. The residue was extracted with methylene chloride (20 mL, 3 times) and water. The organic layer was dried over $\mathrm{Na}_{2} \mathrm{SO}_{4}$ and evaporated. Compound $6 \mathrm{c}$ was purified from this crude material by column chromatography (silicagel, $\mathrm{CH}_{2} \mathrm{Cl}_{2}: \mathrm{MeOH}$ :triethylamine $\left.=10: 1: 0.1\right)(44.5 \mathrm{mg}, 71.4 \%)$. purity $(97.58 \%) ;{ }^{1} \mathrm{H}$ NMR $\left(400 \mathrm{MHz}, \mathrm{CDCl}_{3}\right) \delta 7.51-7.47(\mathrm{~m}, 1 \mathrm{H}), 7.42(\mathrm{~d}, J=8.0 \mathrm{~Hz}, 1 \mathrm{H})$, $7.34(\mathrm{~d}, J=8.0 \mathrm{~Hz}, 1 \mathrm{H}), 7.30-7.27(\mathrm{~m}, 2 \mathrm{H}), 7.16(\mathrm{~d}, J=8.4 \mathrm{~Hz}, 2 \mathrm{H}), 7.05-7.01(\mathrm{~m}, 1 \mathrm{H})$, $5.72(\mathrm{br} \mathrm{s}, 1 \mathrm{H}), 5.07-5.02(\mathrm{~m}, 1 \mathrm{H}), 4.79(\mathrm{~d}, J=13.2 \mathrm{~Hz}, 1 \mathrm{H}), 4.11(\mathrm{t}, J=10.4,10.0 \mathrm{~Hz}, 1 \mathrm{H})$, 3.84-3.75 (m, 3H), 3.24-3.17 (m, 1H), 2.97 (t, $J=7.2,6.8 \mathrm{~Hz}, 2 \mathrm{H}), 1.75-1.71(\mathrm{~m}, 3 \mathrm{H})$, 1.69-1.54 (m, 3H). ${ }^{13} \mathrm{C}$ NMR (100 MHz, $\left.\mathrm{CDCl}_{3}\right) \delta 160.3,159.6,151.1,137.6,132.8,132.4$, 130.2, 128.8, 125.3, 121.3, 120.5, 110.4, 64.3, 53.5, 42.4, 40.0, 34.7, 26.5, 25.3, 20.2. HRMS calcd for $\mathrm{C}_{22} \mathrm{H}_{26} \mathrm{ClN}_{4} \mathrm{O}\left([\mathrm{M}+\mathrm{H}]^{+}\right) \mathrm{m} / z$ 397.1795, found $\mathrm{m} / \mathrm{z} 397.1794$; $\mathrm{mp} 153.2-$ $155.3^{\circ} \mathrm{C}$

N-(4-bromophenethyl)-2-chloroquinazolin-4-amine (4d)-A solution of compound 3 (100 mg, $0.56 \mathrm{mmol})$ in n-BuOH (3 mL) was treated with DIEA (215.9 mg, $1.67 \mathrm{mmol})$ and 4-bromophenethylamine (112.0 $\mathrm{mg}, 0.56 \mathrm{mmol})$. The reaction mixture was stirred for 2 $\mathrm{h}$ at $40^{\circ} \mathrm{C}$ and the solvent was evaporated. The residue was extracted with methylene chloride (30 mL, 3 times) and water. The organic layer was dried over $\mathrm{Na}_{2} \mathrm{SO}_{4}$ and evaporated. Compound $\mathbf{4 d}$ was purified by column chromatography (silicagel, $\mathrm{n}$-hexane/ EtOAc $=3: 1)(152.6 \mathrm{mg}, 75.1 \%) .{ }^{1} \mathrm{H}$ NMR $\left(400 \mathrm{MHz}, \mathrm{CDCl}_{3}\right) \delta 7.73-7.70(\mathrm{~m}, 2 \mathrm{H}), 7.57$ $(\mathrm{d}, J=8.0 \mathrm{~Hz}, 1 \mathrm{H}), 7.44-7.39(\mathrm{~m}, 3 \mathrm{H}), 7.11(\mathrm{~d}, J=8.4 \mathrm{~Hz}, 2 \mathrm{H}), 6.14(\mathrm{br} \mathrm{s}, 1 \mathrm{H}), 3.91(\mathrm{q}, J=$ $7.2,6.8,5.6 \mathrm{~Hz}, 2 \mathrm{H}), 2.99$ (t, $J=7.2,6.8 \mathrm{~Hz}, 2 \mathrm{H}) .{ }^{13} \mathrm{C} \mathrm{NMR}\left(100 \mathrm{MHz}, \mathrm{CDCl}_{3}\right) \delta 160.9$, $157.7,150.8,137.5,131.9,130.6,127.8,126.3,120.7,120.6,113.2,42.4,34.5$. LC-MS (ESI, formic) $\mathrm{m} / \mathrm{z} 362.0[\mathrm{M}+\mathrm{H}]^{+}$.

(1-(4-((4-bromophenethyl)amino)quinazolin-2-yl)pyrrolidin-2-yl)methanol (5d) -A solution of $\mathbf{4 d}(50 \mathrm{mg}, 0.138 \mathrm{mmol})$ in $\mathrm{n}-\mathrm{BuOH}(2 \mathrm{~mL})$ was treated with DIEA (53.5 
$\mathrm{mg}, 0.414 \mathrm{mmol}$ ) and L-prolinol (41.8 $\mathrm{mg}, 0.414 \mathrm{mmol})$. The reaction mixture was stirred overnight at $120^{\circ} \mathrm{C}$ and the solvent was evaporated. The residue was dissolved in methylene chloride and extracted with water. The organic layer was dried over $\mathrm{Na}_{2} \mathrm{SO}_{4}$ and evaporated. Compound $\mathbf{5 d}$ was purified from this crude material by column chromatography (silicagel, $\mathrm{CH}_{2} \mathrm{Cl}_{2}: \mathrm{MeOH}$ :triethylamine = 10:1:0.1) (47.3 mg, 80.2\%). purity (98.43\%); ${ }^{1} \mathrm{H}$ NMR (400 $\left.\mathrm{MHz}, \mathrm{CDCl}_{3}\right) \delta 7.56(\mathrm{~d}, J=8.0 \mathrm{~Hz}, 1 \mathrm{H}), 7.48-7.40(\mathrm{~m}, 4 \mathrm{H}), 7.10(\mathrm{~d}, J=8.0 \mathrm{~Hz}, 2 \mathrm{H})$, 7.04-7.00 (m, 1H), 4.40-4.36 (m, 1H), 3.91-3.85 (m, 1H), 3.82-3.77 (m, 3H), 3.71-3.60 (m, 2H), $2.97(\mathrm{t}, J=7.2 \mathrm{~Hz}, 2 \mathrm{H}), 2.19-2.10(\mathrm{~m}, 1 \mathrm{H}), 2.03-1.84(\mathrm{~m}, 2 \mathrm{H}), 1.75-1.67(\mathrm{~m}, 1 \mathrm{H}) .{ }^{13} \mathrm{C}$ NMR (100 MHz, $\left.\mathrm{CDCl}_{3}\right) \delta 159.5,157.1,138.1,133.1,131.7,130.6,121.7,121.5,120.4$, 110.1, 68.0, 61.0, 48.5, 42.5, 34.6, 29.7, 23.9, 14.1. HRMS calcd for $\mathrm{C}_{21} \mathrm{H}_{24} \mathrm{BrN}_{4} \mathrm{O}([\mathrm{M}+$ $\mathrm{H}]^{+}$) $\mathrm{m} / \mathrm{z} 427.1133$, found $\mathrm{m} / \mathrm{z} 427.1126$.

(1-(4-((4-bromophenethyl)amino)quinazolin-2-yl)piperidin-2-yl)methanol (6d)— A solution of $\mathbf{4 d}(47.7 \mathrm{mg}, 0.138 \mathrm{mmol})$ in $\mathrm{n}-\mathrm{BuOH}(2 \mathrm{~mL})$ was treated with DIEA $(53.5$ $\mathrm{mg}, 0.414 \mathrm{mmol}$ ) and 2-piperidinemethanol (41.8 $\mathrm{mg}, 0.414 \mathrm{mmol})$. The reaction mixture was stirred overnight at $120{ }^{\circ} \mathrm{C}$ and the solvent was evaporated. The residue was dissolved in methylene chloride and extracted with water. The organic layer was dried over $\mathrm{Na}_{2} \mathrm{SO}_{4}$ and evaporated. Compound $\mathbf{6 d}$ was purified from this crude material by column chromatography (silicagel, $\mathrm{CH}_{2} \mathrm{Cl}_{2}: \mathrm{MeOH}$ :triethylamine = 10:1:0.1) $(45.7 \mathrm{mg}, 75.0 \%)$. purity $(96.17 \%) ;{ }^{1} \mathrm{H}$ NMR $\left(400 \mathrm{MHz}, \mathrm{CDCl}_{3}\right) \delta$ 7.52-7.45 (m, 2H), $7.38(\mathrm{~d}, J=8.0 \mathrm{~Hz}, 1 \mathrm{H}), 7.36-7.32(\mathrm{~m}, 2 \mathrm{H})$, 7.28-7.24 (m, 2H), 7.06-7.02 (m, 1H), 6.00 (br s, 1H), 5.05-5.01 (m, 1H), 4.82 (d, J= 13.2 $\mathrm{Hz}, 1 \mathrm{H}), 4.11(\mathrm{t}, J=10.0 \mathrm{~Hz}, 1 \mathrm{H}), 3.86-3.78(\mathrm{~m}, 3 \mathrm{H}), 3.23-3.16(\mathrm{~m}, 1 \mathrm{H}), 3.01(\mathrm{t}, J=7.0 \mathrm{~Hz}$, 2H), 1.78-1.72 (m, 3H), 1.68-1.58 (m, 4H). ${ }^{13} \mathrm{C}$ NMR (100 MHz, $\left.\mathrm{CDCl}_{3}\right) \delta$ 159.5, 139.0, 133.0, 128.8, 126.6, 121.7, 120.8, 110.3, 63.8, 53.7, 42.5, 40.0, 35.2, 29.7, 26.4, 25.3, 20.1. HRMS calcd for $\mathrm{C}_{22} \mathrm{H}_{26} \mathrm{BrN}_{4} \mathrm{O}\left([\mathrm{M}+\mathrm{H}]^{+}\right) \mathrm{m} / \mathrm{z} 441.1290$, found $\mathrm{m} / \mathrm{z} 441.1280$; mp 141.3$145.3^{\circ} \mathrm{C}$.

2-chloro-N-(4-methylphenethyl)quinazolin-4-amine (4e)-A solution of compound 3 (100 mg, $0.56 \mathrm{mmol})$ in $\mathrm{n}-\mathrm{BuOH}(3 \mathrm{~mL})$ was treated with DIEA (215.9 mg, $1.67 \mathrm{mmol})$ and 4-methylphenethylamine $(75.7 \mathrm{mg}, 0.56 \mathrm{mmol})$. The reaction mixture was stirred for $2 \mathrm{~h}$ at $40{ }^{\circ} \mathrm{C}$ and the solvent was evaporated. The residue was extracted with methylene chloride (20 mL, 3 times) and water. The organic layer was dried over $\mathrm{Na}_{2} \mathrm{SO}_{4}$ and evaporated. Compound $\mathbf{4 e}$ was purified from this crude material by column chromatography (silicagel, n-hexane/EtOAc = 3:1) $(122.5 \mathrm{mg}, 73.5 \%) .{ }^{1} \mathrm{H}-\mathrm{NMR}\left(400 \mathrm{MHz}, \mathrm{CDCl}_{3}\right) \delta$ 7.77-7.74 (m, $1 \mathrm{H}), 7.71(\mathrm{ddd}, J=8.4,6.8,1.6 \mathrm{~Hz}, 1 \mathrm{H}), 7.49$ (d, $J=8.4 \mathrm{~Hz}, 1 \mathrm{H}), 7.40(\mathrm{ddd}, J=8.4,6.8,1.6$ $\mathrm{Hz}, 1 \mathrm{H}), 7.17-7.12(\mathrm{~m}, 4 \mathrm{H}), 5.91$ (br s, 1H), 3.92 (q, $J=6.8 \mathrm{~Hz}, 2 \mathrm{H}), 2.99$ (t, $J=6.8 \mathrm{~Hz}$, 2H), 2.35 (s, 3H). ${ }^{13} \mathrm{C} \mathrm{NMR}\left(100 \mathrm{MHz}, \mathrm{CDCl}_{3}\right) \delta 160.8,157.8,150.8,136.4,135.3,133.4$, 129.6, 128.7, 127.9, 126.2, 120.5, 113.3, 42.5, 34.6, 21.1. LC-MS (ESI, formic) $\mathrm{m} / \mathrm{z} 298.1$ $[\mathrm{M}+\mathrm{H}]^{+}$.

(1-(4-((4-methylphenethyl)amino)quinazolin-2-yl)pyrrolidin-2-yl)methanol (5e) -A solution of $4 \mathbf{e}(50 \mathrm{mg}, 0.168 \mathrm{mmol})$ in $\mathrm{n}-\mathrm{BuOH}(2 \mathrm{~mL})$ was treated with DIEA (65.1 $\mathrm{mg}, 0.504 \mathrm{mmol})$ and L-prolinol $(51.0 \mathrm{mg}, 0.504 \mathrm{mmol})$. The reaction mixture was stirred overnight at $120^{\circ} \mathrm{C}$ and the solvent was evaporated. The residue was extracted with methylene chloride ( $20 \mathrm{~mL}, 3$ times) and water. The organic layer was dried over $\mathrm{Na}_{2} \mathrm{SO}_{4}$ 
and evaporated. Compound 5e was purified from this crude material by column chromatography (silicagel, $\mathrm{CH}_{2} \mathrm{Cl}_{2}: \mathrm{MeOH}$ :triethylamine $\left.=10: 1: 0.1\right)(41.2 \mathrm{mg}, 67.7 \%)$. purity $(98.80 \%) ;{ }^{1} \mathrm{H} \mathrm{NMR}\left(400 \mathrm{MHz}, \mathrm{CDCl}_{3}\right) \delta 7.48(\mathrm{ddd}, J=8.4,6.8,1.2 \mathrm{~Hz}, 1 \mathrm{H}), 7.41$ (d, $J=8.0 \mathrm{~Hz}, 1 \mathrm{H}), 7.36(\mathrm{~d}, J=8.0 \mathrm{~Hz}, 1 \mathrm{H}), 7.16-7.12(\mathrm{~m}, 4 \mathrm{H}), 7.01$ (ddd, $J=8.4,6.8,1.2$ $\mathrm{Hz}, 1 \mathrm{H}), 5.86(\mathrm{br} \mathrm{s}, 1 \mathrm{H}), 4.40-4.35(\mathrm{~m}, 1 \mathrm{H}), 3.99-3.93(\mathrm{~m}, 1 \mathrm{H}), 3.86-3.81(\mathrm{~m}, 1 \mathrm{H}), 3.81-3.78$ (m, 2H), 3.72-3.63 (m, 2H), $2.98(\mathrm{t}, J=7.0 \mathrm{~Hz}, 2 \mathrm{H}), 2.34(\mathrm{~s}, 3 \mathrm{H}), 2.20-2.12(\mathrm{~m}, 1 \mathrm{H})$, 1.99-1.82 (m, 2H), 1.71-1.63 (m, 1H). ${ }^{13} \mathrm{C}$ NMR (100 MHz, $\left.\mathrm{CDCl}_{3}\right) \delta 159.6,158.5,136.1$, 136.0, 132.8, 129.4, 128.7, 124.6, 121.1, 120.7, 110.2, 68.8, 61.1, 48.5, 42.6, 34.8, 30.0, 29.7, 24.1, 21.1. HRMS (FAB) calcd for $\mathrm{C}_{22} \mathrm{H}_{27} \mathrm{~N}_{4} \mathrm{O}\left([\mathrm{M}+\mathrm{H}]^{+}\right) \mathrm{m} / \mathrm{z} 363.2185$, found $\mathrm{m} / \mathrm{z}$ 363.2178; mp $144.2-146.6^{\circ} \mathrm{C}$.

(1-(4-((4-methylphenethyl)amino)quinazolin-2-yl)piperidin-2-yl)methanol (6e)A solution of $4 \mathbf{e}(50 \mathrm{mg}, 0.168 \mathrm{mmol})$ in $\mathrm{n}-\mathrm{BuOH}(2 \mathrm{~mL})$ was treated with DIEA $(65.1 \mathrm{mg}$, $0.504 \mathrm{mmol})$ and 2-piperidinemethanol $(58.0 \mathrm{mg}, 0.504 \mathrm{mmol})$. The reaction mixture was stirred overnight at $120^{\circ} \mathrm{C}$ and the solvent was evaporated. The residue was extracted with methylene chloride ( $20 \mathrm{~mL}, 3$ times) and water. The organic layer was dried over $\mathrm{Na}_{2} \mathrm{SO}_{4}$ and evaporated. Compound $\mathbf{6 e}$ was purified from this crude material by column chromatography (silicagel, $\mathrm{CH}_{2} \mathrm{Cl}_{2}: \mathrm{MeOH}$ :triethylamine $\left.=10: 1: 0.1\right)(44.7 \mathrm{mg}, 70.1 \%$ ). purity (97.12\%); $\left.{ }^{1} \mathrm{H} \mathrm{NMR} \mathrm{(400} \mathrm{MHz,} \mathrm{CDCl}_{3}\right) \delta 7.49$ (ddd, $\left.J=8.4,6.8,1.6 \mathrm{~Hz}, 1 \mathrm{H}\right), 7.42$ (d, $J=8.0 \mathrm{~Hz}, 1 \mathrm{H}), 7.32-7.30(\mathrm{~d}, J=8.0 \mathrm{~Hz}, 1 \mathrm{H}), 7.17-7.12(\mathrm{~m}, 4 \mathrm{H}), 7.04-7.00(\mathrm{~m}, 1 \mathrm{H})$, $5.62(\mathrm{br} \mathrm{s}, 1 \mathrm{H}), 5.09-5.03(\mathrm{~m}, 1 \mathrm{H}), 4.84-4.79(\mathrm{~m}, 1 \mathrm{H}), 4.12(\mathrm{t}, J=10.4 \mathrm{~Hz}, 1 \mathrm{H}), 3.91-3.75$ $(\mathrm{m}, 3 \mathrm{H}), 3.24-3.17(\mathrm{~m}, 1 \mathrm{H}), 2.97(\mathrm{t}, J=7.2,6.8 \mathrm{~Hz}, 2 \mathrm{H}), 2.35(\mathrm{~s}, 3 \mathrm{H}), 1.78-1.72(\mathrm{~m}, 3 \mathrm{H})$, $1.67-1.56(\mathrm{~m}, 4 \mathrm{H}) .{ }^{13} \mathrm{C} \mathrm{NMR}\left(100 \mathrm{MHz}, \mathrm{CDCl}_{3}\right) \delta 159.6,136.2,135.9,132.7,129.5,128.7$, 121.1, 120.5, 53.5, 42.5, 40.0, 34.9, 29.7, 26.5, 25.3, 21.1, 20.3. HRMS (FAB) calcd for $\mathrm{C}_{23} \mathrm{H}_{29} \mathrm{~N}_{4} \mathrm{O}\left([\mathrm{M}+\mathrm{H}]^{+}\right) \mathrm{m} / \mathrm{z} 377.2341$, found $\mathrm{m} / \mathrm{z} 377.2343$; mp 143.1-146.8 ${ }^{\circ} \mathrm{C}$.

(1-(4-((4-methoxyphenethyl)amino)quinazolin-2-yl)piperidin-2-yl)methanol (6f) -A solution of $\mathbf{4 f}(313 \mathrm{mg}, 1 \mathrm{mmol})^{9}$ in $\mathrm{n}-\mathrm{BuOH}(15 \mathrm{~mL})$ was treated with DIEA (388 $\mathrm{mg}$, $3 \mathrm{mmol}$ ) and 2-piperidinemethanol (3.3 $\mathrm{mg}, 3 \mathrm{mmol})$. The reaction mixture was stirred overnight at $120^{\circ} \mathrm{C}$ and the solvent was evaporated. The residue was extracted with methylene chloride (50 mL, 3 times) and water. The organic layer was dried over $\mathrm{Na}_{2} \mathrm{SO}_{4}$ and evaporated. Compound $\mathbf{6} \mathbf{f}$ was purified from this crude material by column chromatography (silicagel, $\mathrm{CH}_{2} \mathrm{Cl}_{2}: \mathrm{MeOH}$ :triethylamine $\left.=10: 1: 0.1\right)(262 \mathrm{mg}, 69.5 \%)$. purity (96.93\%); ${ }^{1} \mathrm{H}$ NMR $\left(400 \mathrm{MHz}, \mathrm{CDCl}_{3}\right) \delta 7.50(\mathrm{~m}, 1 \mathrm{H}), 7.44(\mathrm{~m}, 1 \mathrm{H}), 7.32(\mathrm{~d}, J=8.4$ $\mathrm{Hz}, 1 \mathrm{H}), 7.16(\mathrm{~m}, 1 \mathrm{H}), 6.88(\mathrm{~m}, 2 \mathrm{H}), 5.95(\mathrm{br} \mathrm{s}, 1 \mathrm{H}), 5.06(\mathrm{~m}, 1 \mathrm{H}), 4.83(\mathrm{~m}, 1 \mathrm{H}), 4.11(\mathrm{~m}$, $1 \mathrm{H}), 3.81(\mathrm{~s}, 3 \mathrm{H}), 2.79(\mathrm{~m}, 2 \mathrm{H}), 3.20(\mathrm{~m}, 1 \mathrm{H}), 2.95(\mathrm{~m}, 1 \mathrm{H}), 1.75(\mathrm{~m}, 2 \mathrm{H}), 1.66(\mathrm{~m}, 4 \mathrm{H}) ;{ }^{13} \mathrm{C}$ NMR $\left(100 \mathrm{MHz}, \mathrm{CDCl}_{3}\right) \delta 161.5,159.6,152.1,138.7,132.8,128.8,127.8,127.6,125.6$, 121.1, 120.6, 110.4, 64.3, 53.4, 45.3, 40.0, 26.4, 25.3, 20.3. LC-MS ESI, formic) $\mathrm{m} / \mathrm{z} 393.1$ $[\mathrm{M}+\mathrm{H}]^{+}$. HRMS (FAB) calcd for $\mathrm{C}_{23} \mathrm{H}_{29} \mathrm{~N}_{4} \mathrm{O}_{2}\left([\mathrm{M}+\mathrm{H}]^{+}\right) \mathrm{m} / \mathrm{z} 392.2212$, found $\mathrm{m} / \mathrm{z}$ 392.2130 .

(1-(4-(benzylamino)quinazolin-2-yl)piperidin-2-yl)methanol (9a)-A solution of 7a $(270 \mathrm{mg}, 1 \mathrm{mmol})^{49}$ in $\mathrm{n}-\mathrm{BuOH}(15 \mathrm{~mL})$ was treated with DIEA (388 mg, $\left.3 \mathrm{mmol}\right)$ and $2-$ piperidinemethanol $(3.3 \mathrm{~g}, 3 \mathrm{mmol})$. The reaction mixture was stirred overnight at $120^{\circ} \mathrm{C}$ and the solvent was evaporated. The residue was extracted with methylene chloride $(50 \mathrm{~mL}$, 
3 times) and water. The organic layer was dried over $\mathrm{Na}_{2} \mathrm{SO}_{4}$ and evaporated. Compound $9 \mathbf{a}$ was purified from this crude material by column chromatography (silicagel, $\mathrm{CH}_{2} \mathrm{Cl}_{2}: \mathrm{MeOH}$ :triethylamine $\left.=10: 1: 0.1\right)(212 \mathrm{mg}, 60.9 \%)$. purity $(100 \%) ;{ }^{1} \mathrm{H} \mathrm{NMR}(400$ $\left.\mathrm{MHz}, \mathrm{CDCl}_{3}\right) \delta 7.52-7.32(\mathrm{~m}, 8 \mathrm{H}), 7.04(\mathrm{t}, J=8.4 \mathrm{~Hz}, 1 \mathrm{H}), 5.80(\mathrm{br} \mathrm{s}, 1 \mathrm{H}), 5.03(\mathrm{t}, J=4.8$ $\mathrm{Hz}, 1 \mathrm{H}), 4.84-4.74(\mathrm{~m}, 3 \mathrm{H}), 4.06(\mathrm{t}, J=10.8 \mathrm{~Hz}, 1 \mathrm{H}), 3.73(\mathrm{t}, J=6.8 \mathrm{~Hz}, 1 \mathrm{H}), 3.16(\mathrm{~m}, 1 \mathrm{H})$, 1.70-1.55 (m, 6H). ${ }^{13} \mathrm{C}$ NMR $\left(100 \mathrm{MHz}, \mathrm{CDCl}_{3}\right) \delta 160.3,159.5,151.6,137.2,133.2,132.8$, $129.0,128.8,125.5,121.2,120.6,110.4,64.3,53.4,44.6,40.0,26.4,25.2,20.2$. LC-MS (ESI, formic) $\mathrm{m} / z 349.2[\mathrm{M}+\mathrm{H}]^{+}$. HRMS (FAB) calcd for $\mathrm{C}_{21} \mathrm{H}_{25} \mathrm{~N}_{4} \mathrm{O}\left([\mathrm{M}+\mathrm{H}]^{+}\right) \mathrm{m} / z$ 349.2028 , found $\mathrm{m} / \mathrm{z} 349.1950$.

(1-(4-((4-clorobenzyl)amino)quinazolin-2-yl)piperidin-2-yl)methanol (9b)-A solution of $\mathbf{7 b}(304 \mathrm{mg}, 1 \mathrm{mmol})^{21}$ in n-BuOH $(15 \mathrm{~mL})$ was treated with DIEA (388 mg, 3 $\mathrm{mmol}$ ) and 2-piperidinemethanol ( $345 \mathrm{mg}, 3 \mathrm{mmol})$. The reaction mixture was stirred overnight at $120^{\circ} \mathrm{C}$ and the solvent was evaporated. The residue was extracted with methylene chloride (50 mL, 3 times) and water. The organic layer was dried over $\mathrm{Na}_{2} \mathrm{SO}_{4}$ and evaporated. Compound $\mathbf{9 b}$ was purified from this crude material by column chromatography (silicagel, $\mathrm{CH}_{2} \mathrm{Cl}_{2}: \mathrm{MeOH}$ :triethylamine $\left.=10: 1: 0.1\right)(263 \mathrm{mg}, 68.6 \%)$. purity $(100 \%) ;{ }^{1} \mathrm{H} \mathrm{NMR}\left(400 \mathrm{MHz}, \mathrm{CDCl}_{3}\right) \delta 7.52-7.46(\mathrm{~m}, 2 \mathrm{H}), 7.40(\mathrm{~d}, J=8.0 \mathrm{~Hz}, 1 \mathrm{H})$, 7.30-7.26 (m, 4H), $7.04(\mathrm{t}, J=7.6 \mathrm{~Hz}, 1 \mathrm{H}), 5.95(\mathrm{br} \mathrm{s}, 1 \mathrm{H}), 4.98(\mathrm{~m}, 1 \mathrm{H}), 4.80-4.69(\mathrm{~m}, 3 \mathrm{H})$, $4.06(\mathrm{t}, J=10.4 \mathrm{~Hz}, 1 \mathrm{H}), 3.73(\mathrm{t}, J=6.8 \mathrm{~Hz}, 1 \mathrm{H}), 3.14(\mathrm{~m}, 1 \mathrm{H}), 1.70-1.51(\mathrm{~m}, 6 \mathrm{H}) .{ }^{13} \mathrm{C}$ NMR (100 MHz, $\left.\mathrm{CDCl}_{3}\right) \delta 161.3,159.6,158.4,132.7,131.0,129.8,125.4,121.0,120.5$, 114.2, 110.6, 64.5, 55.3, 53.4, 42.6, 40.0, 34.4, 26.6, 25.3, 20.3. LC-MS (ESI, formic) $\mathrm{m} / \mathrm{z}$ $383.1[\mathrm{M}+\mathrm{H}]^{+}$. HRMS (FAB) calcd for $\mathrm{C}_{21} \mathrm{H}_{24} \mathrm{ClN}_{4} \mathrm{O}\left([\mathrm{M}+\mathrm{H}]^{+}\right) \mathrm{m} / z$ 383.1639, found $\mathrm{m} / \mathrm{z} 383.1657$.

2-chloro-N-(3-fluorophenethyl)quinazolin-4-amine (4g)-We followed the general procedure. A solution of compound $3(140 \mathrm{mg}, 0.7 \mathrm{mmol})$ in $\mathrm{n}-\mathrm{BuOH}(7 \mathrm{~mL})$ was treated with DIEA (98.6 mg, $0.77 \mathrm{mmol}$ ) and 3-fluorophenethylamine (107 mg, $0.77 \mathrm{mmol})$. Compound $\mathbf{4 g}$ was purified from this crude material by column chromatography (silicagel, $\mathrm{n}$-hexane/EtOAc $=3: 1)(128.2 \mathrm{mg}, 60.8 \%)$.

${ }^{1} \mathrm{H}-\mathrm{NMR}\left(400 \mathrm{MHz}, \mathrm{CDCl}_{3}\right) \delta$ 7.69-7.60 (m, 2H), $7.49(\mathrm{~d}, \mathrm{~J}=8.0 \mathrm{~Hz}, 1 \mathrm{H}), 7.34(\mathrm{t}, \mathrm{J}=8.0$ $\mathrm{Hz}, 7.25-7.19(\mathrm{~m}, 1 \mathrm{H}), 6.95$ (d, J = 7.6 Hz, 1H), 6.93-6.87 (m, 2H), $6.02(\mathrm{~s}, 1 \mathrm{H},-\mathrm{NH}), 3.86$ $\left(\mathrm{dd}, \mathrm{J}=12.8,6.8 \mathrm{~Hz}, 2 \mathrm{H},-\mathrm{CH}_{2^{-}}\right), 2.96\left(\mathrm{t}, \mathrm{J}=6.8 \mathrm{~Hz}, 2 \mathrm{H},-\mathrm{CH}_{2^{-}}\right) .{ }^{13} \mathrm{C}-\mathrm{NMR}(100 \mathrm{MHz}$, $\left.\mathrm{CDCl}_{3}\right) \delta 160.8,157.7,150.7,141.1,133.6,130.2,127.8,126.3,124.5,120.6,115.8,113.8$, 113.2, 42.3, 34.8. LC-MS (ESI, formic) $\mathrm{m} / \mathrm{z} .302 .1\left([\mathrm{M}+\mathrm{H}]^{+}\right)$.

\section{(S)-(1-(4-((3-fluorophenethyl)amino)quinazolin-2-yl)pyrrolidin-2-yl)methanol}

(5f) -A solution of $4 \mathbf{g}(40 \mathrm{mg}, 0.13 \mathrm{mmol})$ in $\mathrm{n}-\mathrm{BuOH}(4 \mathrm{~mL})$ was treated with DIEA (33.3 $\mathrm{mg}, 0.26 \mathrm{mmol})$ and L-prolinol $(26.8 \mathrm{mg}, 0.26 \mathrm{mmol})$. The reaction mixture was stirred 24 hrs at $120{ }^{\circ} \mathrm{C}$ and the solvent was evaporated. The residue was extracted with methylene chloride (10 mL, 3 times) and water. The organic layer was dried over $\mathrm{Na}_{2} \mathrm{SO}_{4}$ and evaporated. Compound $\mathbf{5 f}$ was purified from this crude material by prep-HPLC (UV $254 \mathrm{~nm}$, $4.0 \mathrm{~mL} / \mathrm{min}, \mathrm{H}_{2} \mathrm{O} / \mathrm{ACN}$ (0.01\% TFA) 5-60\%, 0-30 min. 
) (30.3 mg, 63.7\%). purity (99.90\%); ${ }^{1} \mathrm{H}-\mathrm{NMR}\left(400 \mathrm{MHz}, \mathrm{CDCl}_{3}\right) \delta 12.38(\mathrm{~s}, 1 \mathrm{H},-\mathrm{OH})$, 9.37 (s, $1 \mathrm{H},-\mathrm{NH}), 8.00$ (d, $J=8.0 \mathrm{~Hz}, 1 \mathrm{H}), 7.42(\mathrm{td}, J=8.4,0.8 \mathrm{~Hz}, 1 \mathrm{H}), 7.34-7.23(\mathrm{~m}, 2 \mathrm{H})$, 7.09 (td, $J=8.0,0.4 \mathrm{~Hz}, 1 \mathrm{H}), 7.03(\mathrm{~d}, J=7.6 \mathrm{~Hz}, 1 \mathrm{H}), 6.95$ (d, $J=8.4 \mathrm{~Hz}, 2 \mathrm{H}), 4.29$ (brs, $1 \mathrm{H}), 3.96-3.88(\mathrm{~m}, 1 \mathrm{H}), 3.88-3.55(\mathrm{~m}, 6 \mathrm{H}), 2.99(\mathrm{t}, J=8.0 \mathrm{~Hz}, 2 \mathrm{H}), 2.28-2.14(\mathrm{~m}, 1 \mathrm{H})$, 2.14-1.99 (m, 2H), 1.99-1.88 (m, 1H). ${ }^{13} \mathrm{C}-\mathrm{NMR}\left(100 \mathrm{MHz}, \mathrm{CDCl}_{3}\right) \delta$ 164.8, 163.2, 162.8, $162.4,159.7,152.1,141.8,141.7,139.2,134.8,130.8,130.8,125.2,125.1,124.8,124.5$, 117.7, 116.3, 116.1, 116.0, 114.3, 114.1, 110.2, 65.7, 61.9, 49.6, 43.5, 35.1, 29.8, 23.6. LCMS (ESI, formic) $\mathrm{m} / z .367 .2\left([\mathrm{M}+\mathrm{H}]^{+}\right)$. HRMS (FAB) calcd for $\mathrm{C}_{21} \mathrm{H}_{24} \mathrm{FN}_{4} \mathrm{O}\left([\mathrm{M}+\mathrm{H}]^{+}\right)$ $\mathrm{m} / \mathrm{z}$. 367.1934, found $\mathrm{m} / \mathrm{z}$. 367.1936.

(1-(4-((3-fluorophenethyl)amino)quinazolin-2-yl)piperidin-2-yl)methanol (6g)A solution of $4 \mathbf{g}$ ( $40 \mathrm{mg}, 0.13 \mathrm{mmol})$ in $\mathrm{n}-\mathrm{BuOH}(4 \mathrm{~mL})$ was treated with DIEA (33.3 $\mathrm{mg}$, $0.26 \mathrm{mmol})$ and 2-piperidinemethanol $(27.0 \mathrm{~g}, 0.26 \mathrm{mmol})$. The reaction mixture was stirred $48 \mathrm{hrs}$ at $120^{\circ} \mathrm{C}$ and the solvent was evaporated. The residue was extracted with methylene chloride (10 mL, 3 times) and water. The organic layer was dried over $\mathrm{Na}_{2} \mathrm{SO}_{4}$ and evaporated. Compound $\mathbf{4 g}$ was purified from this crude material by prep-HPLC (UV 254 $\mathrm{nm}, 4.0 \mathrm{~mL} / \mathrm{min}, \mathrm{H}_{2} \mathrm{O} / \mathrm{ACN}$ (0.01\% TFA) 5-60\%, 0-30 min.

) (24.8 mg, 50.0\%). purity (97.15\%); ${ }^{1} \mathrm{H}-\mathrm{NMR}\left(400 \mathrm{MHz}, \mathrm{CDCl}_{3}+\mathrm{CD}_{3} \mathrm{OD}\right) \delta 8.53(\mathrm{~s}, 1 \mathrm{H},-$ $\mathrm{NH}), 7.75(\mathrm{~d}, J=8.0 \mathrm{~Hz}, 1 \mathrm{H}), 7.70(\mathrm{~d}, J=8.4 \mathrm{~Hz}, 1 \mathrm{H}), 7.25-7.18(\mathrm{~m}, 2 \mathrm{H}), 6.98(\mathrm{~d}, J=12.0$ $\mathrm{Hz}, 1 \mathrm{H}), 6.92-6.84(\mathrm{~m}, 2 \mathrm{H}), 4.75$ (s, 1H), $3.94(\mathrm{dd}, J=12.0,10.0 \mathrm{~Hz}, 1 \mathrm{H}), 3.72-3.70(\mathrm{~m}$, $3 \mathrm{H}), 3.34-3.25(\mathrm{~m}, 2 \mathrm{H}), 3.13(\mathrm{~m}, 1 \mathrm{H}), 2.95\left(\mathrm{t}, J=7.2 \mathrm{~Hz}, 2 \mathrm{H}\right.$, benzylic- $\left.\mathrm{CH}_{2}\right), 1.90-1.80(\mathrm{~m}$, $2 \mathrm{H}), 1.79-1.43(\mathrm{~m}, 4 \mathrm{H}) .{ }^{13} \mathrm{C}-\mathrm{NMR}\left(100 \mathrm{MHz}, \mathrm{CDCl}_{3}+\mathrm{CD}_{3} \mathrm{OD}\right) \delta 164.1,161.7,159.4,152.7$, 141.1, 141.0, 139.5, 134.8, 130.2, 130.1, 124.6, 124.4, 124.3, 122.5, 117.9, 115.6, 115.3, 113.6, 113.4, 109.6, 60.1, 54.6, 42.9, 40.3, 34.4, 25.3, 25.1, 19.0. LC-MS (ESI, formic) $\mathrm{m} / \mathrm{z}$. $381.2\left([\mathrm{M}+\mathrm{H}]^{+}\right)$. HRMS (FAB) calcd for $\mathrm{C}_{22} \mathrm{H}_{26} \mathrm{FN}_{4} \mathrm{O}\left([\mathrm{M}+\mathrm{H}]^{+}\right) \mathrm{m} / \mathrm{z} .381 .2091$, found $\mathrm{m} / \mathrm{z} .381 .2088$.

2-chloro-N-(3-chlorophenethyl)quinazolin-4-amine (4h)-We followed the general procedure. A solution of compound $\mathbf{3}(140 \mathrm{mg}, 0.7 \mathrm{mmol})$ in $\mathrm{n}-\mathrm{BuOH}(6 \mathrm{~mL})$ was treated with DIEA (98.6 mg, $0.77 \mathrm{mmol}$ ) and 3-chlorophenethylamine (120 mg, $0.77 \mathrm{mmol}$ ).

Compound $4 \mathrm{~h}$ was purified from this crude material by column chromatography (silicagel, n-hexane/EtOAc = 3:1) $(142.2 \mathrm{mg}, 64.1 \%) .{ }^{1} \mathrm{H}-\mathrm{NMR}\left(400 \mathrm{MHz}, \mathrm{CDCl}_{3}\right) \delta$ 7.81-7.72 (m, 2H), $7.62(\mathrm{~d}, \mathrm{~J}=8.0 \mathrm{~Hz}, 1 \mathrm{H}), 7.47(\mathrm{t}, \mathrm{J}=8.0 \mathrm{~Hz}, 1 \mathrm{H}), 7.31-7.21(\mathrm{~m}, 2 \mathrm{H}), 7.15(\mathrm{dd}, \mathrm{J}=6.0$, $1.6 \mathrm{~Hz}, 1 \mathrm{H}), 6.39(\mathrm{~s}, 1 \mathrm{H},-\mathrm{NH}), 3.94\left(\mathrm{dd}, \mathrm{J}=12.8,7.2 \mathrm{~Hz}, 2 \mathrm{H},-\mathrm{CH}_{2^{-}}\right), 3.04(\mathrm{t}, \mathrm{J}=7.2 \mathrm{~Hz}$, $\left.2 \mathrm{H},-\mathrm{CH}_{2}-\right) .{ }^{13} \mathrm{C}-\mathrm{NMR}\left(100 \mathrm{MHz}, \mathrm{CDCl}_{3}\right) \delta 160.7,157.2,149.8,140.5,134.6,133.8,130.1$, 129.0, 127.0, 126.5, 120.8, 113.0, 42.5, 34.7. LC-MS (ESI, formic) $\mathrm{m} / \mathrm{z} .318 .1\left([\mathrm{M}+\mathrm{H}]^{+}\right.$);

(S)-(1-(4-((3-chlorophenethyl)amino)quinazolin-2-yl)pyrrolidin-2-yl)methanol

$(5 \mathbf{g})$-We followed the general procedure. A solution of $\mathbf{4 h}(40 \mathrm{mg}, 0.13 \mathrm{mmol})$ in $\mathrm{n}-\mathrm{BuOH}$ $(4 \mathrm{~mL})$ was treated with DIEA (33.3 mg, $0.26 \mathrm{mmol})$ and L-prolinol $(25.5 \mathrm{mg}, 0.26 \mathrm{mmol})$. Compound $\mathbf{5 g}$ was purified from this crude material by prep-HPLC (UV $254 \mathrm{~nm}, 4.0 \mathrm{~mL} /$ $\min , \mathrm{H}_{2} \mathrm{O} / \mathrm{ACN}\left(0.01 \%\right.$ TFA) 5-60\%, 0-30 min), (30.4 mg, 61.2\%). purity (99.90\%); ${ }^{1} \mathrm{H}-$ NMR $\left(400 \mathrm{MHz}, \mathrm{CDCl}_{3}\right) \delta 12.63(\mathrm{~s}, 1 \mathrm{H}), 9.47(\mathrm{~s}, 1 \mathrm{H}), 8.01(\mathrm{~d}, J=8.0 \mathrm{~Hz}, 1 \mathrm{H}), 7.42$ (t, $J=$ 8.0, 0.8Hz, 1H), 7.29-7.17 (m, 4H), 7.17-7.07 (m, 2H), 4.27 (s, 1H), 4.06 (brs, 1H), 3.89 (s, $1 \mathrm{H}), 3.82-3.57(\mathrm{~m}, 4 \mathrm{H}), 2.97\left(\mathrm{t}, J=7.6 \mathrm{~Hz}, 2 \mathrm{H}\right.$, benzyl- $\left.\mathrm{CH}_{2}-\right), 2.28-2.10(\mathrm{~m}, 1 \mathrm{H}), 2.10-1.97$ 
(m, 2H), 1.97-1.88 (m, 1H). ${ }^{13} \mathrm{C}-\mathrm{NMR}\left(100 \mathrm{MHz}, \mathrm{CDCl}_{3}\right) \delta 163.5,163.1,162.8,162.4$, 159.8, 152.1, 141.3, 139.2, 135.0, 134.8, 129.5, 127.7, 127.4, 124.8, 124.5, 118.9, 117.7, 116.0, 110.2, 65.7, 62.0, 49.6, 43.6, 35.1, 29.8, 23.6. LC-MS (ESI, formic) $\mathrm{m} / z .383 .2([\mathrm{M}+$ $\mathrm{H}]^{+}$). HRMS (FAB) calculated for $\mathrm{C}_{21} \mathrm{H}_{24} \mathrm{ClN}_{4} \mathrm{O}\left([\mathrm{M}+\mathrm{H}]^{+}\right) \mathrm{m} / \mathrm{z}$. 383.1639, found $\mathrm{m} / \mathrm{z}$. 383.1635 .

(1-(4-((3-chlorophenethyl)amino)quinazolin-2-yl)piperidin-2-yl)methanol (6h)We followed the general procedure. A solution of $4 \mathbf{h}(40 \mathrm{mg}, 0.12 \mathrm{mmol})$ in $\mathrm{n}-\mathrm{BuOH}(4 \mathrm{~mL})$ was treated with DIEA (30.7 mg, $0.24 \mathrm{mmol}$ ) and 2-piperidinemethanol (26.0 mg, 0.24 $\mathrm{mmol}$ ). Compound $\mathbf{6 h}$ was purified from this crude material by prep-HPLC (UV $254 \mathrm{~nm}$, $\left.4.0 \mathrm{~mL} / \mathrm{min}, \mathrm{H}_{2} \mathrm{O} / \mathrm{ACN}(0.01 \% \mathrm{TFA}) 5-60 \%, 0-30 \mathrm{~min}\right)$. (29.8 $\left.\mathrm{mg}, 62.5 \%\right)$. purity (99.50\%); ${ }^{1} \mathrm{H}-\mathrm{NMR}\left(400 \mathrm{MHz}, \mathrm{CDCl}_{3}+\mathrm{CD}_{3} \mathrm{OD}\right) \delta 8.65$ (brs, $\left.1 \mathrm{H},-\mathrm{NH}\right), 7.75(\mathrm{~d}, J=8.4 \mathrm{~Hz}$, $1 \mathrm{H}), 7.61(\mathrm{~d}, J=8.4 \mathrm{~Hz}, 1 \mathrm{H}), 7.50(\mathrm{t}, J=8.4 \mathrm{~Hz}, 1 \mathrm{H}), 7.23-7.15(\mathrm{~m}, 4 \mathrm{H}), 7.09-7.00(\mathrm{~m}, 1 \mathrm{H})$, $4.72(\mathrm{~s}, 1 \mathrm{H}), 3.96(\mathrm{dd}, J=12.0,10.0 \mathrm{~Hz}, 1 \mathrm{H}), 3.78-3.63(\mathrm{~m}, 3 \mathrm{H}), 3.35(\mathrm{~s}, 2 \mathrm{H}), 3.14(\mathrm{~s}, 1 \mathrm{H})$, $2.91(\mathrm{t}, J=7.6 \mathrm{~Hz}, 2 \mathrm{H}), 1.80-1.76(\mathrm{~m}, 2 \mathrm{H}), 1.70-1.45(\mathrm{~m}, 4 \mathrm{H}) .{ }^{13} \mathrm{C}-\mathrm{NMR}(100 \mathrm{MHz}$, $\left.\mathrm{CDCl}_{3}+\mathrm{CD}_{3} \mathrm{OD}\right) \delta 159.4,152.6,140.6,139.4,134.7,134.3,129.9,128.7,126.9,126.8$, 124.6, 122.7, 117.7, 109.5, 60.1, 54.7, 42.9, 40.2, 34.3, 25.3, 25.0, 19.0. LC-MS (ESI, formic) $\mathrm{m} / z .397 .2\left([\mathrm{M}+\mathrm{H}]^{+}\right)$. HRMS (FAB) calculated for $\mathrm{C}_{22} \mathrm{H}_{26} \mathrm{ClN}_{4} \mathrm{O}\left([\mathrm{M}+\mathrm{H}]^{+}\right) \mathrm{m} / z$. 397.1795, found $\mathrm{m} / \mathrm{z} .397 .1802$.

N-(3-bromophenethyl)-2-chloroquinazolin-4-amine (4i)-We followed the general procedure. A solution of compound $\mathbf{3}(140 \mathrm{mg}, 0.7 \mathrm{mmol})$ in $\mathrm{n}-\mathrm{BuOH}(6 \mathrm{~mL})$ was treated with DIEA (98.6 mg, $0.77 \mathrm{mmol}$ ) and 3-bromophenethylamine (154 mg, $0.77 \mathrm{mmol}$ ).

Compound $4 \mathbf{i}$ was purified from this crude material by column chromatography (silicagel, $\mathrm{n}$ hexane/EtOAc = 3:1 $)(128.2 \mathrm{mg}, 50.7 \%) .{ }^{1} \mathrm{H}-\mathrm{NMR}\left(400 \mathrm{MHz}, \mathrm{CDCl}_{3}\right) \delta$ 7.71-762 (m, 2H), $7.49(\mathrm{~d}, J=8.4 \mathrm{~Hz}, 1 \mathrm{H}), 7.38-7.30(\mathrm{~m}, 2 \mathrm{H}), 7.14-7.08(\mathrm{~m}, 1 \mathrm{H}), 5.99(\mathrm{~s}, 1 \mathrm{H},-\mathrm{NH}), 3.86(\mathrm{dd}$, $\left.\mathrm{J}=12.4,6.8 \mathrm{~Hz}, 2 \mathrm{H},-\mathrm{CH}_{2^{-}}\right), 2.94\left(\mathrm{t}, \mathrm{J}=7.2 \mathrm{~Hz}, 2 \mathrm{H},-\mathrm{CH}_{2^{-}}\right) .{ }^{13} \mathrm{C}-\mathrm{NMR}\left(100 \mathrm{MHz}, \mathrm{CDCl}_{3}\right)$

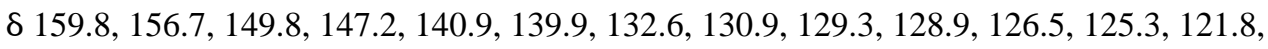
119.6, 112.2, 41.3, 33.7. LC-MS (ESI) $\mathrm{m} / z .362 .0\left([\mathrm{M}+\mathrm{H}]^{+}\right)$;

\section{(S)-(1-(4-((3-bromophenethyl)amino)quinazolin-2-yl)pyrrolidin-2-yl)methanol}

(5h)-We followed the general procedure. A solution of $4 \mathbf{i}(40 \mathrm{mg}, 0.11 \mathrm{mmol})$ in $\mathrm{n}-\mathrm{BuOH}$ $(4 \mathrm{~mL})$ was treated with DIEA (28.6 mg, $0.22 \mathrm{mmol})$ and L-prolinol $(22.3 \mathrm{mg}, 0.22 \mathrm{mmol})$. Compound $\mathbf{5 h}$ was purified from this crude material by prep-HPLC (UV $254 \mathrm{~nm}, 4.0 \mathrm{~mL} /$ min, $\mathrm{H}_{2} \mathrm{O} / \mathrm{ACN}$ (0.01\% TFA) 5-60\%, 0-30 min), (19.8 mg, 40.8\%). purity (99.90\%); ${ }^{1} \mathrm{H}-$ NMR $\left(400 \mathrm{MHz}, \mathrm{CDCl}_{3}\right) \delta 12.35$ (brs, $\left.1 \mathrm{H}\right), 9.28$ (brs, $\left.1 \mathrm{H},-\mathrm{NH}\right), 7.99(\mathrm{~d}, J=8.0,1 \mathrm{H})$, 7.48-7.35 (m, 3H), 7.26 (brs, 1H), 7.21-7.15 (m, 2H), 4.29 (brs, 1H), 3.97-3.74 (m, 3H), 3.75-3.58 (m, 1H), 3.42 (brs, 3H), $2.97\left(\mathrm{t}, J=7.6 \mathrm{~Hz}, 2 \mathrm{H}\right.$, benzyl- $\left.\mathrm{CH}_{2}-\right), 2.29-2.15(\mathrm{~m}, 1 \mathrm{H})$, 2.12-1.88 (m, 3H). ${ }^{13} \mathrm{C}-\mathrm{NMR}\left(100 \mathrm{MHz}, \mathrm{CDCl}_{3}+\mathrm{CD}_{3} \mathrm{OD}\right) \delta 159.5,141.0,134.6,131.7$, 130.2, 129.6, 127.5, 124.5, 123.4, 122.5, 121.5, 117.3, 109.5, 64.2, 60.9, 48.9, 42.8, 34.4. 28.5, 22.8. LC-MS (ESI, formic) $\mathrm{m} / z .427 .1\left([\mathrm{M}+\mathrm{H}]^{+}\right)$. HRMS (FAB) calcd for $\mathrm{C}_{21} \mathrm{H}_{24} \mathrm{BrN}_{4} \mathrm{O}\left([\mathrm{M}+\mathrm{H}]^{+}\right) \mathrm{m} / z$ 427.1133, found $\mathrm{m} / z 427.1132$.

(1-(4-((3-bromophenethyl)amino)quinazolin-2-yl)piperidin-2-yl)methanol (6i)We followed the general procedure. A solution of $4 \mathbf{i}(40 \mathrm{mg}, 0.11 \mathrm{mmol})$ in $\mathrm{n}-\mathrm{BuOH}(4 \mathrm{~mL})$ 
was treated with DIEA (28.2 $\mathrm{mg}, 0.22 \mathrm{mmol})$ and 2-piperidinemethanol $(24.0 \mathrm{mg}, 0.22$ mmol). Compound $6 \mathbf{i}$ was purified from this crude material by prep-HPLC (UV $254 \mathrm{~nm}, 4.0$ $\left.\mathrm{mL} / \mathrm{min}, \mathrm{H}_{2} \mathrm{O} / \mathrm{ACN}(0.01 \% \mathrm{TFA}) 5-60 \%, 0-30 \mathrm{~min}\right)$, (19.8 mg, 40.8\%). purity (99.39\%); ${ }^{1} \mathrm{H}-\mathrm{NMR}\left(400 \mathrm{MHz}, \mathrm{CDCl}_{3}\right) \delta 12.08$ (brs, $\left.1 \mathrm{H}\right), 8.46$ (s, $\left.1 \mathrm{H}\right), 7.71(\mathrm{~d}, J=7.6 \mathrm{~Hz}$, 1H), 7.49 (d, $J=8.0 \mathrm{~Hz}, 1 \mathrm{H}), 7.44-7.32(\mathrm{~m}, 3 \mathrm{H}), 7.24-7.08$ (m, 3H), 4.74 (brs, $1 \mathrm{H}), 4.09$ (t, $J$ $=10.8 \mathrm{~Hz}, 1 \mathrm{H}), 3.88(\mathrm{~s}, 1 \mathrm{H}), 3.71(\mathrm{~s}, 1 \mathrm{H}), 3.61-3.49(\mathrm{~m}, 1 \mathrm{H}), 3.31(\mathrm{~s}, 2 \mathrm{H}), 3.14(\mathrm{~s}, 1 \mathrm{H}), 2.92$ (t, $J=7.6 \mathrm{~Hz}, 2 \mathrm{H}$, benzyl- $\left.\mathrm{CH}_{2}-\right), 1.95-1.79(\mathrm{~m}, 2 \mathrm{H}), 1.78-1.48(\mathrm{~m}, 4 \mathrm{H}) .{ }^{13} \mathrm{C}-\mathrm{NMR}$ $\left(100 \mathrm{MHz}, \mathrm{CDCl}_{3}\right) \delta 159.7,153.2,141.4,139.8,135.2,132.3,131.0,130.5,128.0,125.3$, 123.6, 123.3, 118.3, 109.9, 61.4, 55.7, 43.6, 40.8, 35.0, 26.3, 25.7, 19.8. LC-MS (ESI, formic) $\mathrm{m} / \mathrm{z}$. $441.1\left([\mathrm{M}+\mathrm{H}]^{+}\right)$. HRMS (FAB) calcd for $\mathrm{C}_{22} \mathrm{H}_{26} \mathrm{BrN}_{4} \mathrm{O}\left([\mathrm{M}+\mathrm{H}]^{+}\right) \mathrm{m} / z$. 441.1290; found $\mathrm{m} / \mathrm{z}$. 441.1290 .

2-chloro-N-(3-methoxyphenethyl)quinazolin-4-amine (4j)-We followed the general procedure. A solution of compound $\mathbf{3}(140 \mathrm{mg}, 0.7 \mathrm{mmol})$ in $\mathrm{n}-\mathrm{BuOH}(6 \mathrm{~mL})$ was treated with DIEA (98.6 mg, $0.77 \mathrm{mmol})$ and 3-methoxyphenethylamine (118 mg, 0.77 $\mathrm{mmol})$. Compound $\mathbf{4} \mathbf{j}$ was purified from this crude material by column chromatography (silicagel, n-hexane/EtOAc = 3:1) $(128.5 \mathrm{mg}, 57.8 \%) .{ }^{1} \mathrm{H}-\mathrm{NMR}\left(400 \mathrm{MHz}, \mathrm{CDCl}_{3}\right) \delta$ 7.66-7.58 (m, 2H), $7.47(\mathrm{~d}, J=8.0 \mathrm{~Hz}, 1 \mathrm{H}), 7.31(\mathrm{t}, J=8.4 \mathrm{~Hz}, 1 \mathrm{H}), 7.16(\mathrm{t}, J=8.8 \mathrm{~Hz}, 1 \mathrm{H})$, 6.73-6.70 (m, 2H), 6.09 (s, $1 \mathrm{H},-\mathrm{NH}), 3.84\left(\mathrm{dd}, J=12.4,6.8 \mathrm{~Hz}, 2 \mathrm{H},-\mathrm{CH}_{2}-\right), 3.70(\mathrm{~s}, 3 \mathrm{H},-$ $\left.\mathrm{OCH}_{3}\right), 2.92(\mathrm{t}, J=6.8 \mathrm{~Hz}, 2 \mathrm{H}) .{ }^{13} \mathrm{C}-\mathrm{NMR}\left(100 \mathrm{MHz}, \mathrm{CDCl}_{3}\right) \delta 160.9,160.0,157.8,150.8$ $140.1,133.5,129.8,127.7,126.2,121.1,120.7,114.5,113.3,112.2,55.2,42.4,35.1$. LCMS (ESI) $m / z .314 .1\left([\mathrm{M}+\mathrm{H}]^{+}\right)$.

(S)-(1-(4-((3-methoxyphenethyl)amino)quinazolin-2-yl)pyrrolidin-2-yl)methanol (5i)-We followed the general procedure. A solution of $4 \mathbf{j}$ (40 mg, $0.13 \mathrm{mmol}$ ) in $\mathrm{n}-\mathrm{BuOH}$ $(4 \mathrm{~mL})$ was treated with DIEA (33.3 mg, $0.26 \mathrm{mmol})$ and L-prolinol $(25.9 \mathrm{mg}, 0.26 \mathrm{mmol})$. Compound $\mathbf{5 i}$ was purified from this crude material by prep-HPLC (UV $254 \mathrm{~nm}, 4.0 \mathrm{~mL} /$ min, $\left.\mathrm{H}_{2} \mathrm{O} / \mathrm{ACN}(0.01 \% \mathrm{TFA}) 5-60 \%, 0-30 \mathrm{~min}\right),(29.3 \mathrm{mg}, 59.6 \%)$. purity $(99.80 \%) ;{ }^{1} \mathrm{H}-$ NMR (400 MHz, CD $\left.{ }_{3} \mathrm{OD}\right) \delta 8.06(\mathrm{dd}, J=8.0,1.2 \mathrm{~Hz}, 1 \mathrm{H}), 7.80(\mathrm{dd}, J=8.4,1.2 \mathrm{~Hz}, 1 \mathrm{H})$, $7.44(\mathrm{td}, J=8.0,0.8 \mathrm{~Hz}, 1 \mathrm{H}), 7.19(\mathrm{t}, J=7.6 \mathrm{~Hz}, 1 \mathrm{H}), 6.88-6.81(\mathrm{~m}, 2 \mathrm{H}), 6.80-6.73(\mathrm{~m}, 1 \mathrm{H})$, 3.98-3.90 (m, 2H), 3.90-3.85 (m, 1H), $3.73(\mathrm{~s}, 3 \mathrm{H}), 3.02(\mathrm{t}, J=7.2 \mathrm{~Hz}, 2 \mathrm{H}), 2.40-1.90(\mathrm{~m}$, $4 \mathrm{H}) .{ }^{13} \mathrm{C}-\mathrm{NMR}\left(100 \mathrm{MHz}, \mathrm{CDCl}_{3}+\mathrm{CD}_{3} \mathrm{OD}\right) \delta 159.7,159.2,140.2,134.5,129.6,124.5$, 123.4, 121.0, 117.2, 114.6, 111.8, 109.6, 64.27, 61.0, 55.1, 50.0, 43.2, 34.7, 28.9, 22.6. LCMS (ESI, formic) $m / z .379 .2\left([\mathrm{M}+\mathrm{H}]^{+}\right)$. HRMS (FAB) calculated for $\mathrm{C}_{22} \mathrm{H}_{27} \mathrm{~N}_{4} \mathrm{O}_{2}([\mathrm{M}+$ $\mathrm{H}]^{+}$) $\mathrm{m} / \mathrm{z} .379 .2134$, found $\mathrm{m} / \mathrm{z} .379 .2132$.

(1-(4-((3-methoxyphenethyl)amino)quinazolin-2-yl)piperidin-2-yl)methanol (6j)

-We followed the general procedure. A solution of $4 \mathbf{j}$ ( $40 \mathrm{mg}, 0.13 \mathrm{mmol}$ ) in $\mathrm{n}-\mathrm{BuOH}(4$ $\mathrm{mL}$ ) was treated with DIEA $(28.2 \mathrm{mg}, 0.26 \mathrm{mmol})$ and 2-piperidinemethanol $(26.0 \mathrm{mg}, 0.26$ mmol). Compound $\mathbf{6 j}$ was purified from this crude material by prep-HPLC (UV $254 \mathrm{~nm}, 4.0$ $\mathrm{mL} / \mathrm{min}, \mathrm{H}_{2} \mathrm{O} / \mathrm{ACN}(0.01 \%$ TFA) 5-60\%, 0-30 min), (32.1 mg, 62.7\%). purity (96.76\%); ${ }^{1} \mathrm{H}-\mathrm{NMR}\left(400 \mathrm{MHz}, \mathrm{CDCl}_{3}+\mathrm{CD}_{3} \mathrm{OD}\right) \delta 7.68(\mathrm{~d}, J=8.0 \mathrm{~Hz}, 2 \mathrm{H}), 7.51(\mathrm{~m}, 1 \mathrm{H})$, 7.24-7.15 (m, 2H), 6.70-6.80 (m, 3H), $4.78(\mathrm{~s}, 1 \mathrm{H}), 4.05-3.90(\mathrm{~m}, 1 \mathrm{H}), 3.75(\mathrm{~s}, 3 \mathrm{H})$, 3.20-3.10 (m, 1H), 2.95-2.85 (m, 4H) 1.90-1.80 (m, 2H), 1.80-1.45 (m, 4H). ${ }^{13} \mathrm{C}-\mathrm{NMR}(100$ $\left.\mathrm{MHz}, \mathrm{CDCl}_{3}+\mathrm{CD}_{3} \mathrm{OD}\right) \delta 159.8,159.2,140.0,139.5,134.7,129.7,124.6,122.4,121.0$, 
118.0, 114.6, 111.8, 109.4, 60.1, 55.1, 54.7, 43.1, 34.7, 25.4, 25.1, 19.1. LC-MS (ESI, formic) $\mathrm{m} / z .393 .2\left([\mathrm{M}+\mathrm{H}]^{+}\right)$. HRMS (FAB) calculated for $\mathrm{C}_{22} \mathrm{H}_{29} \mathrm{~N}_{4} \mathrm{O}_{2}\left([\mathrm{M}+\mathrm{H}]^{+}\right) \mathrm{m} / z$. 393.2291, found $\mathrm{m} / \mathrm{z}$. 393.2285.

2-chloro-N-(2-fluorophenethyl)quinazolin-4-amine (4k)-We followed the general procedure. A solution of compound $\mathbf{3}(140 \mathrm{mg}, 0.7 \mathrm{mmol})$ in $\mathrm{n}-\mathrm{BuOH}(6 \mathrm{~mL})$ was treated with DIEA (98.6 mg, $0.77 \mathrm{mmol}$ ) and 2-fluorophenethylamine (107 mg, $0.77 \mathrm{mmol})$. Compound $\mathbf{4 k}$ was purified from this crude material by column chromatography (silicagel, n-hexane/EtOAc = 3:1) $(137.2 \mathrm{mg}, 65.1 \%) .{ }^{1} \mathrm{H}-\mathrm{NMR}\left(400 \mathrm{MHz}, \mathrm{CDCl}_{3}\right) \delta$ 7.68-7.58 (m, $2 \mathrm{H}), 7.52(\mathrm{~d}, \mathrm{~J}=8.0 \mathrm{~Hz}, 1 \mathrm{H}), 7.34(\mathrm{t}, \mathrm{J}=8.4 \mathrm{~Hz}, 1 \mathrm{H}), 7.20-7.11(\mathrm{~m}, 2 \mathrm{H}), 7.06-6.94(\mathrm{~m}, 2 \mathrm{H})$, $6.13(\mathrm{~s}, 1 \mathrm{H},-\mathrm{NH}), 3.84\left(\mathrm{dd}, \mathrm{J}=12.4,6.4 \mathrm{~Hz}, 2 \mathrm{H},-\mathrm{CH}_{2^{-}}\right), 3.01(\mathrm{t}, \mathrm{J}=6.4 \mathrm{~Hz}, 2 \mathrm{H},-$ $\mathrm{CH}_{2}$ ). ${ }^{13} \mathrm{C}-\mathrm{NMR}\left(100 \mathrm{MHz}, \mathrm{CDCl}_{3}\right) \delta 161.0,157.7,150.8,133.5,131.3,128.7,128.7$, 127.7, 126.2, 125.6, 124.5, 120.7, 115.6, 115.4, 113.3, 41.8, 28.5. LC-MS (ESI) $\mathrm{m} / z .302 .1$ $\left([\mathrm{M}+\mathrm{H}]^{+}\right)$.

(S)-(1-(4-((2-fluorophenethyl)amino)quinazolin-2-yl)pyrrolidin-2-yl)methanol (5j) -We followed the general procedure. A solution of $4 \mathbf{k}(50 \mathrm{mg}, 0.16 \mathrm{mmol})$ in $\mathrm{n}-\mathrm{BuOH}$ $(4 \mathrm{~mL}$ ) was treated with DIEA (42.2 $\mathrm{mg}, 0.33 \mathrm{mmol}$ ) and L-prolinol (34 mg, $0.33 \mathrm{mmol}$ ). Compound $\mathbf{5 j}$ was purified from this crude material by prep-HPLC (UV $254 \mathrm{~nm}, 4.0 \mathrm{~mL} /$ min, $\left.\mathrm{H}_{2} \mathrm{O} / \mathrm{ACN}(0.01 \% \mathrm{TFA}) 5-60 \%, 0-30 \mathrm{~min}\right),(47.1 \mathrm{mg}, 77.5 \%)$. purity $(96.39 \%) ;{ }^{1} \mathrm{H}-$ NMR $\left(400 \mathrm{MHz}, \mathrm{CDCl}_{3}\right) \delta 8.05(\mathrm{dd}, J=8.4,0.8,1 \mathrm{H}), 7.81(\mathrm{t}, J=8.4 \mathrm{~Hz}, 1 \mathrm{H}), 7.45(\mathrm{t}, J=$ 8.4 Hz, 1H), 7.38-7.22 (m, 2H), 7.13-7.01 (m, 2H), 4.00-3.85 (m, 3H), 3.85-3.67 (m, 2H), $3.14(\mathrm{t}, J=7.2,2 \mathrm{H}), 2.38-1.89(\mathrm{~m}, 6 \mathrm{H}) .{ }^{13} \mathrm{C}-\mathrm{NMR}\left(100 \mathrm{MHz}, \mathrm{CDCl}_{3}\right) \delta$ 162.3, 160.3, 159.5, 151.1, 139.0, 134.5, 131.3, 131.2, 128.5, 128.4, 125.8, 124.5, 124.3, 123.5, 117.4, 115.4, 115.2, 109.4, 64.2, 60.7, 41.8, 28.9, 28.5, 22.6. LC-MS (ESI, formic) $\mathrm{m} / \mathrm{z} .367 .2\left([\mathrm{M}+\mathrm{H}]^{+}\right)$. HRMS (FAB) calculated for $\mathrm{C}_{21} \mathrm{H}_{24} \mathrm{FN}_{4} \mathrm{O}\left([\mathrm{M}+\mathrm{H}]^{+}\right) \mathrm{m} / z$. 367.1934, found $m / z$. 367.1937.

(1-(4-((2-fluorophenethyl)amino)quinazolin-2-yl)piperidin-2-yl)methanol (6k)-

We followed the general procedure. A solution of $4 \mathbf{k}(50 \mathrm{mg}, 0.16 \mathrm{mmol})$ in $\mathrm{n}-\mathrm{BuOH}(4 \mathrm{~mL})$ was treated with DIEA (42.2 mg, $0.33 \mathrm{mmol})$ and 2-piperidinemethanol $(38.0 \mathrm{mg}, 0.33$ $\mathrm{mmol}$ ). Compound $6 \mathbf{k}$ was purified from this crude material by prep-HPLC (UV $254 \mathrm{~nm}$, $\left.4.0 \mathrm{~mL} / \mathrm{min}, \mathrm{H}_{2} \mathrm{O} / \mathrm{ACN}(0.01 \% \mathrm{TFA}) 5-60 \%, 0-30 \mathrm{~min}\right),(31.1 \mathrm{mg}, 49.2 \%)$. purity (97.27\%); ${ }^{1} \mathrm{H}-\mathrm{NMR}\left(400 \mathrm{MHz}, \mathrm{CDCl}_{3}+\mathrm{CD}_{3} \mathrm{OD}\right) \delta 8.46(\mathrm{t}, J=5.2 \mathrm{~Hz}, 1 \mathrm{H},-\mathrm{NH}), 7.71(\mathrm{~d}, J$ $=8.4 \mathrm{~Hz}, 1 \mathrm{H}), 7.63(\mathrm{~d}, J=8.4 \mathrm{~Hz}, 1 \mathrm{H}), 7.52(\mathrm{t}, J=8.4 \mathrm{~Hz}, 1 \mathrm{H}), 7.25-7.15(\mathrm{~m}, 3 \mathrm{H})$, 7.08-6.97 (m, 2H), $4.76(\mathrm{~s}, 2 \mathrm{H}), 3.97(\mathrm{dd}, J=12.0,10.0 \mathrm{~Hz}, 1 \mathrm{H}), 3.83-3.65(\mathrm{~m}, 3 \mathrm{H})$, $3.18-2.92(\mathrm{~m}, 3 \mathrm{H}), 1.87-1.78(\mathrm{~m}, 2 \mathrm{H}), 1.78-1.40(\mathrm{~m}, 4 \mathrm{H}) .{ }^{13} \mathrm{C}-\mathrm{NMR}(100 \mathrm{MHz}$, $\left.\mathrm{CDCl}_{3}+\mathrm{CD}_{3} \mathrm{OD}\right) \delta 162.5,160.1,159.4,152.6,139.5,134.7,131.2,131.1,128.6,128.5$, 125.3, 125.2, 124.6, 124.4, 124.3, 122.4, 117.9, 115.5, 115.2, 109.4, 60.1, 54.6, 41.8, 28.5, 25.4, 25.1, 19.0. LC-MS (ESI, formic) $\mathrm{m} / z$. $381.2\left([\mathrm{M}+\mathrm{H}]^{+}\right)$. HRMS (FAB) calculated for $\mathrm{C}_{22} \mathrm{H}_{26} \mathrm{FN}_{4} \mathrm{O}\left([\mathrm{M}+\mathrm{H}]^{+}\right) \mathrm{m} / \mathrm{z}$. 381.2091, found $\mathrm{m} / \mathrm{z}$. 381.2090.

2-chloro-N-(2-chlorophenethyl)quinazolin-4-amine (4I)-We followed the general procedure. A solution of compound $\mathbf{3}(160 \mathrm{mg}, 0.81 \mathrm{mmol})$ in $\mathrm{n}-\mathrm{BuOH}(6 \mathrm{~mL})$ was treated with DIEA (114 mg, $0.89 \mathrm{mmol}$ ) and 2-chlorophenethylamine (126 mg, $0.81 \mathrm{mmol})$.

Compound $\mathbf{4 l}$ was purified from this crude material by column chromatography (silicagel, $\mathrm{n}$ - 
hexane/EtOAc $=3: 1)(142.5 \mathrm{mg}, 55.5 \%) .{ }^{1} \mathrm{H}-\mathrm{NMR}\left(400 \mathrm{MHz}, \mathrm{CDCl}_{3}\right) \delta 7.83-7.70(\mathrm{~m}, 2 \mathrm{H})$, 7.59 (d, $J=8.0 \mathrm{~Hz}, 1 \mathrm{H}), 7.50-7.38(\mathrm{~m}, 2 \mathrm{H}), 7.34-7.27$ (m, 2H), 7.27-7.20 (m, 2H). 6.07 (s, $1 \mathrm{H},-\mathrm{NH}), 4.00(\mathrm{dd}, J=12.4,6.8 \mathrm{~Hz}, 2 \mathrm{H}), 3.23(\mathrm{t}, J=6.8 \mathrm{~Hz}, 2 \mathrm{H}) .{ }^{13} \mathrm{C}-\mathrm{NMR}(100 \mathrm{MHz}$, $\left.\mathrm{CDCl}_{3}\right) \delta 161.0,158.0,151.2,148.0,136.4,134.1,133.5,131.2,129.8,128.4,127.9,127.3$, 126.3, 120.6, 41.6, 32.6. LC-MS (ESI) $\mathrm{m} / z .318 .1\left([\mathrm{M}+\mathrm{H}]^{+}\right)$.

(S)-(1-(4-((2-chlorophenethyl)amino)quinazolin-2-yl)pyrrolidin-2-yl)methanol (5k)-We followed the general procedure. A solution of 41 (50 mg, $0.16 \mathrm{mmol}) \mathrm{in} \mathrm{n}-\mathrm{BuOH}$ $(4 \mathrm{~mL})$ was treated with DIEA ( $41 \mathrm{mg}, 0.32 \mathrm{mmol})$ and L-prolinol $(33 \mathrm{mg}, 0.32 \mathrm{mmol})$. Compound 5k was purified from this crude material by prep-HPLC (UV $254 \mathrm{~nm}, 4.0 \mathrm{~mL} /$ min, $\mathrm{H}_{2} \mathrm{O} / \mathrm{ACN}(0.01 \%$ TFA) $5-60 \%, 0-30 \mathrm{~min}),(38.7 \mathrm{mg}, 63.3 \%)$. purity $(99.90 \%) ;{ }^{1} \mathrm{H}-$ NMR (400 MHz, $\left.\mathrm{CDCl}_{3}+\mathrm{CD}_{3} \mathrm{OD}\right) \delta 7.83(\mathrm{~d}, J=8.0 \mathrm{~Hz}, 1 \mathrm{H}), 7.42(\mathrm{t}, J=7.2 \mathrm{~Hz}, 1 \mathrm{H}), 7.33$ (m, 1H), 7.30-7.26 (m, 1H), 7.20-7.17 (m, 1H), 7.13-7.07 (m, 3H), 4.24 (brs, 1H), 3.90-3.65 (m, 4H), 3.65-3.55 (m, 2H), $3.05(\mathrm{t}, J=7.2 \mathrm{~Hz}, 2 \mathrm{H}), 2.13-2.0(\mathrm{~m}, 1 \mathrm{H}), 2.0-1.80(\mathrm{~m}$, $3 \mathrm{H}) .{ }^{13} \mathrm{C}-\mathrm{NMR}\left(100 \mathrm{MHz}, \mathrm{CDCl}_{3}+\mathrm{CD}_{3} \mathrm{OD}\right) \delta 159.3,151.5,138.5,136.2,134.5,134.0$, 131.1, 129.5, 128.2, 127.1, 124.4, 123.3, 117.3, 109.4, 64.3, 60.9, 41.3, 32.7, 28.9, 22.7. LCMS (ESI, formic) $\mathrm{m} / z$. $383.2\left([\mathrm{M}+\mathrm{H}]^{+}\right)$. HRMS (FAB) calculated for $\mathrm{C}_{21} \mathrm{H}_{24} \mathrm{ClN}_{4} \mathrm{O}([\mathrm{M}+$ $\mathrm{H}]^{+}$) $\mathrm{m} / \mathrm{z} .383 .1639$, found $\mathrm{m} / \mathrm{z} .383 .1642$.

(1-(4-((2-chlorophenethyl)amino)quinazolin-2-yl)piperidin-2-yl)methanol (6I)We followed the general procedure. A solution of $41(50 \mathrm{mg}, 0.16 \mathrm{mmol})$ in $\mathrm{n}-\mathrm{BuOH}(4 \mathrm{~mL})$ was treated with DIEA (41 mg, $0.32 \mathrm{mmol}$ ) and 2-piperidinemethanol (37.0 mg, 0.32 $\mathrm{mmol}$ ). Compound $6 \mathbf{1}$ was purified from this crude material by prep-HPLC (UV $254 \mathrm{~nm}, 4.0$ $\mathrm{mL} / \mathrm{min}, \mathrm{H}_{2} \mathrm{O} / \mathrm{ACN}$ (0.01\% TFA) 5-60\%, 0-30 min), (28.7 mg, 45.3\%). purity (96.99\%); ${ }^{1} \mathrm{H}-\mathrm{NMR}\left(400 \mathrm{MHz}, \mathrm{CDCl}_{3}+\mathrm{CD}_{3} \mathrm{OD}\right) \delta 8.48(\mathrm{~s}, 1 \mathrm{H},-\mathrm{NH}), 7.73(\mathrm{~d}, J=8.0 \mathrm{~Hz}$, $1 \mathrm{H}), 7.70(\mathrm{~d}, J=8.4 \mathrm{~Hz}, 1 \mathrm{H}), 7.52(\mathrm{t}, J=7.2 \mathrm{~Hz}, 1 \mathrm{H}), 7.36-7.30(\mathrm{~m}, 1 \mathrm{H}), 7.25-7.12(\mathrm{~m}, 4 \mathrm{H})$, $4.76(\mathrm{~s}, 1 \mathrm{H}), 3.95(\mathrm{t}, J=11.6 \mathrm{~Hz}, 1 \mathrm{H}), 3.90-3.80(\mathrm{~m}, 1 \mathrm{H}), 3.80-3.70(\mathrm{~m}, 2 \mathrm{H}), 3.25-3.10(\mathrm{~m}$, 2H), 3.10 (t, $J=7.6 \mathrm{~Hz}, 2 \mathrm{H}), 1.90-1.80(\mathrm{~m}, 2 \mathrm{H}), 1.78-1.45$ (m, 4H). ${ }^{13} \mathrm{C}-\mathrm{NMR}(100 \mathrm{MHz}$, $\left.\mathrm{CDCl}_{3}+\mathrm{CD}_{3} \mathrm{OD}\right) \delta 159.4,152.6,139.5,136.1,134.7,134.0,131.0,129.6,128.3,127.1$, 124.6, 122.5, 117.9, 109.5, 60.1, 54.6, 41.3, 40.2, 32.8, 25.4, 25.1, 19.0. LC-MS (ESI, formic) $\mathrm{m} / \mathrm{z} .397 .2\left([\mathrm{M}+\mathrm{H}]^{+}\right)$. HRMS (FAB) calcd for $\mathrm{C}_{22} \mathrm{H}_{26} \mathrm{ClN}_{4} \mathrm{O}\left([\mathrm{M}+\mathrm{H}]^{+}\right) \mathrm{m} / z$. 397.1795, found $\mathrm{m} / \mathrm{z} .397 .1799$.

N-(2-bromophenethyl)-2-chloroquinazolin-4-amine (4m)-We followed the general procedure. A solution of compound $\mathbf{3}(160 \mathrm{mg}, 0.81 \mathrm{mmol})$ in $\mathrm{n}-\mathrm{BuOH}(6 \mathrm{~mL})$ was treated with DIEA (114 mg, $0.89 \mathrm{mmol}$ ) and 2-chlorophenethylamine (162 mg, $0.81 \mathrm{mmol})$. Compound $\mathbf{4 m}$ was purified from this crude material by column chromatography (silicagel, n-hexane/EtOAc $=3: 1)(118.6 \mathrm{mg}, 40.1 \%) .{ }^{1} \mathrm{H}-\mathrm{NMR}(400 \mathrm{MHz}$, DMSO-d 6 ) $\delta 8.88(\mathrm{t}, J=$ $5.2 \mathrm{~Hz}, 1 \mathrm{H}, \mathrm{N}-\mathrm{H}), 8.21(\mathrm{~d}, J=7.6 \mathrm{~Hz}, 1 \mathrm{H}), 7.79(\mathrm{t}, J=8.4 \mathrm{~Hz}, 1 \mathrm{H}), 7.58(\mathrm{t}, J=15.6 \mathrm{~Hz}$, $2 \mathrm{H}), 7.52(\mathrm{t}, J=8.4 \mathrm{~Hz}, 1 \mathrm{H}), 7.40-7.26(\mathrm{~m}, 2 \mathrm{H}), 7.16(\mathrm{td}, \mathrm{J}=8.6,2.0 \mathrm{~Hz}, 1 \mathrm{H}), 3.70-3.60(\mathrm{~m}$, $\left.2 \mathrm{H},-\mathrm{CH}_{2}-\right), 3.11\left(\mathrm{t}, \mathrm{J}=7.6 \mathrm{~Hz}, 2 \mathrm{H},-\mathrm{CH}_{2}-\right) .{ }^{13} \mathrm{C}-\mathrm{NMR}\left(100 \mathrm{MHz}, \mathrm{DMSO}-\mathrm{d}_{6}\right) \delta 161.6$, 157.4, 150.7, 138.8, 134.1, 133.0, 131.6, 129.0, 128.3, 127.1, 126.6, 124.5, 123.5, 114.0, 41.2, 34.8; LRMS (ESI) $\mathrm{m} / z .363 .2\left([\mathrm{M}+\mathrm{H}]^{+}\right)$. 
(S)-(1-(4-((2-bromophenethyl)amino)quinazolin-2-yl)pyrrolidin-2-yl)methanol (5I)-We followed the general procedure. A solution of $4 \mathbf{m}$ (40 mg, $0.11 \mathrm{mmol})$ in $\mathrm{n}-\mathrm{BuOH}$ $(4 \mathrm{~mL})$ was treated with DIEA ( $28 \mathrm{mg}, 0.22 \mathrm{mmol})$ and L-prolinol $(23 \mathrm{mg}, 0.22 \mathrm{mmol})$. Compound $\mathbf{5 l}$ was purified from this crude material by prep-HPLC (UV $254 \mathrm{~nm}, 4.0 \mathrm{~mL} /$ min, $\mathrm{H}_{2} \mathrm{O} / \mathrm{ACN}(0.01 \%$ TFA) $5-60 \%, 0-30 \mathrm{~min}),(28.4 \mathrm{mg}, 60.6 \%)$. purity $(98.73 \%) ;{ }^{1} \mathrm{H}-$ NMR $\left(400 \mathrm{MHz}, \mathrm{CDCl}_{3}+\mathrm{CD}_{3} \mathrm{OD}\right) \delta 7.86(\mathrm{~d}, J=7.6 \mathrm{~Hz}, 1 \mathrm{H}), 7.45(\mathrm{~d}, J=8.0 \mathrm{~Hz}, 1 \mathrm{H}), 7.40$ (t, $J=8.0 \mathrm{~Hz}, 1 \mathrm{H}), 7.29$ (brs, $1 \mathrm{H}), 7.21-7.11(\mathrm{~m}, 2 \mathrm{H}), 7.08(\mathrm{t}, J=7.8 \mathrm{~Hz}, 1 \mathrm{H}), 7.00$ (dd, $J=$ 7.6, $1.6 \mathrm{~Hz}, 1 \mathrm{H}), 4.21$ (brs, $1 \mathrm{H}), 3.82-3.65(\mathrm{~m}, 4 \mathrm{H}), 3.65-3.52(\mathrm{~m}, 2 \mathrm{H}), 3.06$ (t, $J=7.2 \mathrm{~Hz}$, $2 \mathrm{H}), 2.20-2.00(\mathrm{~m}, 1 \mathrm{H}), 2.00-1.75(\mathrm{~m}, 3 \mathrm{H}) .{ }^{13} \mathrm{C}-\mathrm{NMR}\left(100 \mathrm{MHz}, \mathrm{CDCl}_{3}+\mathrm{CD}_{3} \mathrm{OD}\right) \delta 159.3$, 151.3, 138.7, 138.0, 134.5, 132.8, 131.1, 128.4, 127.7, 124.4, 123.4, 118.1, 117.2, 109.5, 64.4, 61.0, 50.3, 41.5, 41.4, 35.1, 28.9, 22.7. LC-MS (ESI, formic) $\mathrm{m} / \mathrm{z} .427 .1\left([\mathrm{M}+\mathrm{H}]^{+}\right)$. HRMS (FAB) calcd for $\mathrm{C}_{21} \mathrm{H}_{23} \mathrm{BrN}_{4} \mathrm{O}\left([\mathrm{M}+\mathrm{H}]^{+}\right) \mathrm{m} / z$. 427.1133, found $\mathrm{m} / z$. 427.1134.

(1-(4-((2-bromophenethyl)amino)quinazolin-2-yl)piperidin-2-yl)methanol (6m)We followed the general procedure. A solution of $4 \mathbf{m}(40 \mathrm{mg}, 0.11 \mathrm{mmol})$ in $\mathrm{n}-\mathrm{BuOH}(4$ $\mathrm{mL}$ ) was treated with DIEA $(28.2 \mathrm{mg}, 0.32 \mathrm{mmol})$ and 2-piperidinemethanol $(25.3 \mathrm{mg}, 0.22$ mmol). Compound $6 \mathbf{l}$ was purified from this crude material by prep-HPLC (UV $254 \mathrm{~nm}, 4.0$ $\mathrm{mL} / \mathrm{min}, \mathrm{H}_{2} \mathrm{O} / \mathrm{ACN}$ (0.01\% TFA) 5-60\%, 0-30 min), (19.8 mg, 40.9\%). purity (98.30\%); ${ }^{1} \mathrm{H}-\mathrm{NMR}\left(400 \mathrm{MHz}, \mathrm{CDCl}_{3}+\mathrm{CD}_{3} \mathrm{OD}\right) \delta 8.25$ (brs, $\left.1 \mathrm{H},-\mathrm{NH}\right), 7.73-7.64(\mathrm{~m}, 2 \mathrm{H})$, $7.55(\mathrm{~d}, J=7.6 \mathrm{~Hz}, 1 \mathrm{H}), 7.47(\mathrm{t}, J=7.6 \mathrm{~Hz}, 1 \mathrm{H}), 7.27-7.19(\mathrm{~m}, 2 \mathrm{H}), 7.19-7.08(\mathrm{~m}, 2 \mathrm{H}), 4.86$ (brs, $1 \mathrm{H},-\mathrm{OH}), 4.01(\mathrm{t}, J=11.6 \mathrm{~Hz}, 1 \mathrm{H}), 3.78-3.67(\mathrm{~m}, 1 \mathrm{H}), 3.13(\mathrm{t}, J=7.2 \mathrm{~Hz}, 3 \mathrm{H})$, 1.90-1.78 (m, 2H), 1.78-1.40 (m, 4H). ${ }^{13} \mathrm{C}-\mathrm{NMR}\left(100 \mathrm{MHz}, \mathrm{CDCl}_{3}+\mathrm{CD}_{3} \mathrm{OD}\right) \delta 159.2$, 137.9, 134.6, 133.0, 131.1, 128.6, 127.8, 124.6, 124.4, 122.4, 118.0, 109.2, 60.3, 41.3, 35.3, 25.5, 25.3, 19.1. LC-MS (ESI, formic) $\mathrm{m} / z .441 .1\left([\mathrm{M}+\mathrm{H}]^{+}\right)$. HRMS (FAB) calcd for ([M + $\left.\mathrm{H}]^{+}\right) \mathrm{C}_{22} \mathrm{H}_{25} \mathrm{BrN}_{4} \mathrm{O} \mathrm{m} / \mathrm{z}$. 441.1290, found $\mathrm{m} / \mathrm{z}$. 441.1287.

2-chloro-N-(2-methoxyphenethyl)quinazolin-4-amine (4n)-We followed the general procedure. A solution of compound $3(160 \mathrm{mg}, 0.81 \mathrm{mmol})$ in $\mathrm{n}-\mathrm{BuOH}(6 \mathrm{~mL})$ was treated with DIEA (114 mg, $0.89 \mathrm{mmol}$ ) and 2-methoxyphenethylamine (122 mg, 0.81 $\mathrm{mmol})$. Compound $\mathbf{4 n}$ was purified from this crude material by column chromatography (silicagel, n-hexane/EtOAc = 3:1) $(134.3 \mathrm{mg}, 53.0 \%) .{ }^{1} \mathrm{H}-\mathrm{NMR}\left(400 \mathrm{MHz}, \mathrm{CDCl}_{3}\right) \delta$ 7.68-7.58 (m, 2H), $7.45(\mathrm{~d}, \mathrm{~J}=8.0 \mathrm{~Hz}, 1 \mathrm{H}), 7.33(\mathrm{t}, \mathrm{J}=8.0 \mathrm{~Hz}, 1 \mathrm{H}), 7.20-7.15(\mathrm{~m}, 1 \mathrm{H}), 7.12$ $(\mathrm{dd}, \mathrm{J}=7.2,1.2 \mathrm{~Hz}, 1 \mathrm{H}), 6.91-6.81(\mathrm{~m}, 2 \mathrm{H}), 6.50(\mathrm{~s}, 1 \mathrm{H},-\mathrm{NH}), 3.85\left(\mathrm{~s}, 3 \mathrm{H},-\mathrm{OCH}_{3}\right), 3.78$ $\left(\mathrm{m}, 2 \mathrm{H},-\mathrm{CH}_{2}-\right), 2.99\left(\mathrm{t}, \mathrm{J}=6.4 \mathrm{~Hz}, 2 \mathrm{H},-\mathrm{CH}_{2}-\right) .{ }^{13} \mathrm{C}-\mathrm{NMR}\left(100 \mathrm{MHz}, \mathrm{CDCl}_{3}\right) \delta 160.9$, 157.9, 157.3, 150.7, 133.2, 130.9, 128.3, 127.8, 127.5, 125.9, 121.4, 120.6, 113.4, 110.9, 55.7, 43.0, 29.4. LC-MS (ESI) $\mathrm{m} / \mathrm{z} .314 .1\left([\mathrm{M}+\mathrm{H}]^{+}\right)$.

(S)-(1-(4-((2-methoxyphenethyl)amino)quinazolin-2-yl)pyrrolidin-2-yl)methanol $(5 \mathrm{~m})-W e$ followed the general procedure. A solution of $4 \mathbf{n}(40 \mathrm{mg}, 0.11 \mathrm{mmol}) \mathrm{in} \mathrm{n}-\mathrm{BuOH}$ $(4 \mathrm{~mL})$ was treated with DIEA (28.2 mg, $0.22 \mathrm{mmol}$ ) and L-prolinol (22 mg, $0.22 \mathrm{mmol})$. Compound $\mathbf{5 l}$ was purified from this crude material by prep-HPLC (UV $254 \mathrm{~nm}, 4.0 \mathrm{~mL} /$ min, $\mathrm{H}_{2} \mathrm{O} / \mathrm{ACN}(0.01 \%$ TFA) $5-60 \%, 0-30 \mathrm{~min}),(28.1 \mathrm{mg}, 67.5 \%)$. purity $(99.90 \%) ;{ }^{1} \mathrm{H}-$ NMR $\left(400 \mathrm{MHz}, \mathrm{CD}_{3} \mathrm{OD}\right) \delta 8.04(\mathrm{~d}, J=8.0,0.8 \mathrm{~Hz}, 1 \mathrm{H}), 7.79(\mathrm{td}, J=10.0,1.6 \mathrm{~Hz}, 1 \mathrm{H})$, $7.43(\mathrm{td}, J=8.0,0.8 \mathrm{~Hz}, 1 \mathrm{H}), 7.25-7.13(\mathrm{~m}, 3 \mathrm{H}), 6.92(\mathrm{~d}, J=7.6 \mathrm{~Hz}, 1 \mathrm{H}), 6.84(\mathrm{td}, J=7.6$, $1.2 \mathrm{~Hz}, 1 \mathrm{H}), 4.48(\mathrm{~s}, 1 \mathrm{H}), 4.00-3.85(\mathrm{~m}, 3 \mathrm{H}), 3.75(\mathrm{~s}, 3 \mathrm{H}), 3.75-3.60(\mathrm{~m}, 2 \mathrm{H}), 3.33(\mathrm{~d}, \mathrm{~J}=$ 
6.8, 2H, - $\mathrm{CH}_{2}-\mathrm{NH}$ ), 3.08 (t, $J=6.8 \mathrm{~Hz}, 2 \mathrm{H}$, benzylic), $2.4-1.90$ (m, $\left.4 \mathrm{H}\right) .{ }^{13} \mathrm{C}-\mathrm{NMR}$ $\left(100 \mathrm{MHz}, \mathrm{CDCl}_{3}+\mathrm{CD}_{3} \mathrm{OD}\right) \delta 159.3,157.4,134.7,130.6,128.1,127.0,124.5,122.8,120.9$, 117.6, 110.6, 109.5, 63.9, 60.8, 55.4, 42.6, 42.4, 29.4, 28.7, 22.5. LC-MS (ESI, formic) $\mathrm{m} / \mathrm{z}$. $379.2\left([\mathrm{M}+\mathrm{H}]^{+}\right)$. HRMS (FAB) calcd for $\mathrm{C}_{22} \mathrm{H}_{27} \mathrm{~N}_{4} \mathrm{O}_{2}\left([\mathrm{M}+\mathrm{H}]^{+}\right) \mathrm{m} / z .379 .2134$, found $\mathrm{m} / \mathrm{z} .379 .2134$.

(1-(4-((2-methoxyphenethyl)amino)quinazolin-2-yl)piperidin-2-yl)methanol (6n) -We followed the general procedure. A solution of $\mathbf{4 m}$ (40 mg, $0.11 \mathrm{mmol})$ in n-BuOH (4 $\mathrm{mL}$ ) was treated with DIEA $(28.2 \mathrm{mg}, 0.32 \mathrm{mmol})$ and 2-piperidinemethanol $(25.3 \mathrm{~g}, 0.22$ $\mathrm{mmol}$ ). Compound $\mathbf{6 1}$ was purified from this crude material by prep-HPLC (UV $254 \mathrm{~nm}, 4.0$ $\left.\mathrm{mL} / \mathrm{min}, \mathrm{H}_{2} \mathrm{O} / \mathrm{ACN}(0.01 \% \mathrm{TFA}) 5-60 \%, 0-30 \mathrm{~min}\right)$, (17.7 mg, 41.0\%). purity (95.10\%); ${ }^{1} \mathrm{H}-\mathrm{NMR}\left(400 \mathrm{MHz}, \mathrm{CDCl}_{3}+\mathrm{CD}_{3} \mathrm{OD}\right) \delta 8.02(\mathrm{~s}, 1 \mathrm{H},-\mathrm{NH}), 7.85(\mathrm{~d}, J=8.4 \mathrm{~Hz}$, $1 \mathrm{H}), 7.65-7.52(\mathrm{~m}, 2 \mathrm{H}), 7.28-7.7 .18(\mathrm{~m}, 2 \mathrm{H}), 7.13(\mathrm{~d}, J=7.2 \mathrm{~Hz}, 1 \mathrm{H}), 6.97-6.84(\mathrm{~m}, 2 \mathrm{H})$, $4.82(\mathrm{~s}, 1 \mathrm{H}), 3.94(\mathrm{dd}, J=12.0,10.0 \mathrm{~Hz}, 1 \mathrm{H}), 3.82(\mathrm{~s}, 3 \mathrm{H}), 3.82-3.70(\mathrm{~m}, 3 \mathrm{H}), 3.18-3.05(\mathrm{~m}$, $3 \mathrm{H}), 3.01(\mathrm{t}, J=6.8 \mathrm{~Hz}, 2 \mathrm{H}), 1.90-1.78(\mathrm{~m}, 2 \mathrm{H}), 1.76-1.45(\mathrm{~m}, 4 \mathrm{H}) .{ }^{13} \mathrm{C}-\mathrm{NMR}(100 \mathrm{MHz}$, $\left.\mathrm{CDCl}_{3}+\mathrm{CD}_{3} \mathrm{OD}\right) \delta 159.2,157.4,152.6,139.7,134.8,130.6,128.3,127.0,124.5,121.9$, 121.1, 118.3, 110.8, 109.5, 60.0, 55.5, 54.6, 42.6, 40.2, 29.4, 25.3, 25.1, 19.0. LC-MS (ESI, formic) $\mathrm{m} / z .393 .2\left([\mathrm{M}+\mathrm{H}]^{+}\right)$. HRMS (FAB) calcd for $\mathrm{C}_{23} \mathrm{H}_{29} \mathrm{~N}_{4} \mathrm{O}_{2}\left([\mathrm{M}+\mathrm{H}]^{+}\right) \mathrm{m} / z$. 393.2291, found $\mathrm{m} / \mathrm{z}$. 393.2292 .

2-chloro-N-(3,4-dimethoxybenzyl)quinazolin-4-amine (7d)-We followed the general procedure. A solution of compound $\mathbf{3}(160 \mathrm{mg}, 0.81 \mathrm{mmol})$ in $\mathrm{n}-\mathrm{BuOH}(6 \mathrm{~mL})$ was treated with DIEA (114 mg, $0.89 \mathrm{mmol})$ and 3,4-dimethoxybenzylamine (142.2 mg, 0.85 mmol). Compound 7d was purified from this crude material by column chromatography (silicagel, n-hexane/EtOAc $=3: 1)(213.2 \mathrm{mg}, 80.0 \%) .{ }^{1} \mathrm{H}-\mathrm{NMR}(400 \mathrm{MHz}$, $\left.\mathrm{CDCl}_{3}+\mathrm{CD}_{3} \mathrm{OD}\right) \delta 7.75(\mathrm{~d}, J=8.0 \mathrm{~Hz}, 1 \mathrm{H}), 7.63-7.59(\mathrm{~m}, 2 \mathrm{H}), 7.36-7.32(\mathrm{~m}, 1 \mathrm{H}), 6.96(\mathrm{~s}$, $1 \mathrm{H}), 6.88(\mathrm{~d}, J=8.0 \mathrm{~Hz}, 1 \mathrm{H}), 6.76(\mathrm{~d}, J=8.4,1 \mathrm{H}) 4.68\left(\mathrm{~s}, 2 \mathrm{H},-\mathrm{CH}_{2}-\right), 3.80\left(\mathrm{~s}, 3 \mathrm{H},-\mathrm{OCH}_{3}\right)$, 3.79 (s, $\left.3 \mathrm{H},-\mathrm{OCH}_{3}\right) .{ }^{13} \mathrm{C}-\mathrm{NMR}\left(100 \mathrm{MHz}, \mathrm{CDCl}_{3}+\mathrm{CD}_{3} \mathrm{OD}\right) \delta 160.8,157.5,150.3,149.0$, 148.6, 133.5, 130.2, 126.9, 126.2, 121.5, 120.7, 113.3, 112.0, 111.2, $55.9\left(\mathrm{OCH}_{3}\right), 55.8$ $\left(\mathrm{OCH}_{3}\right), 45.2\left(-\mathrm{CH}_{2}-\right)$. LC-MS (ESI, formic) $\mathrm{m} / \mathrm{z} .330 .1\left([\mathrm{M}+\mathrm{H}]^{+}\right)$.

(S)-(1-(4-((3,4-dimethoxybenzyl)amino)quinazolin-2-yl)pyrrolidin-2-yl)methanol (8d)-We followed the general procedure. A solution of $7 \mathbf{d}(45 \mathrm{mg}, 0.14 \mathrm{mmol})$ in $\mathrm{n}-\mathrm{BuOH}$ $(3 \mathrm{~mL})$ was treated with DIEA ( $34.7 \mathrm{mg}, 0.27 \mathrm{mmol}$ ) and L-prolinol ( $28 \mathrm{mg}, 0.27 \mathrm{mmol})$. Compound 8d was purified from this crude material by prep-HPLC (UV $254 \mathrm{~nm}, 4.0 \mathrm{~mL} /$ min, $\mathrm{H}_{2} \mathrm{O} / \mathrm{ACN}$ (0.01\% TFA) 5-60\%, 0-30 min), (33.2 mg, 62.0\%). purity (99.82\%); ${ }^{1} \mathrm{H}-$ NMR (400 MHz, $\left.\mathrm{CDCl}_{3}+\mathrm{CD}_{3} \mathrm{OD}\right) \delta 7.98(\mathrm{~d}, J=8.0 \mathrm{~Hz}, 1 \mathrm{H}), 7.34$ (brs, 2H), 7.10-7.08 (m, 1H), 7.0 (brs, 1H), 6.93 (d, $J=8.0 \mathrm{~Hz}, 1 \mathrm{H}), 6.81(\mathrm{~d}, J=8.0 \mathrm{~Hz}, 1 \mathrm{H}), 4.66-4.62(\mathrm{~m}, 2 \mathrm{H}), 4.30$ (m, 1H), 3.89 (s, 3H), 3.85 (s, 3H), $3.77(\mathrm{dd}, J=11.6,4.4 \mathrm{~Hz}, 2 \mathrm{H}), 3.67(\mathrm{~m}, 2 \mathrm{H}), 2.16-2.12$ (m, 1H), 2.10-1.90 (m, 3H). ${ }^{13} \mathrm{C}-\mathrm{NMR}\left(100 \mathrm{MHz}, \mathrm{CDCl}_{3}+\mathrm{CD}_{3} \mathrm{OD}\right) \delta$ 159.0, 149.1, 148.6, 134.6, 130.0, 124.4, 123.5, 120.7, 117.2, 111.8, 111.1, 109.5, 64.3, 61.0, 56.0, 55.0, 45.2, 28.9, 22.7. LC-MS (ESI, formic) $\mathrm{m} / z .395 .2\left([\mathrm{M}+\mathrm{H}]^{+}\right)$. HRMS (FAB) calcd for $\mathrm{C}_{22} \mathrm{H}_{27} \mathrm{~N}_{4} \mathrm{O}_{3}\left([\mathrm{M}+\mathrm{H}]^{+}\right) \mathrm{m} / z$. 395.2083, found $\mathrm{m} / \mathrm{z}$. 395.2076. 
(1-(4-((3,4-dimethoxybenzyl)amino)quinazolin-2-yl)piperidin-2-yl)methanol (9d)

-We followed the general procedure. A solution of 7d (45 mg, $0.14 \mathrm{mmol})$ in n-BuOH (3 $\mathrm{mL}$ ) was treated with DIEA (35 mg, $0.27 \mathrm{mmol})$ and 2-piperidinethanol (31 mg, 0.27 mmol). Compound 9d was purified from this crude material by prep-HPLC (UV $254 \mathrm{~nm}$, $4.0 \mathrm{~mL} / \mathrm{min}, \mathrm{H}_{2} \mathrm{O} / \mathrm{ACN}$ (0.01\% TFA) 5-60\%, 0-30 min), (25.3 mg, 45.6\%). purity (99.36\%); ${ }^{1} \mathrm{H}-\mathrm{NMR}\left(400 \mathrm{MHz}, \mathrm{CD}_{3} \mathrm{OD}\right) \delta 8.14$ (dd, $\left.J=8.0,0.8 \mathrm{~Hz}, 1 \mathrm{H}\right), 7.80$ (t, $J=8.4$, $1.2 \mathrm{~Hz}, 1 \mathrm{H}), 7.63(\mathrm{~d}, J=8.4 \mathrm{~Hz}, 1 \mathrm{H}), 7.46(\mathrm{t}, J=8.4,1.2 \mathrm{~Hz}, 1 \mathrm{H}), 7.05(\mathrm{~d}, J=2.0 \mathrm{~Hz}, 1 \mathrm{H})$, 6.99 (dd, $J=8.0,2.0 \mathrm{~Hz}, 1 \mathrm{H}), 6.93(\mathrm{~d}, J=8.4 \mathrm{~Hz}, 1 \mathrm{H}), 4.85$ (d, $J=, 2 \mathrm{H}), 3.99$ (dd, $J=11.6$, $9.2 \mathrm{~Hz}, 1 \mathrm{H}), 3.84(\mathrm{~s}, 3 \mathrm{H}), 3.85(\mathrm{~s}, 3 \mathrm{H}), 3.76(\mathrm{~m}, 1 \mathrm{H}), 3.28(\mathrm{~m}, 1 \mathrm{H}), 1.98-1.85(\mathrm{~m}, 2 \mathrm{H})$, 1.81-1.68 (m, 3H), 1.68-1.51 (m, 1H). ${ }^{13} \mathrm{C}-\mathrm{NMR}\left(100 \mathrm{MHz}, \mathrm{CD}_{3} \mathrm{OD}\right) \delta$ 161.0, 154.1, 150.7, $150.1,140.9,136.3,131.9,126.2,124.6,121.4,118.4,116.8,113.2,112.9,111.3,61.0$, 56.6, 55.5, 46.3, 41.8, 30.7, 26.2, 26.1, 24.2, 20.0. LC-MS (ESI, formic) $\mathrm{m} / \mathrm{z} .409 .2([\mathrm{M}+$ $\mathrm{H}]^{+}$). HRMS (FAB) calcd for $\mathrm{C}_{23} \mathrm{H}_{28} \mathrm{~N}_{4} \mathrm{O}_{3}\left([\mathrm{M}+\mathrm{H}]^{+}\right) \mathrm{m} / z$. 409.2240, found $\mathrm{m} / \mathrm{z} .409 .2242$.

2-chloro-N-(4-methoxybenzyl)quinazolin-4-amine (7c)-A solution of compound 3 $(100 \mathrm{mg}, 0.56 \mathrm{mmol})$ in $\mathrm{n}-\mathrm{BuOH}(3 \mathrm{~mL})$ was treated with DIEA $(215.9 \mathrm{mg}, 1.67 \mathrm{mmol})$ and 4-methoxybenzylamine $(68.9 \mathrm{mg}, 0.56 \mathrm{mmol})$. The resulting mixture was stirred for $2 \mathrm{~h}$ at $40{ }^{\circ} \mathrm{C}$ and the solvent was evaporated. The residue was extracted with methylene chloride (30 mL, 3 times) and water. The organic layer was dried over $\mathrm{Na}_{2} \mathrm{SO}_{4}$ and evaporated. Compound $\mathbf{7} \mathbf{c}$ was purified from this crude material by column chromatography (silicagel, n-hexane/EtOAc $=3: 1)(137.2 \mathrm{mg}, 81.7 \%) .{ }^{1} \mathrm{H} \mathrm{NMR}\left(400 \mathrm{MHz}, \mathrm{CDCl}_{3}\right) \delta$ 7.78-7.76 (m, $1 \mathrm{H}), 7.72$ (ddd, $J=8.4,6.8,1.2 \mathrm{~Hz}, 1 \mathrm{H}), 7.65(\mathrm{~d}, 8.4 \mathrm{~Hz}, 1 \mathrm{H}), 7.42$ (ddd, $J=8.4,6.8,1.6$ $\mathrm{Hz}, 1 \mathrm{H}), 7.35-7.31$ (m, 2H), 6.09 (br s, $1 \mathrm{H}), 4.78$ (d, $J=5.2 \mathrm{~Hz}, 2 \mathrm{H}), 3.81$ (s, 3H). ${ }^{13} \mathrm{C}$ NMR $\left(100 \mathrm{MHz}, \mathrm{CDCl}_{3}\right) \delta 160.6,159.5,157.8,150.9,133.5,129.8,129.3,127.9,126.2,120.8$, 114.3, 113.2, 55.4, 45.3. LC-MS (ESI, formic) $\mathrm{m} / z 300.1[\mathrm{M}+\mathrm{H}]^{+}$.

\section{(S)-(1-(4-((4-methoxybenzyl)amino)quinazolin-2-yl)pyrrolidin-2-yl)methanol}

(8c) - A solution of $4 \mathrm{i}(80 \mathrm{mg}, 0.27 \mathrm{mmol})$ in $\mathrm{n}-\mathrm{BuOH}(4 \mathrm{~mL})$ was treated with DIEA (69 $\mathrm{mg}, 0.54 \mathrm{mmol})$ and L-prolinol $(54.0 \mathrm{mg}, 0.54 \mathrm{mmol})$. The reaction mixture was stirred overnight at $120^{\circ} \mathrm{C}$ and the solvent was evaporated. The residue was extracted with methylene chloride ( $20 \mathrm{~mL}, 3$ times) and water. The organic layer was dried over $\mathrm{Na}_{2} \mathrm{SO}_{4}$ and evaporated. Compound $9 \mathrm{c}$ was purified from this crude material by column chromatography (silicagel, $\left.\mathrm{CH}_{2} \mathrm{Cl}_{2}: \mathrm{MeOH}=20: 1\right)(62.3 \mathrm{mg}, 63.4 \%)$. purity $(97.50 \%) ;{ }^{1} \mathrm{H}-$ NMR (400 MHz, $\left.\mathrm{CDCl}_{3}\right): \delta 7.51(\mathrm{~d}, J=8.4 \mathrm{~Hz}, 1 \mathrm{H}), 7.42-7.28(\mathrm{~m}, 2 \mathrm{H}), 7.24(\mathrm{~d}, J=8.8 \mathrm{~Hz}$, $2 \mathrm{H}), 6.94(\mathrm{td}, J=8.0,0.8 \mathrm{~Hz}, 1 \mathrm{H}), 6.79(\mathrm{~d}, J=8.4 \mathrm{~Hz}, 2 \mathrm{H}), 4.70-4.58(\mathrm{~m}, 2 \mathrm{H}), 4.25(\mathrm{~m}$, $1 \mathrm{H}), 3.80(\mathrm{~m}, 1 \mathrm{H}), 3.72(\mathrm{~s}, 3 \mathrm{H}), 3.66(\mathrm{dd}, J=10.8,2.4 \mathrm{~Hz}, 1 \mathrm{H}), 3.59$ (dd, $J=11.2,9.2 \mathrm{~Hz}$, $1 \mathrm{H}), 3.53(\mathrm{~m}, 1 \mathrm{H}), 2.10-2.00(\mathrm{~m}, 1 \mathrm{H}), 1.94-1.72(\mathrm{~m}, 2 \mathrm{H}), 1.65-1.55(\mathrm{~m}, 1 \mathrm{H}) .{ }^{13} \mathrm{C}-\mathrm{NMR}$ $\left(100 \mathrm{MHz}, \mathrm{CDCl}_{3}\right): \delta 162.9,162.2,159.5,159.0,157.9,133.0,130.7,129.2,123.8,121.4$, 121.3, 114.0, 110.2, 68.0, 60.8, 55.3, 48.5, 44.6, 29.7, 23.9. HRMS (FAB) calculated for $\mathrm{C}_{21} \mathrm{H}_{25} \mathrm{~N}_{4} \mathrm{O}_{2}\left([\mathrm{M}+\mathrm{H}]^{+}\right) \mathrm{m} / \mathrm{z}: 365.1978$, found $\mathrm{m} / \mathrm{z}: 365.1971$.

(1-(4-((4-methoxybenzyl)amino)quinazolin-2-yl)piperidin-2-yl)methanol (9c)-A solution of $4 \mathbf{i}(50 \mathrm{mg}, 0.167 \mathrm{mmol})$ in $\mathrm{n}-\mathrm{BuOH}(2 \mathrm{~mL})$ was treated with DIEA $(64.7 \mathrm{mg}, 0.5$ $\mathrm{mmol})$ and 2-piperidinemethanol $(55.77 \mathrm{mg}, 0.48 \mathrm{mmol})$. The reaction mixture was stirred overnight at $120^{\circ} \mathrm{C}$ and the solvent was evaporated. The residue was extracted with 
methylene chloride ( $20 \mathrm{~mL}, 3$ times) and water. The organic layer was dried over $\mathrm{Na}_{2} \mathrm{SO}_{4}$ and evaporated. Compound $\mathbf{9 c}$ was purified from this crude material by column chromatography (silicagel, $\mathrm{CH}_{2} \mathrm{Cl}_{2}: \mathrm{MeOH}$ :triethylamine $\left.=10: 1: 0.1\right)(46.8 \mathrm{mg}, 74.0 \%)$. purity (96.28\%); ${ }^{1} \mathrm{H}$ NMR $\left(400 \mathrm{MHz}, \mathrm{CDCl}_{3}\right) \delta 7.50-7.39(\mathrm{~m}, 3 \mathrm{H}), 7.32(\mathrm{~d}, J=8.4 \mathrm{~Hz}, 2 \mathrm{H})$, 7.03-6.99 (m, 1H), 6.90-6.86 (m, 2H), $5.90(\mathrm{br} \mathrm{s}, 1 \mathrm{H}), 5.29(\mathrm{~s}, 2 \mathrm{H}), 5.06-5.00(\mathrm{~m}, 1 \mathrm{H}), 4.77$ (d, $J=15.2 \mathrm{~Hz}, 1 \mathrm{H}), 4.75-4.64(\mathrm{~m}, 2 \mathrm{H}), 4.07$ (t, $J=10.4,10.0 \mathrm{~Hz}, 1 \mathrm{H}), 3.80$ (s, 3H), 3.73 $(\mathrm{dd}, J=10.8,4.0 \mathrm{~Hz}, 1 \mathrm{H}), 3.20-3.13(\mathrm{~m}, 1 \mathrm{H}), 1.73-1.51(\mathrm{~m}, 6 \mathrm{H}) .{ }^{13} \mathrm{C}$ NMR $(100 \mathrm{MHz}$, $\left.\mathrm{CDCl}_{3}\right) \delta 160.5,159.5,159.1,132.7,130.7,129.2,125.4,121.1,120.7,114.1,110.5,64.3$, 55.3, 53.4, 53.4, 44.8, 39.9, 26.4, 25.3, 20.2. HRMS (FAB) calculated for $\mathrm{C}_{22} \mathrm{H}_{27} \mathrm{~N}_{4} \mathrm{O}_{2}([\mathrm{M}$ $\left.+\mathrm{H}]^{+}\right) \mathrm{m} / \mathrm{z} 379.2134$, found $\mathrm{m} / \mathrm{z} 379.2141$; $\mathrm{mp}$ 175.5-179.2.

(R)-(1-(4-((4-methoxybenzyl)amino)quinazolin-2-yl)piperidin-2-yl)methanol (R-9c) - This compound was generated from (R)-2-piperidinemethanol using the same procedure as for compound 9c. Purity (99.66\%); ${ }^{1} \mathrm{H}$ NMR (400 MHz, DMSO-d $\left.{ }_{6}\right) \delta 11.75$ (br, 1H), $9.97(\mathrm{~s}, 1 \mathrm{H}), 8.27(\mathrm{~d}, \mathrm{~J}=6.0 \mathrm{~Hz}, 1 \mathrm{H}), 7.81-7.73(\mathrm{~m}, 2 \mathrm{H}), 7.34-7.44(\mathrm{~m}, 3 \mathrm{H}), 6.90$ $(\mathrm{m}, 2 \mathrm{H}), 4.72(\mathrm{~d}, J=3.6 \mathrm{~Hz}, 1 \mathrm{H}), 3.63(\mathrm{~s}, 3 \mathrm{H}), 3.60(\mathrm{~m}, 1 \mathrm{H}), 3.17(\mathrm{~m}, 1 \mathrm{H}), 1.85-1.57(\mathrm{~m}$, $6 \mathrm{H}) .{ }^{13} \mathrm{C}-\mathrm{NMR}\left(100 \mathrm{MHz}, \mathrm{CDCl}_{3}+\mathrm{CD}_{3} \mathrm{OD}\right) \delta 159.2,159.1,152.6,139.4,134.7,129.3$, 129.2, 129.1, 124.6, 122.8, 117.7, 114.0, 109.6, 60.1, 55.2, 54.6, 44.9, 40.2, 25.2, 24.9, 18.9. HRMS (FAB) calculated for $\mathrm{C}_{22} \mathrm{H}_{27} \mathrm{~N}_{4} \mathrm{O}_{2}\left([\mathrm{M}+\mathrm{H}]^{+}\right) \mathrm{m} / \mathrm{z} 379.2134$, found $\mathrm{m} / \mathrm{z} 379.2132$. $[\mathrm{a}]_{\mathrm{D}}{ }^{20} 0.281$ (c $\left.0.3, \mathrm{CH}_{3} \mathrm{OH}\right)$

\section{(S)-(1-(4-((4-methoxybenzyl)amino)quinazolin-2-yl)piperidin-2-yl)methanol}

(S-9c)-This compound was generated from (S)-2-piperidinemethanol using the same procedure as for compound 9c. Purity $(99.19 \%) ;{ }^{1} \mathrm{H}$ NMR (400 MHz, DMSO-d 6 ) $\delta 11.78$ (br, 1H), $9.97(\mathrm{~s}, 1 \mathrm{H}), 8.28(\mathrm{~d}, \mathrm{~J}=6.0 \mathrm{~Hz}, 1 \mathrm{H}), 7.82-7.72(\mathrm{~m}, 2 \mathrm{H}), 7.35-7.43(\mathrm{~m}, 3 \mathrm{H}), 6.92$ $(\mathrm{m}, 2 \mathrm{H}), 4.73(\mathrm{~d}, J=3.6 \mathrm{~Hz}, 1 \mathrm{H}), 3.65(\mathrm{~s}, 3 \mathrm{H}), 3.60(\mathrm{~m}, 1 \mathrm{H}), 3.18(\mathrm{~m}, 1 \mathrm{H}), 1.82-1.56(\mathrm{~m}$, $6 \mathrm{H}) .{ }^{13} \mathrm{C}-\mathrm{NMR}\left(100 \mathrm{MHz}, \mathrm{CDCl}_{3}+\mathrm{CD}_{3} \mathrm{OD}\right) \delta 159.5,158.8,133.4,130.4,128.9,122.3$, 122.2, 121.8, 113.9, 110.3, 61.7, 55.2, 53.5, 44.5, 40.1, 25.5, 25.0, 19.5. HRMS (FAB) calculated for $\mathrm{C}_{22} \mathrm{H}_{27} \mathrm{~N}_{4} \mathrm{O}_{2}\left([\mathrm{M}+\mathrm{H}]^{+}\right) \mathrm{m} / z$. 379.2134, found $\mathrm{m} / \mathrm{z}$. 379.2136. $[\mathrm{a}]_{\mathrm{D}}{ }^{20}-0.052$ (c $0.3, \mathrm{CH}_{3} \mathrm{OH}$ )

\section{Acknowledgments}

We thank Dr. L. Thompson for comments on the manuscript. This work was supported by Oklahoma Center for the Advancement of Science and Technology, National Institutes of Health (5P20GM103636) to W.W, and the Korea Institute of Science and Technology Institutional Program (2Z04371) to J.W.L.

\section{ABBREVIATIONS USED}

Tm

ER

STAT1

INS- 1 cell

DIEA tunicamycin

endoplasmic reticulum

signal transducer and activator of transcription 1

rat insulinoma cell line

$N, N$-diisopropylethylamine 


\begin{tabular}{|c|c|}
\hline UPR & unfolded protein response \\
\hline SAR & structure-activity relationship \\
\hline $\mathbf{E C}_{50}$ & half maximal effective concentration \\
\hline RT-PCR & reverse transcription polymerase chain reaction \\
\hline BFA & brefeldin A \\
\hline CHOP & $\mathrm{C} / \mathrm{EBP}$ homologous protein \\
\hline PARP & Poly(ADP-ribose) polymerase \\
\hline eIF2a & eukaryotic translation initiator factor $2 a$ \\
\hline TUNEL & $\begin{array}{l}\text { Terminal deoxynucleotidyl transferase dUTP nick end } \\
\text { labeling }\end{array}$ \\
\hline GSIS & Glucose Stimulated Insulin Secretion \\
\hline PERK & PKR-like ER kinase \\
\hline XBP1 & X-box binding protein 1 \\
\hline ATF6 & activating transcription factor 6 \\
\hline ATF4 & activating transcription factor 4 \\
\hline FBS & fetal bovine serum \\
\hline PDX1 & pancreatic and duodenal homeobox 1 \\
\hline MafA & $\begin{array}{l}\text { v-maf musculoaponeurotic fibrosarcoma oncogene family, } \\
\text { protein A }\end{array}$ \\
\hline INS1 & insulin 1 \\
\hline INS2 & insulin 2. \\
\hline
\end{tabular}

\section{References}

1. Vetere A, Choudhary A, Burns SM, Wagner BK. Targeting the Pancreatic Beta-Cell to Treat Diabetes. Nat. Rev. Drug Discov. 2014; 13:278-289. [PubMed: 24525781]

2. Donath MY, Halban PA. Decreased Beta-Cell Mass in Diabetes: Significance, Mechanisms and Therapeutic Implications. Diabetologia. 2004; 47:581-589. [PubMed: 14767595]

3. Kahn SE. The Relative Contributions of Insulin Resistance and Beta-Cell Dysfunction to the Pathophysiology of Type 2 Diabetes. Diabetologia. 2003; 46:3-19. [PubMed: 12637977]

4. Prentki M, Nolan CJ. Islet Beta Cell Failure in Type 2 Diabetes. J. Clin. Invest. 2006; 116:18021812. [PubMed: 16823478]

5. Muoio DM, Newgard CB. Mechanisms of Disease:Molecular and Metabolic Mechanisms of Insulin Resistance and Beta-Cell Failure in Type 2 Diabetes. Nat. Rev. Mol. Cell Biol. 2008; 9:193-205. [PubMed: 18200017]

6. Fonseca SG, Gromada J, Urano F. Endoplasmic Reticulum Stress and Pancreatic Beta-Cell Death. Trends Endocrinol. Metab. 2011; 22:266-274. [PubMed: 21458293] 
7. Back SH, Kaufman RJ. Endoplasmic Reticulum Stress and Type 2 Diabetes. Ann. Rev. Biochem. 2012; 81:767-793. [PubMed: 22443930]

8. Papa FR. Endoplasmic Reticulum Stress, Pancreatic Beta-Cell Degeneration, and Diabetes. Cold Spring Harb. Perspect. Med. 2012; 2:a007666. [PubMed: 22951443]

9. Eizirik DL, Cardozo AK, Cnop M. The Role for Endoplasmic Reticulum Stress in Diabetes Mellitus. Endocr. Rev. 2008; 29:42-61. [PubMed: 18048764]

10. Tersey SA, Nishiki Y, Templin AT, Cabrera SM, Stull ND, Colvin SC, Evans-Molina C, Rickus JL, Maier B, Mirmira RG. Islet Beta-Cell Endoplasmic Reticulum Stress Precedes the Onset of Type 1 Diabetes in the Nonobese Diabetic Mouse Model. Diabetes. 2012; 61:818-827. [PubMed: 22442300]

11. Engin F, Yermalovich A, Nguyen T, Hummasti S, Fu W, Eizirik DL, Mathis D, Hotamisligil GS. Restoration of the Unfolded Protein Response in Pancreatic Beta Cells Protects Mice against Type 1 Diabetes. Sci. Transl. Med. 2013; 5:211ra156.

12. Hetz C, Chevet E, Harding HP. Targeting the Unfolded Protein Response in Disease. Nat. Rev. Drug Discov. 2013; 12:703-719. [PubMed: 23989796]

13. Bertolotti A, Zhang Y, Hendershot LM, Harding HP, Ron D. Dynamic Interaction of Bip and Er Stress Transducers in the Unfolded-Protein Response. Nat. Cell Biol. 2000; 2:326-332. [PubMed: 10854322]

14. Van Lommel L, Janssens K, Quintens R, Tsukamoto K, Vander Mierde D, Lemaire K, Denef C, Jonas JC, Martens G, Pipeleers D, Schuit FC. Probe-Independent and Direct Quantification of Insulin Mrna and Growth Hormone Mrna in Enriched Cell Preparations. Diabetes. 2006; 55:3214 3220. [PubMed: 17130463]

15. Schuit FC, In't Veld PA, Pipeleers DG. Glucose Stimulates Proinsulin Biosynthesis by a DoseDependent Recruitment of Pancreatic Beta Cells. Proc. Natl. Acad. Sci. U.S.A. 1988; 85:38653869. [PubMed: 3287379]

16. Harding HP, Zhang Y, Khersonsky S, Marciniak S, Scheuner D, Kaufman RJ, Javitt N, Chang YT, Ron D. Bioactive Small Molecules Reveal Antagonism between the Integrated Stress Response and Sterol-Regulated Gene Expression. Cell Metab. 2005; 2:361-371. [PubMed: 16330322]

17. Fribley AM, Cruz PG, Miller JR, Callaghan MU, Cai P, Narula N, Neubig RR, Showalter HD, Larsen SD, Kirchhoff PD, Larsen MJ, Burr DA, Schultz PJ, Jacobs RR, Tamayo-Castillo G, Ron D, Sherman DH, Kaufman RJ. Complementary Cell-Based High-Throughput Screens Identify Novel Modulators of the Unfolded Protein Response. J. Biomol. Screen. 2011; 16:825-835. [PubMed: 21844328]

18. Blais JD, Chin KT, Zito E, Zhang Y, Heldman N, Harding HP, Fass D, Thorpe C, Ron D. A Small Molecule Inhibitor of Endoplasmic Reticulum Oxidation 1 (Ero1) with Selectively Reversible Thiol Reactivity. J. Biol. Chem. 2010; 285:20993-21003. [PubMed: 20442408]

19. Mimura N, Fulciniti M, Gorgun G, Tai YT, Cirstea D, Santo L, Hu Y, Fabre C, Minami J, Ohguchi H, Kiziltepe T, Ikeda H, Kawano Y, French M, Blumenthal M, Tam V, Kertesz NL, Malyankar UM, Hokenson M, Pham T, Zeng Q, Patterson JB, Richardson PG, Munshi NC, Anderson KC. Blockade of Xbp1 Splicing by Inhibition of Ire1alpha Is a Promising Therapeutic Option in Multiple Myeloma. Blood. 2012; 119:5772-5781. [PubMed: 22538852]

20. Papandreou I, Denko NC, Olson M, Van Melckebeke H, Lust S, Tam A, Solow-Cordero DE, Bouley DM, Offner F, Niwa M, Koong AC. Identification of an Ire1alpha Endonuclease Specific Inhibitor with Cytotoxic Activity against Human Multiple Myeloma. Blood. 2011; 117:13111314. [PubMed: 21081713]

21. Wiseman RL, Zhang Y, Lee KP, Harding HP, Haynes CM, Price J, Sicheri F, Ron D. Flavonol Activation Defines an Unanticipated Ligand-Binding Site in the Kinase-Rnase Domain of Ire1. Mol. Cell. 2010; 38:291-304. [PubMed: 20417606]

22. Wang L, Perera BG, Hari SB, Bhhatarai B, Backes BJ, Seeliger MA, Schurer SC, Oakes SA, Papa FR, Maly DJ. Divergent Allosteric Control of the Ire1alpha Endoribonuclease Using Kinase Inhibitors. Nat. Chem. Biol. 2012; 8:982-989. [PubMed: 23086298]

23. Cross BC, Bond PJ, Sadowski PG, Jha BK, Zak J, Goodman JM, Silverman RH, Neubert TA, Baxendale IR, Ron D, Harding HP. The Molecular Basis for Selective Inhibition of 
Unconventional Mrna Splicing by an Ire1-Binding Small Molecule. Proc. Natl. Acad. Sci. U. S. A. 2012; 109:E869-E878. [PubMed: 22315414]

24. Volkmann K, Lucas JL, Vuga D, Wang X, Brumm D, Stiles C, Kriebel D, Der-Sarkissian A, Krishnan K, Schweitzer C, Liu Z, Malyankar UM, Chiovitti D, Canny M, Durocher D, Sicheri F, Patterson JB. Potent and Selective Inhibitors of the Inositol-Requiring Enzyme 1 Endoribonuclease. J. Biol. Chem. 2011; 286:12743-12755. [PubMed: 21303903]

25. Kim I, Shu CW, Xu W, Shiau CW, Grant D, Vasile S, Cosford ND, Reed JC. Chemical Biology Investigation of Cell Death Pathways Activated by Endoplasmic Reticulum Stress Reveals Cytoprotective Modulators of Ask1. J. Biol. Chem. 2009; 284:1593-1603. [PubMed: 19004820]

26. Boyce M, Bryant KF, Jousse C, Long K, Harding HP, Scheuner D, Kaufman RJ, Ma D, Coen DM, Ron D, Yuan J. A Selective Inhibitor of Eif2alpha Dephosphorylation Protects Cells from Er Stress. Science. 2005; 307:935-939. [PubMed: 15705855]

27. Cnop M, Ladriere L, Hekerman P, Ortis F, Cardozo AK, Dogusan Z, Flamez D, Boyce M, Yuan J, Eizirik DL. Selective Inhibition of Eukaryotic Translation Initiation Factor 2 Alpha Dephosphorylation Potentiates Fatty Acid-Induced Endoplasmic Reticulum Stress and Causes Pancreatic Beta-Cell Dysfunction and Apoptosis. J. Biol. Chem. 2007; 282:3989-3997. [PubMed: 17158450]

28. Ladriere L, Igoillo-Esteve M, Cunha DA, Brion JP, Bugliani M, Marchetti P, Eizirik DL, Cnop M. Enhanced Signaling Downstream of Ribonucleic Acid-Activated Protein Kinase-Like Endoplasmic Reticulum Kinase Potentiates Lipotoxic Endoplasmic Reticulum Stress in Human Islets. J. Clin. Endocrinol. Metab. 2010; 95:1442-1449. [PubMed: 20080856]

29. Tran K, Li Y, Duan H, Arora D, Lim HY, Wang W. Identification of Small Molecules That Protect Pancreatic Beta Cells against Endoplasmic Reticulum Stress-Induced Cell Death. ACS Chem. Biol. 2014; 9:2796-2806. [PubMed: 25279668]

30. Chou DH-C, Duvall JR, Gerard B, Liu H, Pandya BA, Suh B-C, Forbeck EM, Faloon P, Wagner BK, Marcaurelle LA. Synthesis of a Novel Suppressor of B-Cell Apoptosis Via Diversity-Oriented Synthesis. ACS Med. Chem. Lett. 2011; 2:698-702. [PubMed: 21927648]

31. Scully SS, Tang AJ, Lundh M, Mosher CM, Perkins KM, Wagner BK. Small-Molecule Inhibitors of Cytokine-Mediated Stat1 Signal Transduction in B-Cells with Improved Aqueous Solubility. J. Med. Chem. 2013; 56:4125-4129. [PubMed: 23617753]

32. Whitman DB, Cox CD, Breslin MJ, Brashear KM, Schreier JD, Bogusky MJ, Bednar RA, Lemaire W, Bruno JG, Hartman GD, Reiss DR, Harrell CM, Kraus RL, Li Y, Garson SL, Doran SM, Prueksaritanont T, Li C, Winrow CJ, Koblan KS, Renger JJ, Coleman PJ. Discovery of a Potent, Cns-Penetrant Orexin Receptor Antagonist Based on an N,N-Disubstituted-1,4-Diazepane Scaffold That Promotes Sleep in Rats. Chem Med Chem. 2009; 4:1069-1074. [PubMed: 19418500]

33. Wang, W.; Schultz, PG. Heterocyclic Compounds That Induce Pancreatic Beta-Cell Expansion. WO2010056907. 2010.

34. Oslowski CM, Urano F. Measuring Er Stress and the Unfolded Protein Response Using Mammalian Tissue Culture System. Methods Enzymol. 2011; 490:71-92. [PubMed: 21266244]

35. Slee EA, Harte MT, Kluck RM, Wolf BB, Casiano CA, Newmeyer DD, Wang HG, Reed JC, Nicholson DW, Alnemri ES, Green DR, Martin SJ. Ordering the Cytochrome C-Initiated Caspase Cascade: Hierarchical Activation of Caspases-2, -3, -6, -7, -8, and -10 in a Caspase-9-Dependent Manner. J. Cell. Biol. 1999; 144:281-292. [PubMed: 9922454]

36. Herceg Z, Wang ZQ. Functions of Poly(Adp-Ribose) Polymerase (Parp) in DNA Repair, Genomic Integrity and Cell Death. Mutat. Res. 2001; 477:97-110. [PubMed: 11376691]

37. Lipson KL, Ghosh R, Urano F. The Role of Ire1alpha in the Degradation of Insulin Mrna in Pancreatic Beta-Cells. PLoS One. 2008; 3:e1648. [PubMed: 18286202]

38. Han D, Lerner AG, Vande Walle L, Upton JP, Xu W, Hagen A, Backes BJ, Oakes SA, Papa FR. Ire1alpha Kinase Activation Modes Control Alternate Endoribonuclease Outputs to Determine Divergent Cell Fates. Cell. 2009; 138:562-575. [PubMed: 19665977]

39. Rutter GA, Pullen TJ, Hodson DJ, Martinez-Sanchez A. Pancreatic Beta-Cell Identity, Glucose Sensing and the Control of Insulin Secretion. Biochem. J. 2015; 466:203-218. [PubMed: 25697093] 
40. Kataoka K, Han SI, Shioda S, Hirai M, Nishizawa M, Handa H. Mafa Is a Glucose-Regulated and Pancreatic Beta-Cell-Specific Transcriptional Activator for the Insulin Gene. J. Biol. Chem. 2002; 277:49903-49910. [PubMed: 12368292]

41. Olson LK, Redmon JB, Towle HC, Robertson RP. Chronic Exposure of Hit Cells to High Glucose Concentrations Paradoxically Decreases Insulin Gene Transcription and Alters Binding of Insulin Gene Regulatory Protein. J. Clin. Invest. 1993; 92:514-519. [PubMed: 8326016]

42. Sharma A, Olson LK, Robertson RP, Stein R. The Reduction of Insulin Gene Transcription in HitT15 Beta Cells Chronically Exposed to High Glucose Concentration Is Associated with the Loss of Ripe3b1 and Stf-1 Transcription Factor Expression. Mol. Endocrinol. 1995; 9:1127-1134. [PubMed: 7491105]

43. Poitout V, Olson LK, Robertson RP. Chronic Exposure of Betatc-6 Cells to Supraphysiologic Concentrations of Glucose Decreases Binding of the Ripe3b1 Insulin Gene Transcription Activator. J. Clin. Invest. 1996; 97:1041-1046. [PubMed: 8613527]

44. Kaneto H, Xu G, Fujii N, Kim S, Bonner-Weir S, Weir GC. Involvement of C-Jun N-Terminal Kinase in Oxidative Stress-Mediated Suppression of Insulin Gene Expression. J. Biol. Chem. 2002; 277:30010-30018. [PubMed: 12011047]

45. Lipson KL, Fonseca SG, Ishigaki S, Nguyen LX, Foss E, Bortell R, Rossini AA, Urano F. Regulation of Insulin Biosynthesis in Pancreatic Beta Cells by an Endoplasmic ReticulumResident Protein Kinase Ire1. Cell Metab. 2006; 4:245-254. [PubMed: 16950141]

46. Wang S, Kaufman RJ. The Impact of the Unfolded Protein Response on Human Disease. J. Cell Biol. 2012; 197:857-867. [PubMed: 22733998]

47. Wang P, Fiaschi-Taesch NM, Vasavada RC, Scott DK, Garcia-Ocana A, Stewart AF. Diabetes Mellitus--Advances and Challenges in Human Beta-Cell Proliferation. Nat. Rev. Endocrinol. 2015; 11:201-212. [PubMed: 25687999]

48. von Herrath M, Nepom GT. Animal Models of Human Type 1 Diabetes. Nat. Immunol. 2009; 10:129-132. [PubMed: 19148193]

49. Anderson MS, Bluestone JA. The Nod Mouse: A Model of Immune Dysregulation. Ann. Rev. Immunol. 2005; 23:447-485. [PubMed: 15771578]

50. Van Horn KS, Burda WN, Fleeman R, Shaw LN, Manetsch R. Antibacterial Activity of a Series of N2,N4-Disubstituted Quinazoline-2,4-Diamines. J. Med. Chem. 2014; 57:3075-3093. [PubMed: 24625106] 


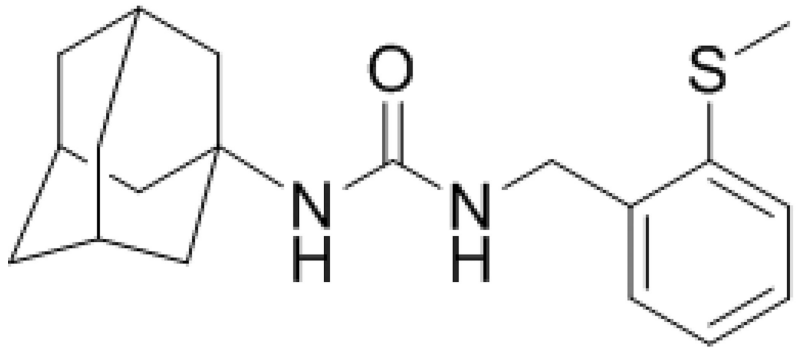

1, KM10103

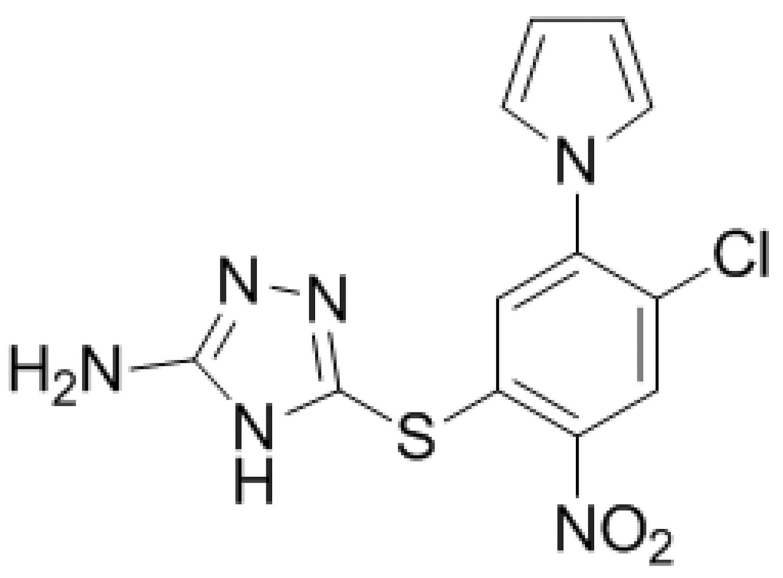

2, $\mathrm{RH} 01687$

Figure 1.

Structures of small molecules protective against $\beta$ cell ER stress. 
A

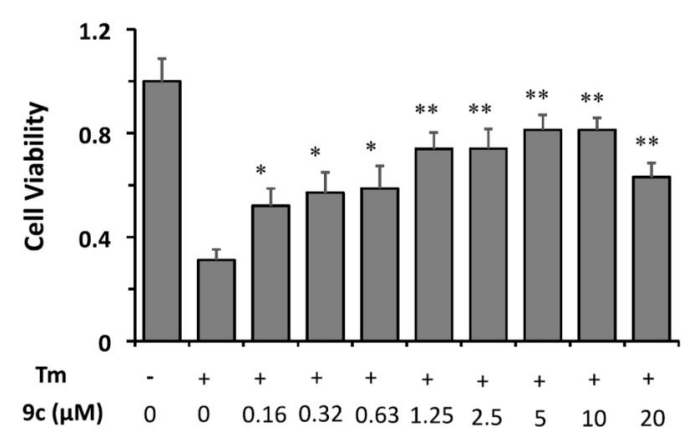

B

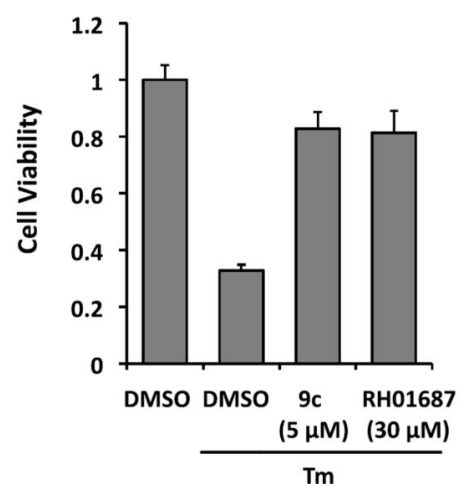

C

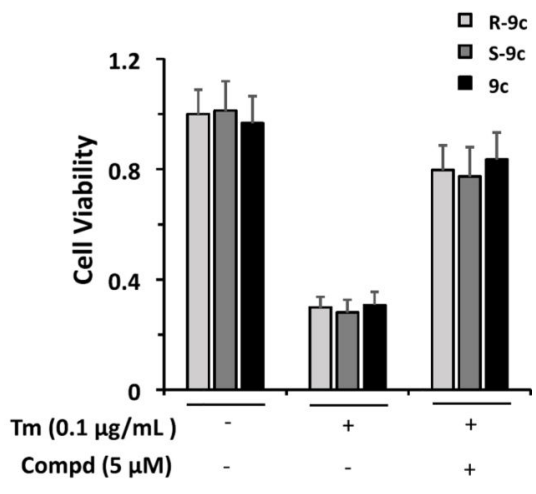

Figure 2.

Protective effects of $\mathbf{9 c}$ and its chiral forms on the viability of INS- 1 cells after Tm treatment. (A) INS-1 cells were treated with or without $\mathrm{Tm}(0.1 \mu \mathrm{g} / \mathrm{mL})$ in the presence of $9 \mathrm{c}$ at the indicated concentrations or DMSO for $72 \mathrm{~h}$. (B) INS-1 cells were treated with 9c (5 $\mu \mathrm{M}), \mathrm{RH} 01687(30 \mu \mathrm{M})$, or DMSO in the presence of Tm $(0.1 \mu \mathrm{g} / \mathrm{mL})$, or with DMSO in the absence of Tm, for $72 \mathrm{~h} .5 \mu \mathrm{M}$ of $9 \mathrm{c}$ and $30 \mu \mathrm{M}$ of RH01687 were used as each at its chosen concentration respectively exhibited the maximum protective activity in INS- 1 cells based on dose-dependent curves. (C) INS-1 cells were treated with or without Tm $(0.1 \mu \mathrm{g} / \mathrm{mL})$ in the presence of compounds $(5 \mu \mathrm{M})$ or DMSO for $72 \mathrm{~h}$. The cell viability was determined using the CellTiter-Glo assay, and was normalized as 1 for DMSO alone (in all figures unless specified). The results are the means of 3 replicate wells and are representative of 3 independent experiments. Bars indicate SD. ** $P<0.01$ compared with Tm alone. DMSO concentration in all conditions (in all figures unless specified) is $0.1 \%$. 
A

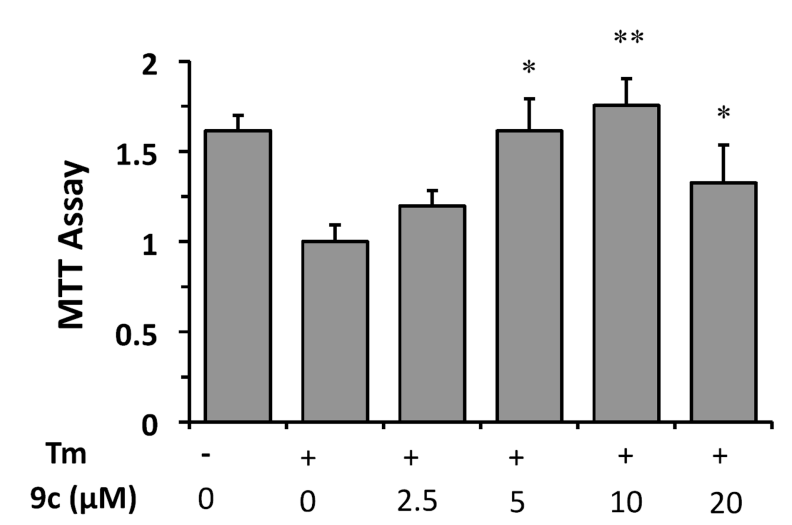

C

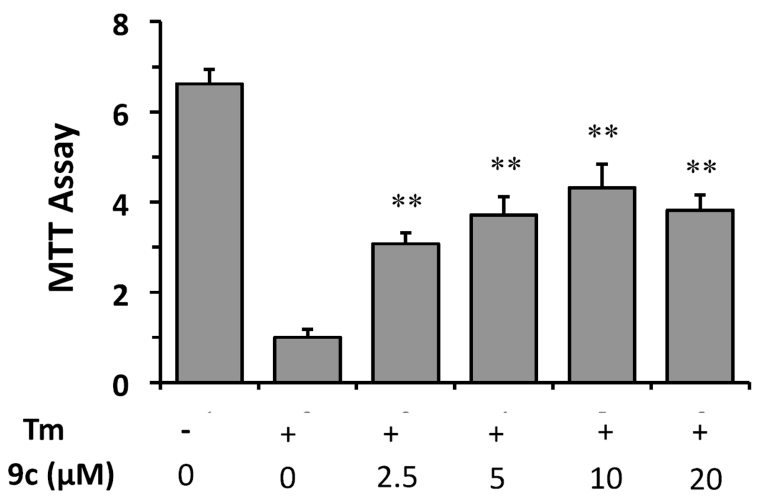

B

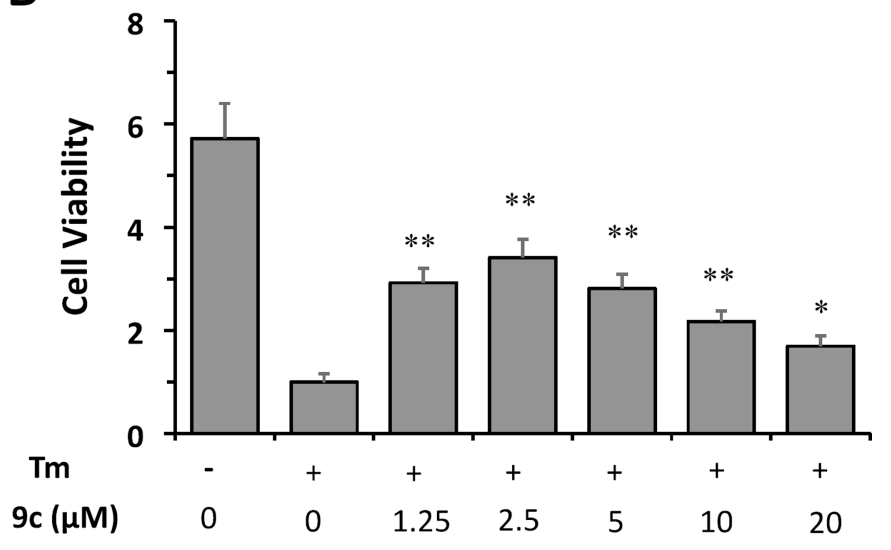

D

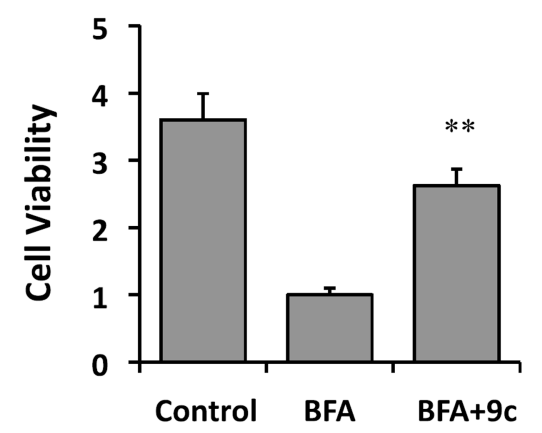

Figure 3.

Compound 9c increases the viability of $\beta$ cells against ER stress. (A) INS-1 cells were treated with or without Tm $(0.1 \mu \mathrm{g} / \mathrm{mL})$ in the presence of $9 \mathrm{c}$ or DMSO for $72 \mathrm{~h}$. The cell viability was determined using MTT. (B, C) $\beta$ TC6 cells were treated with or without Tm $(0.25 \mu \mathrm{g} / \mathrm{mL})$ in the presence of 9c or DMSO for $72 \mathrm{~h}$. The cell viability was determined using CellTiter-Glo assay (B) or MTT (C). (D) INS-1 cells were treated with or without BFA $(0.2 \mu \mathrm{g} / \mathrm{mL})$ in the presence of $9 \mathrm{c}(20 \mu \mathrm{M})$ or DMSO for $72 \mathrm{~h}$. The cell viability was determined by CellTiter-Glo. The results in all panels are the means of 3 replicate wells and are representative of 3 independent experiments. $* P<0.05$ and $* * P<0.01$ compared with Tm or BFA treated alone. Bars indicate SD. 
A

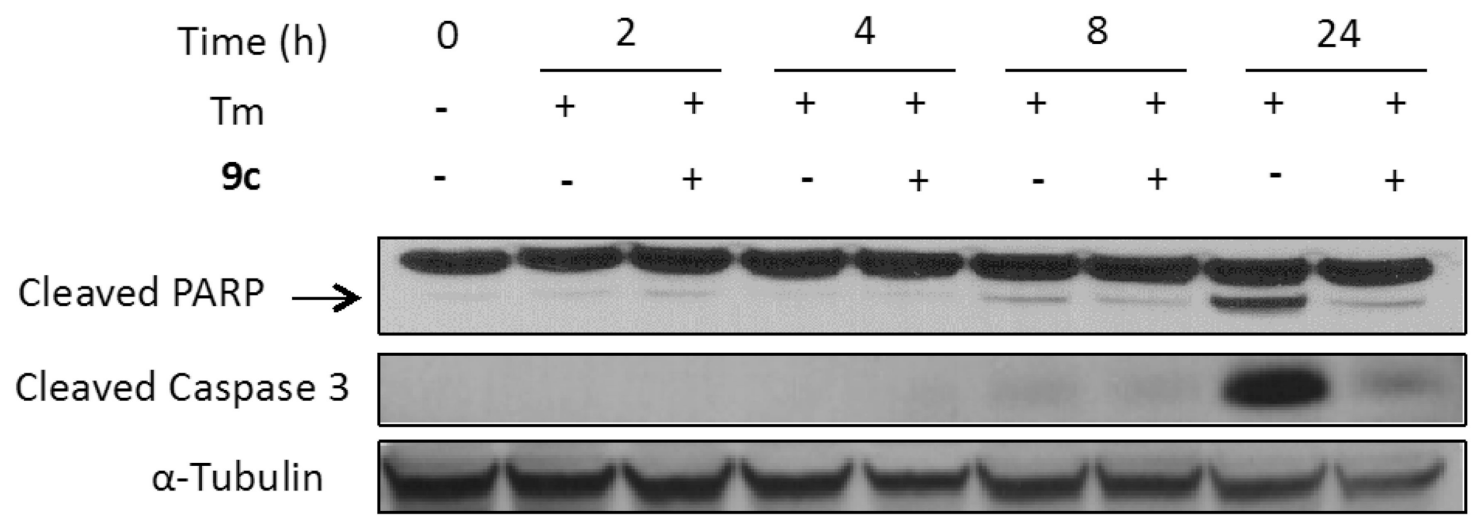

B

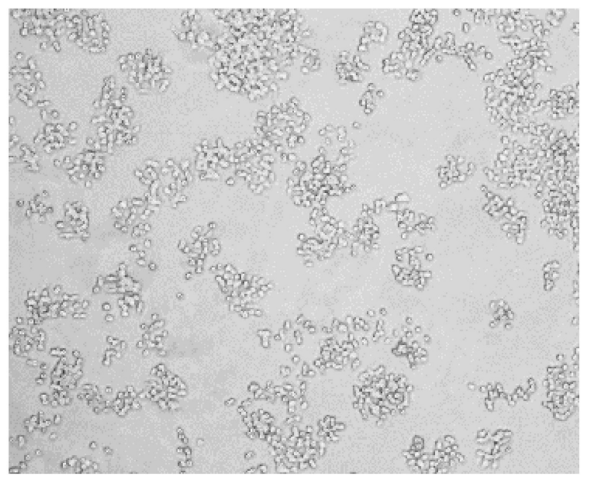

Control

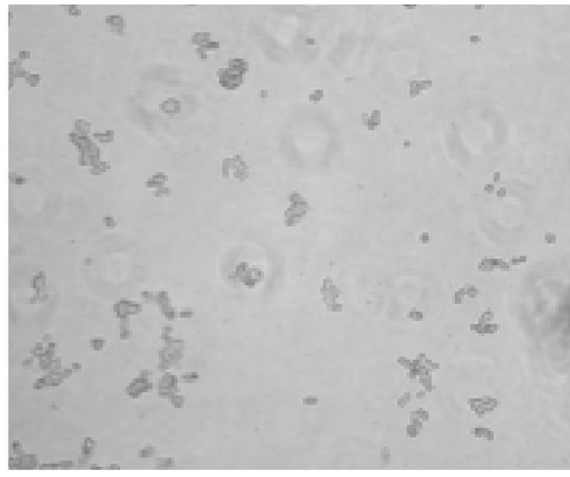

$\mathrm{Tm}$

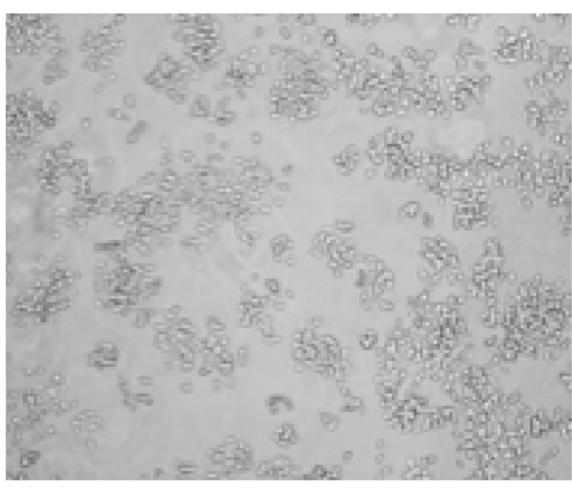

$\mathrm{Tm}+9 \mathrm{c}$

Figure 4.

Compound 9c protects INS-1 cells against Tm-induced apoptosis. (A) INS-1 cells were treated with or without Tm $(0.1 \mu \mathrm{g} / \mathrm{mL})$ in the presence of $9 \mathbf{c}(20 \mu \mathrm{M})$ or DMSO for the indicated times. Cleaved caspase- 3 and PARP were determined by Western blotting. $\mathbf{a}$ Tubulin was used as a loading control. The data shown are representative of 3 independent experiments. (B) INS-1 cells were treated with or without $\mathrm{Tm}(0.1 \mu \mathrm{g} / \mathrm{mL})$ in the presence of 9c $(20 \mu \mathrm{M})$ or DMSO for $24 \mathrm{~h}$, and live-cell phase-contrast images were acquired (magnification $10 \times$ ) 
A

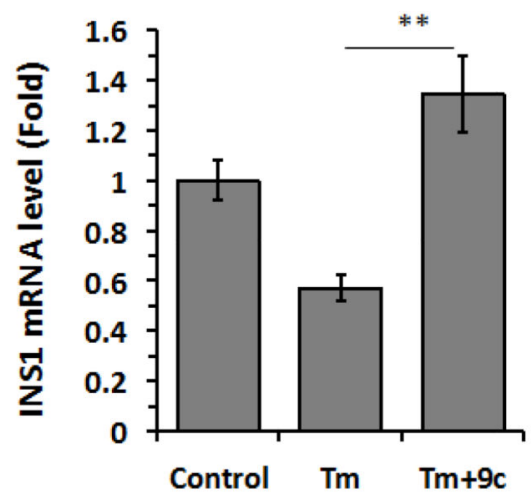

D

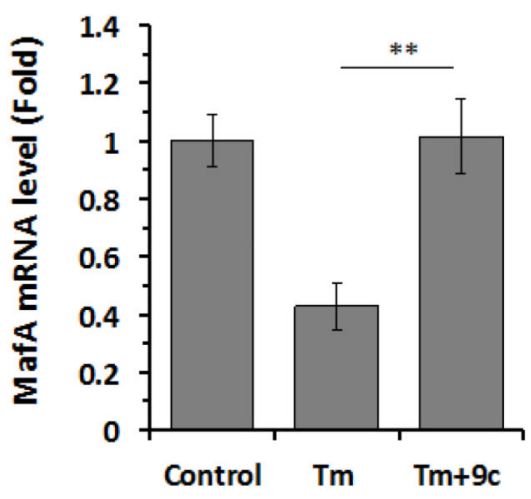

B

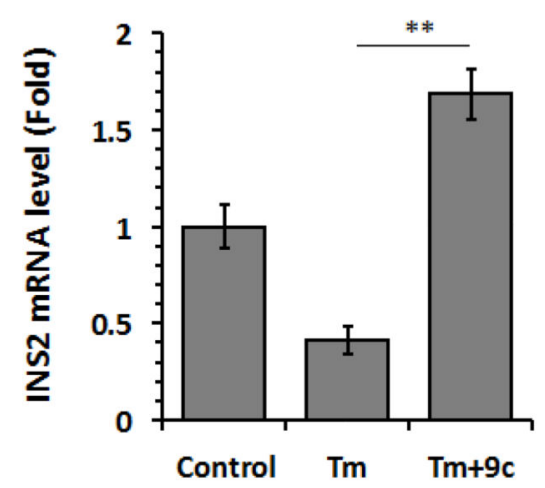

E

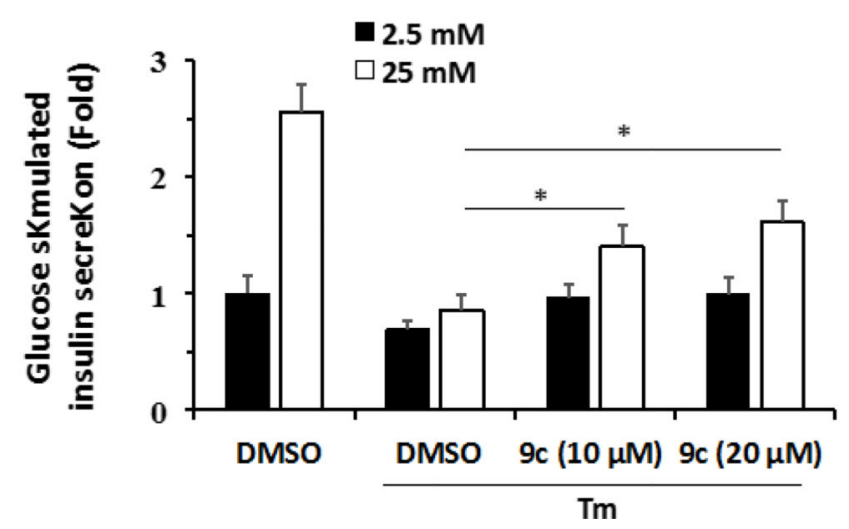

Figure 5.

Compound 9c reverses Tm-suppressed $\beta$ cell function. (A-D) INS-1 cells were treated with or without $\operatorname{Tm}(0.1 \mu \mathrm{g} / \mathrm{mL})$ in the presence of $9 \mathbf{c}(20 \mu \mathrm{M})$ or DMSO for $24 \mathrm{~h}$. The mRNA levels of INS1 (A), INS2 (B), PDX1 (C), and MafA (D), were analyzed by qRT-PCR. The results are the means of 3 replicate wells and are representative of 3 independent experiments. $* P<0.05$ and $* * P<0.01$. Bars indicate SD. (E) Insulin secretion by INS-1 cells incubated with $2.5 \mathrm{mM}$ and $25 \mathrm{mM}$ glucose in the presence of Tm $(0.1 \mu \mathrm{g} / \mathrm{mL})$ and 9c. Secreted insulin was measured by ELISA after $24 \mathrm{~h}$ treatment. $* P<0.05$. The amount of insulin secreted in response to $2.5 \mathrm{mM}$ glucose in the absence of Tm was set to 1.0. 
A

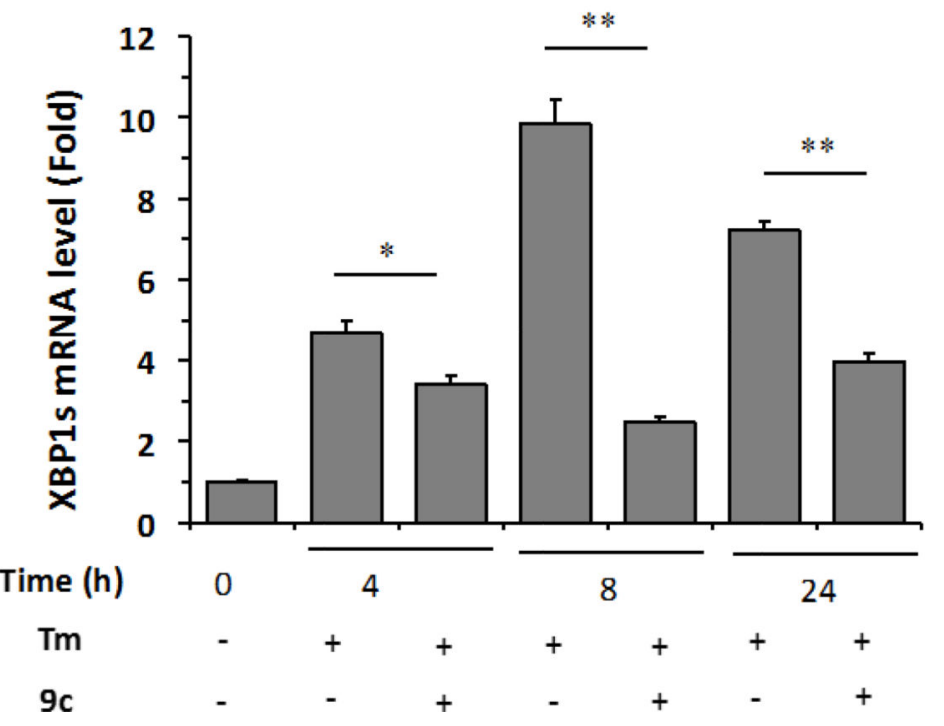

B

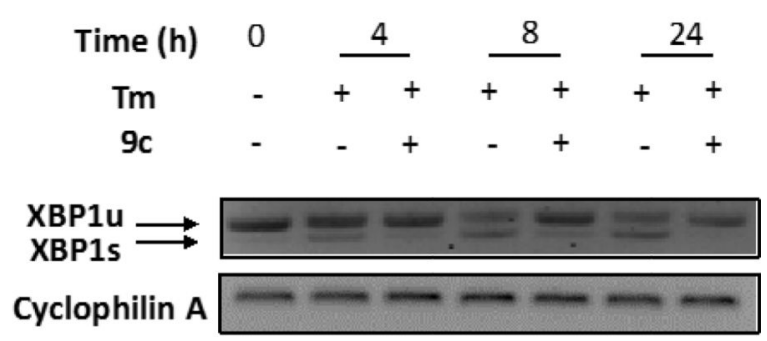

Figure 6.

Compound 9c decreases XBP1s mRNA levels induced by Tm. INS-1 cells were treated with or without $\mathrm{Tm}(0.1 \mu \mathrm{g} / \mathrm{mL})$ in the presence of $9 \mathrm{c}(20 \mu \mathrm{M})$ or DMSO for the indicated times. (A) XBP1s mRNA levels were analyzed by qRT-PCR. The results are expressed as the foldincrease over mRNA levels in untreated control cells and are the means of 3 replicate wells and representative of 3 independent experiments. $* P<0.05$ and $* * P<0.01$. Bars indicate SD. (B) XBP1 mRNA levels were analyzed by RT-PCR and the products were resolved by agarose gel electrophoresis. The full-length (unspliced, XBP1u) and spliced (XBP1s) forms of XBP1 mRNA are indicated. Cyclophilin A mRNA was used as an internal control. The data shown are representative of 3 independent experiments. 
A

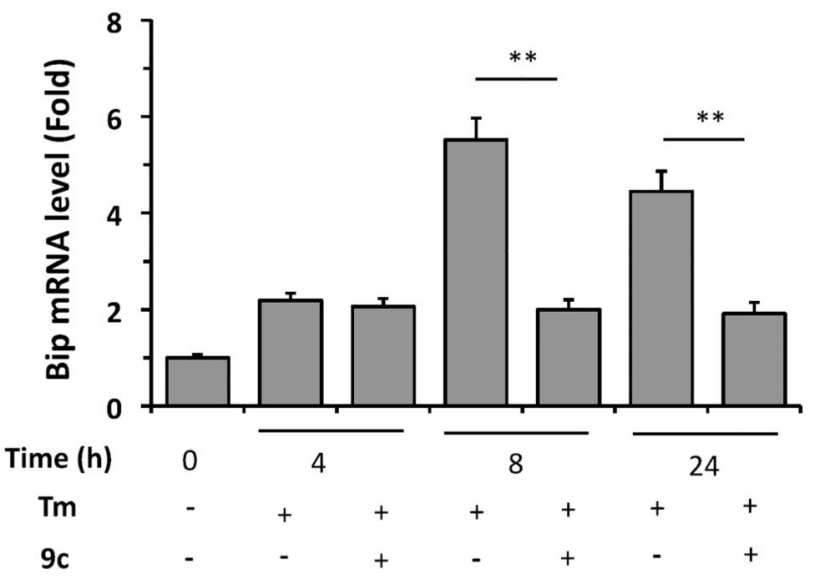

B

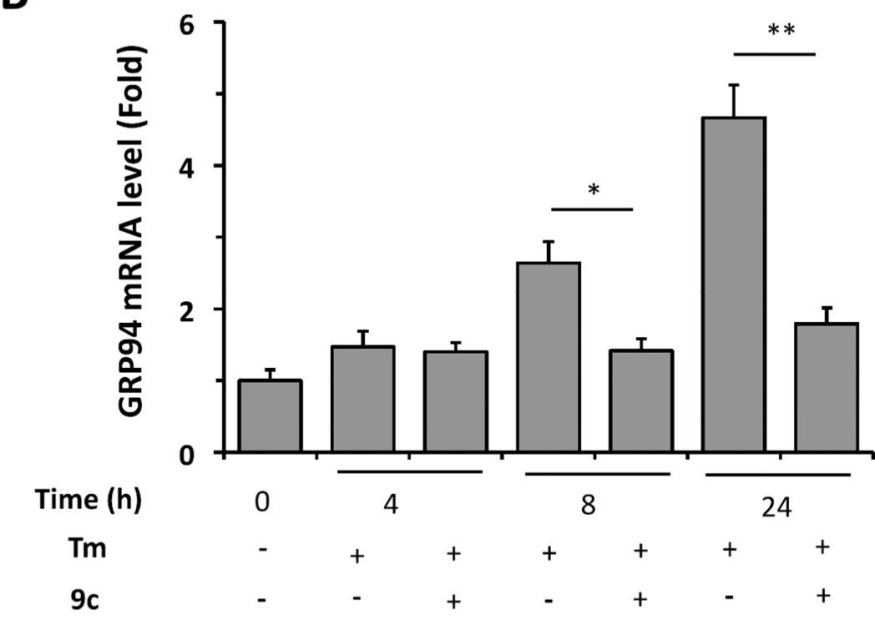

Figure 7.

Compound 9c inhibits Tm-induced Bip and GRP94 expression in INS-1 cells. INS-1 cells were treated with or without $\mathrm{Tm}(0.1 \mu \mathrm{g} / \mathrm{mL})$ in the presence of $9 \mathbf{c}(20 \mu \mathrm{M})$ or DMSO for the indicated times. Bip (A) and GRP94 (B) mRNA levels were analyzed by qRT-PCR. The results are expressed as the fold-increase over mRNA levels in untreated control cells and are the means of 3 replicate wells and representative of 3 independent experiments. $* P<$ 0.05 and $* * P<0.01$. 
A

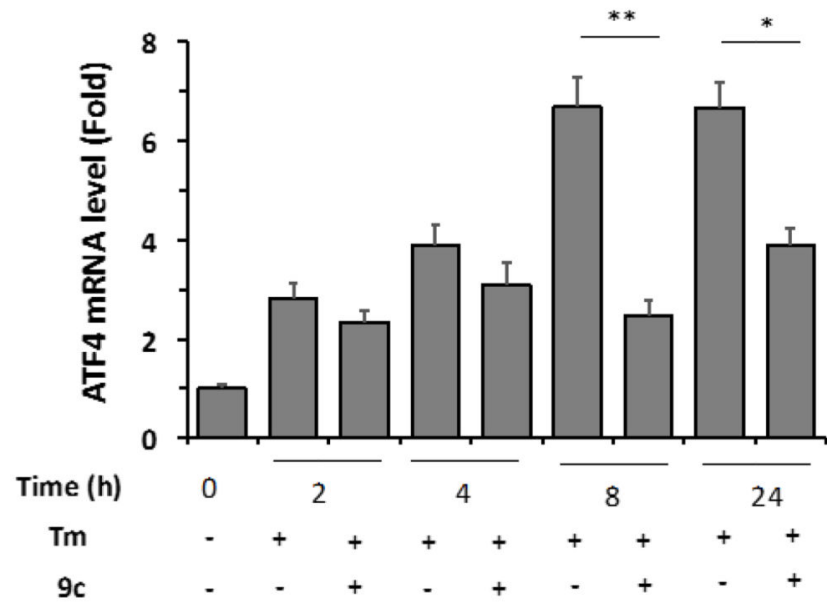

B

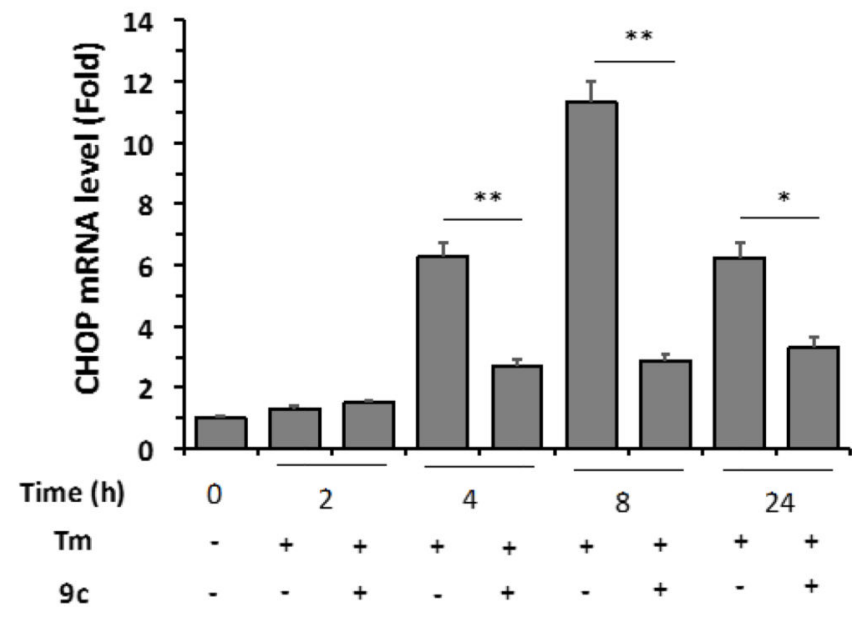

C

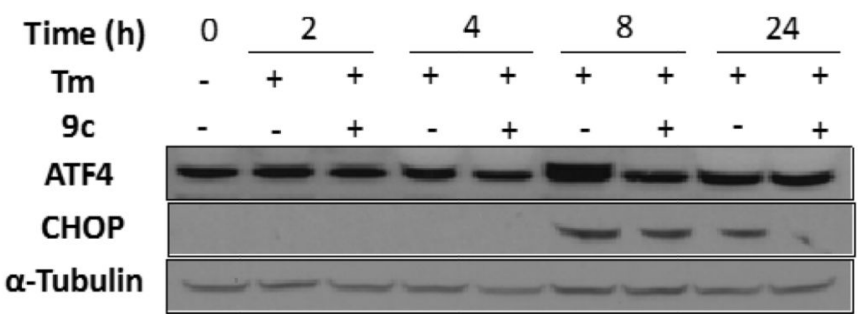

Figure 8.

Compound 9c inhibits Tm-induced ATF4 and CHOP up-regulation in INS-1 cells. (A, B) INS-1 cells were treated with or without $\mathrm{Tm}(0.1 \mu \mathrm{g} / \mathrm{mL})$ in the presence of $9 \mathrm{c}(20 \mu \mathrm{M})$ or DMSO for the indicated times. ATF4 (A) and CHOP (B) mRNA levels were analyzed by qRT-PCR. The results are expressed as the fold-increase over mRNA levels in untreated control cells and are the means of 3 replicate wells and representative of 3 independent experiments. $* P<0.05$ and $* * P<0.01$. Bar indicates SD. (C) INS-1 cells were treated with or without $\mathrm{Tm}(0.1 \mu \mathrm{g} / \mathrm{mL})$ in the presence of $9 \mathrm{c}(20 \mu \mathrm{M})$ or DMSO for the indicated times. ATF4 and CHOP protein levels were determined by Western bloting. $\mathbf{a}$-Tubulin was used as a loading control. The data shown are representative of 3 independent experiments. 
A
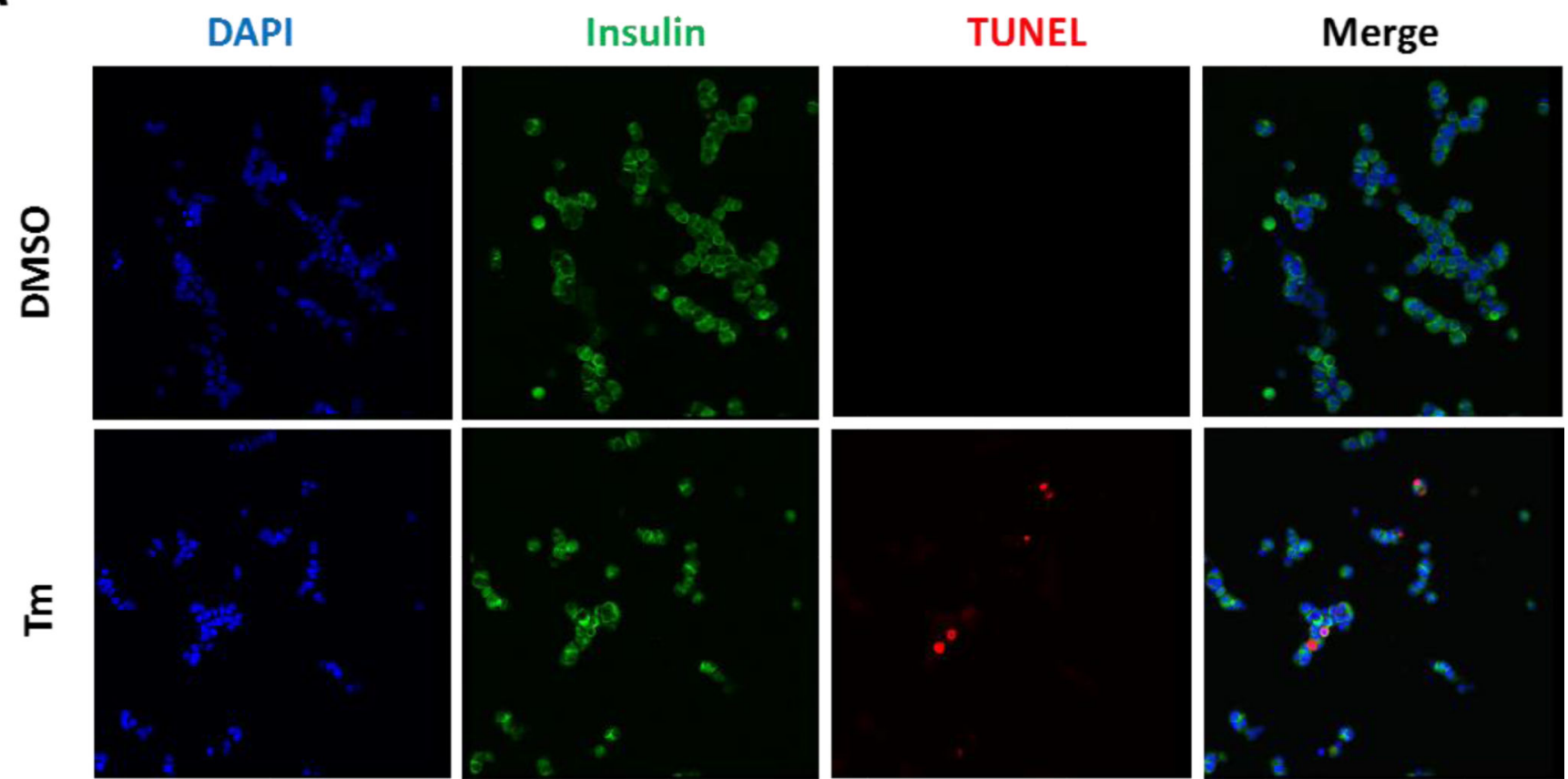

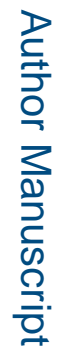
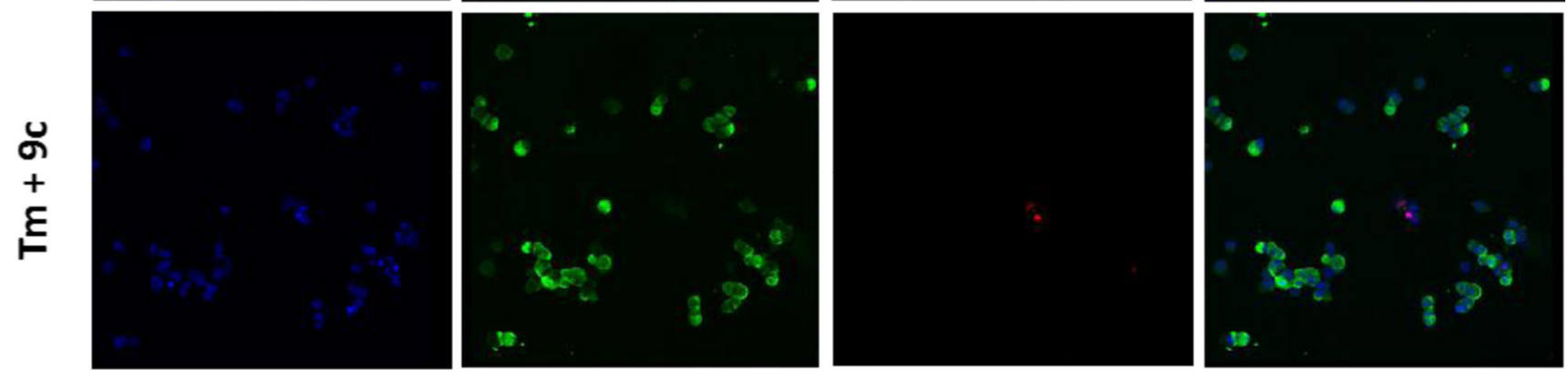

B

C
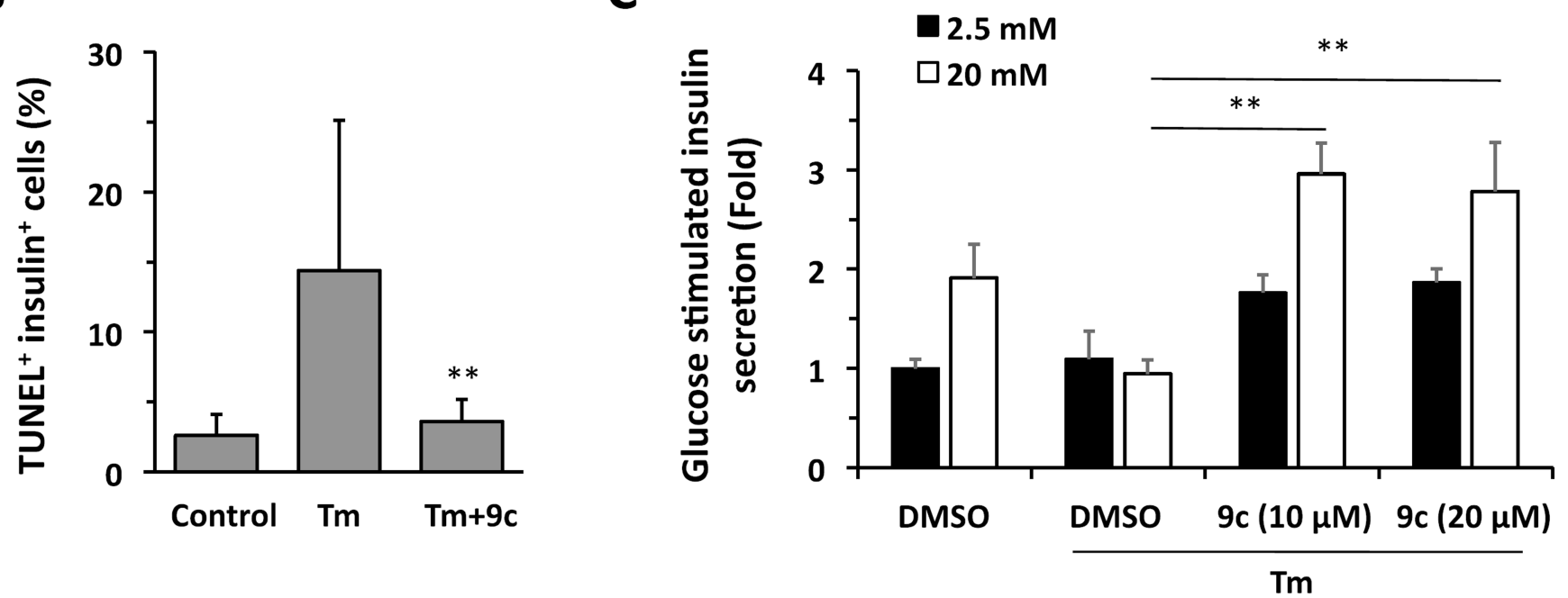

Figure 9. 
Compound 9c protects human $\beta$ cells against Tm-induced ER stress. (A) TUNEL staining of human $\beta$ cells. Primary human islets were treated with $1 \mu \mathrm{g} / \mathrm{mL}$ of Tm with or without compound $9 \mathbf{c}(10 \mu \mathrm{M})$ for $48 \mathrm{~h}$ before TUNEL staining. Anti-insulin antibody was used to mark insulin-positive $\beta$ cells, and DAPI was used as a nuclear marker. Magnification is $40 \times$. (B) Quantification of TUNEL staining from 10 fields of images. ** $P<0.01$ compared with Tm treatment alone. (C) Insulin secretion by human islets (50 of equal size) incubated with $2.5 \mathrm{mM}$ or $20 \mathrm{mM}$ glucose in the presence of $\mathrm{Tm}(1 \mu \mathrm{g} / \mathrm{mL})$ and $\mathbf{9 c}$. Secreted insulin was measured by ELISA after $48 \mathrm{~h}$ treatment. For A and B, the values have been normalized to total cellular protein. The baseline insulin secretion at $2.5 \mathrm{mM}$ glucose was normalized as 1 . $* * P<0.01$. 

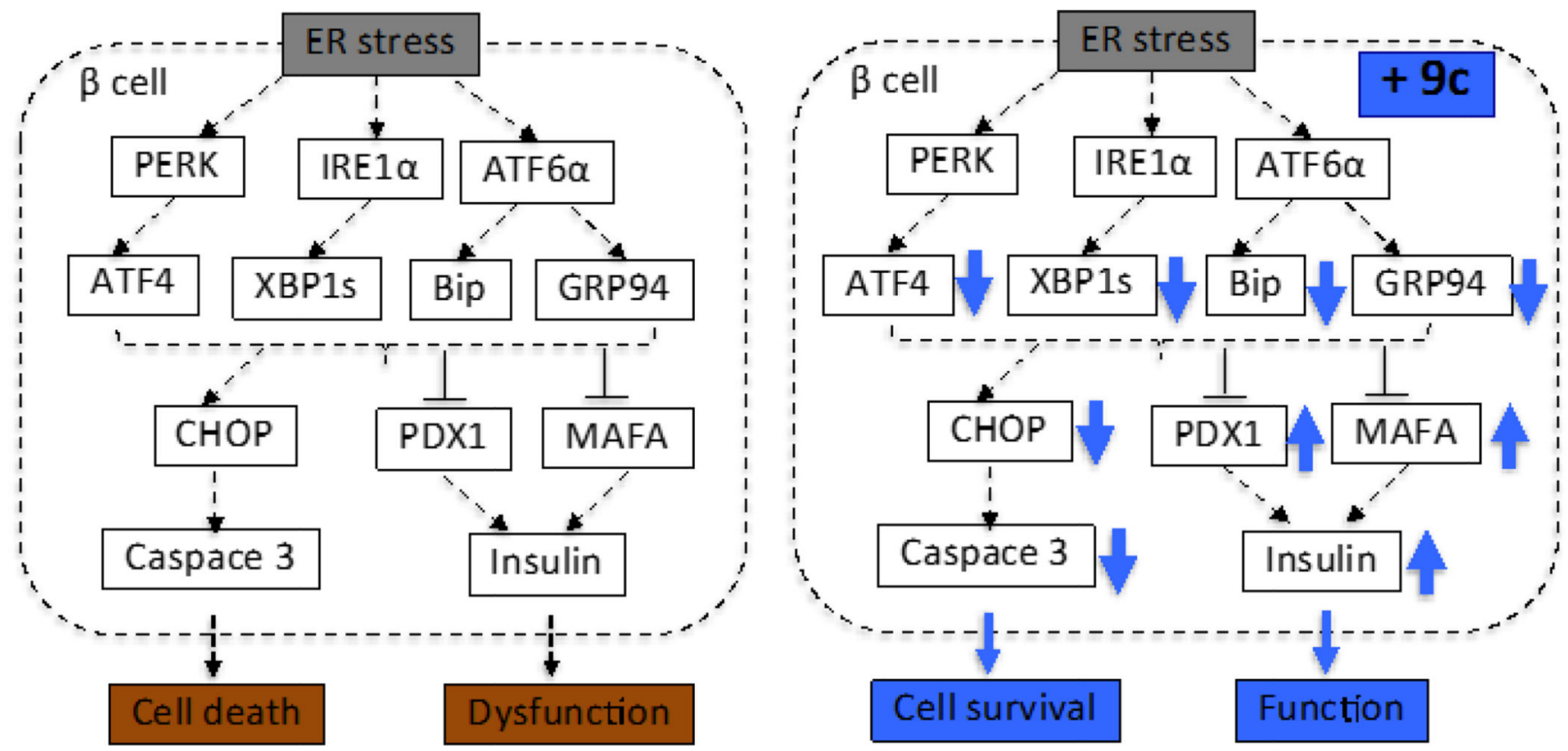

Figure 10.

Proposed model of signaling pathways involved in 9c-mediated $\beta$ cell-protective effects against ER stress. ER stress induces activation of three branches of UPR (PERK, IRE1a, and ATF6), leading to up-regulation of ATF4, XBP1s, Bip, GRP4, CHOP and eventual activation caspase 3 and cell apoptosis, while diminishing the expression of PDX1, MAFA and insulin genes, leading to $\beta$ cell dysfunction. Compound $9 \mathrm{c}$ protects $\beta$ cell against ER stress-mediated dysfunction and death by down-regulating ATF4, XBP1s, Bip, GRP94, CHOP, and caspase 3 and up-regulating PDX1, MAFA and insulin genes. 


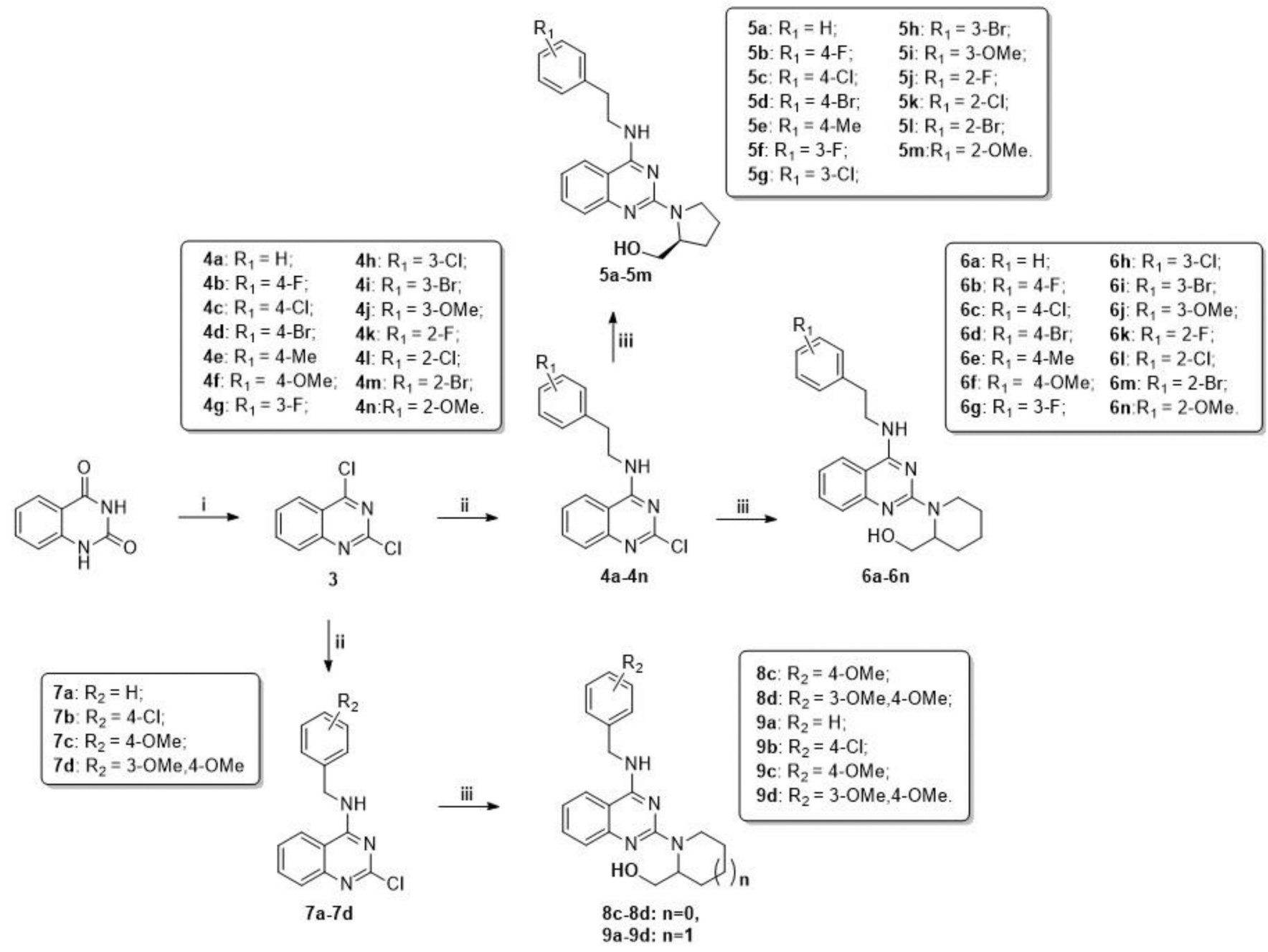

Scheme 1.

Synthesis of 2,4-diaminoquinazoline derivatives. ${ }^{\text {a }}$

aReagents and conditions: (i) dimethylaniline, $\mathrm{POCl}_{3}, 120^{\circ} \mathrm{C}, 24 \mathrm{hrs}, 69 \%$; (ii) aryl amine, DIEA, n-BuOH, $40^{\circ} \mathrm{C}, 2$ hrs, $65-85 \%$; (iii) L-prolinol or 2-piperidinemethanol, DIEA, n-

$\mathrm{BuOH}, 120^{\circ} \mathrm{C}$, overnight, $50-85 \%$. 


\section{Table 1}

Activity of L-prolinol derivatives on the survival of INS-1 cells treated with Tm.

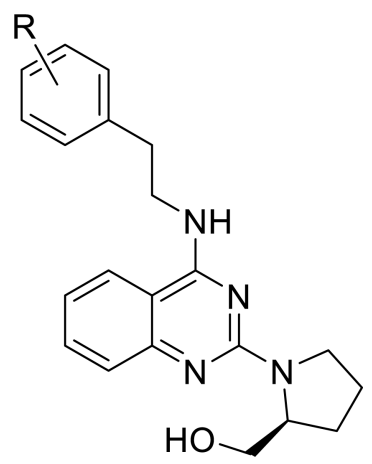

\begin{tabular}{cccc}
\hline Compd & $\mathbf{R}$ & Maximum activity $^{\boldsymbol{a}}$ & $\mathbf{E C}_{\mathbf{5 0}}(\boldsymbol{\mu M})^{\boldsymbol{b}}$ \\
\hline $\mathbf{5 a}$ & $\mathrm{H}$ & $54.4 \%$ & $0.48 \pm 0.19$ \\
$\mathbf{5 b}$ & $4-\mathrm{F}$ & $56.2 \%$ & $2.13 \pm 0.41$ \\
$\mathbf{5 c}$ & $4-\mathrm{Cl}$ & $57.3 \%$ & $0.51 \pm 0.09$ \\
$\mathbf{5 d}$ & $4-\mathrm{Br}$ & $44.1 \%$ & $0.65 \pm 0.16$ \\
$\mathbf{5 e}$ & $4-\mathrm{CH}_{3}$ & $34.2 \%$ & $0.66 \pm 0.21$ \\
$\mathbf{5 f}$ & $3-\mathrm{F}$ & $51.3 \%$ & $1.15 \pm 0.19$ \\
$\mathbf{5 g}$ & $3-\mathrm{Cl}$ & $51.5 \%$ & $1.05 \pm 0.18$ \\
$\mathbf{5 h}$ & $3-\mathrm{Br}$ & $53.2 \%$ & $0.78 \pm 0.24$ \\
$\mathbf{5 i}$ & $3-\mathrm{OMe}$ & $54.9 \%$ & $1.51 \pm 0.13$ \\
$\mathbf{5 j}$ & $2-\mathrm{F}$ & $52.5 \%$ & $1.70 \pm 0.23$ \\
$\mathbf{5 k}$ & $2-\mathrm{Cl}$ & $50.6 \%$ & $1.44 \pm 0.27$ \\
$\mathbf{5 l}$ & $2-\mathrm{Br}$ & $39.0 \%$ & $1.88 \pm 0.32$ \\
$\mathbf{5 m}$ & $2-\mathrm{OMe}$ & $56.6 \%$ & $3.56 \pm 0.15$ \\
\hline
\end{tabular}

${ }^{a}$ Maximum activity value is reported as \% rescue from Tm $(0.1 \mu \mathrm{g} / \mathrm{mL})$-induced reduction of cell viability; the values for Tm treatment alone and control (DMSO, without $\mathrm{Tm}$ ) treatment are designated as $\mathbf{0 \%}$ and $\mathbf{1 0 0 \%}$, respectively in all tables.

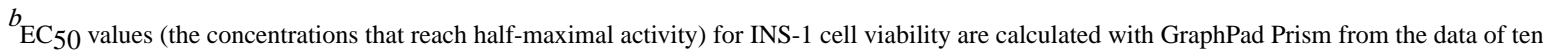
2-fold serial titration points in all tables. All experiments were performed in triplicate. 


\section{Table 2}

Activity of 2-piperidinemethanol derivatives on the survival of INS-1 cells treated with Tm.

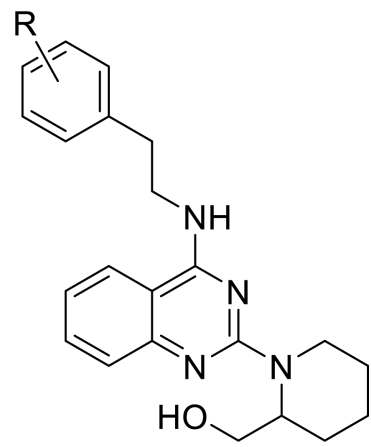

\begin{tabular}{cccc}
\hline Compd & $\mathbf{R}$ & Maximum activity & $\mathbf{E C}_{\mathbf{5 0}}(\boldsymbol{\mu M})$ \\
\hline $\mathbf{6 a}$ & $\mathrm{H}$ & $55.7 \%$ & $0.36 \pm 0.21$ \\
$\mathbf{6 b}$ & $4-\mathrm{F}$ & $47.5 \%$ & $0.31 \pm 0.26$ \\
$\mathbf{6 c}$ & $4-\mathrm{Cl}$ & $57.6 \%$ & $0.17 \pm 0.05$ \\
$\mathbf{6 d}$ & $4-\mathrm{Br}$ & $52.8 \%$ & $0.34 \pm 0.09$ \\
$\mathbf{6 e}$ & $4-\mathrm{CH}_{3}$ & $33.6 \%$ & $0.14 \pm 0.04$ \\
$\mathbf{6 f}$ & $4-\mathrm{OMe}$ & $58.6 \%$ & $0.31 \pm 0.12$ \\
$\mathbf{6 g}$ & $3-\mathrm{F}$ & $57.3 \%$ & $1.88 \pm 0.18$ \\
$\mathbf{6 h}$ & $3-\mathrm{Cl}$ & $46.2 \%$ & $0.79 \pm 0.30$ \\
$\mathbf{6 i}$ & $3-\mathrm{Br}$ & $51.7 \%$ & $0.77 \pm 0.40$ \\
$\mathbf{6 j}$ & $3-\mathrm{OMe}$ & $69.2 \%$ & $2.59 \pm 0.31$ \\
$\mathbf{6 k}$ & $2-\mathrm{F}$ & $60.3 \%$ & $1.46 \pm 0.46$ \\
$\mathbf{6}$ & $2-\mathrm{Cl}$ & $51.4 \%$ & $0.47 \pm 0.45$ \\
$\mathbf{6 m}$ & $2-\mathrm{Br}$ & $44.2 \%$ & $1.41 \pm 0.31$ \\
$\mathbf{6 n}$ & $2-\mathrm{OMe}$ & $46.9 \%$ & $1.60 \pm 0.15$ \\
\hline
\end{tabular}


Table 3

Activity of benzylamine derivatives on the survival of INS-1 cells treated with Tm.
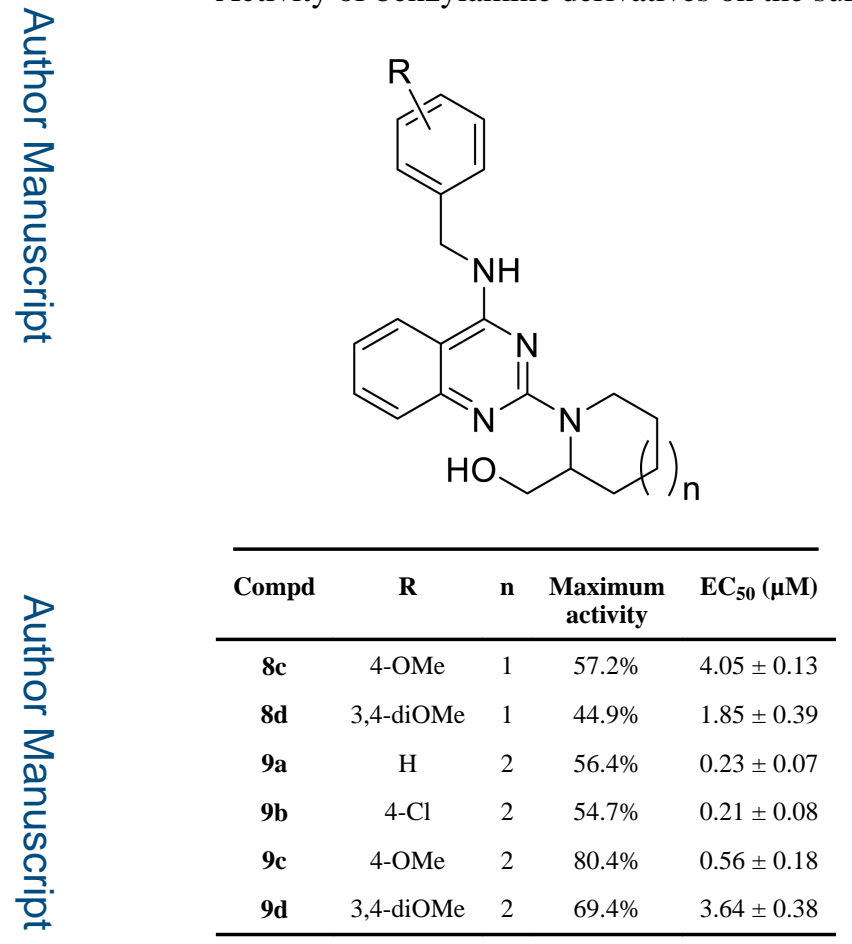

\begin{tabular}{ccccc}
\hline Compd & $\mathbf{R}$ & $\mathbf{n}$ & $\begin{array}{c}\text { Maximum } \\
\text { activity }\end{array}$ & $\mathbf{E C}_{\mathbf{5 0}}(\boldsymbol{\mu M})$ \\
\hline $\mathbf{8 c}$ & $4-\mathrm{OMe}$ & 1 & $57.2 \%$ & $4.05 \pm 0.13$ \\
$\mathbf{8 d}$ & $3,4-\mathrm{diOMe}$ & 1 & $44.9 \%$ & $1.85 \pm 0.39$ \\
$\mathbf{9 a}$ & $\mathrm{H}$ & 2 & $56.4 \%$ & $0.23 \pm 0.07$ \\
$\mathbf{9 b}$ & $4-\mathrm{Cl}$ & 2 & $54.7 \%$ & $0.21 \pm 0.08$ \\
$\mathbf{9 c}$ & $4-\mathrm{OMe}$ & 2 & $80.4 \%$ & $0.56 \pm 0.18$ \\
$\mathbf{9 d}$ & $3,4-\mathrm{diOMe}$ & 2 & $69.4 \%$ & $3.64 \pm 0.38$ \\
\hline
\end{tabular}

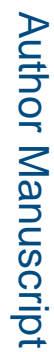

